National Toxicology Program

NTP DEVELOPMENTAL AND

REPRODUCTIVE TOXICITY

TECHNICAL REPORT ON THE

PRENATAL DEVELOPMENT

STUDIES OF

4-METHYLCYCLOHEXANEMETHANOL

(CASRN 34885-03-5) IN

SPRAGUE DAWLEY

(HSD:Sprague Dawley ${ }^{\circledR}$ SD $^{\circledR}$ )

Rats (Gavage Studies)

NTP DART 02

JUNE 2020 


\title{
NTP Developmental and Reproductive Toxicity Technical Report on the Prenatal Development Studies of 4-Methylcyclohexanemethanol \\ (CASRN 34885-03-5) in Sprague Dawley (Hsd:Sprague Dawley ${ }^{\circledR}$ SD $^{\circledR}$ ) Rats \\ (Gavage Studies)
}

DART Report 02

June 2020

\author{
National Toxicology Program \\ Public Health Service \\ U.S. Department of Health and Human Services
}

ISSN: 2690-2052

Research Triangle Park, North Carolina, USA 


\section{Foreword}

The National Toxicology Program (NTP), established in 1978, is an interagency program within the Public Health Service of the U.S. Department of Health and Human Services. Its activities are executed through a partnership of the National Institute for Occupational Safety and Health (part of the Centers for Disease Control and Prevention), the Food and Drug Administration (primarily at the National Center for Toxicological Research), and the National Institute of Environmental Health Sciences (part of the National Institutes of Health), where the program is administratively located. NTP offers a unique venue for the testing, research, and analysis of agents of concern to identify toxic and biological effects, provide information that strengthens the science base, and inform decisions by health regulatory and research agencies to safeguard public health. NTP also works to develop and apply new and improved methods and approaches that advance toxicology and better assess health effects from environmental exposures.

The NTP Technical Report series for developmental and reproductive toxicity studies began in 2019. The studies described in this NTP Technical Report series (i.e., the NTP DART Report series) are designed and conducted to characterize and evaluate the developmental or reproductive toxicity of selected substances in laboratory animals. Substances (e.g., chemicals, physical agents, and mixtures) selected for NTP reproductive and developmental studies are chosen primarily on the basis of human exposure, level of commercial production, and chemical structure. The interpretive conclusions presented in NTP DART Reports are based only on the results of these NTP studies, and extrapolation of these results to other species, including characterization of hazards and risks to humans, requires analyses beyond the intent of these reports. Selection for study per se is not an indicator of a substance's developmental or reproductive toxicity potential.

NTP conducts its studies in compliance with its laboratory health and safety guidelines and the Food and Drug Administration Good Laboratory Practice Regulations and meets or exceeds all applicable federal, state, and local health and safety regulations. Animal care and use are in accordance with the Public Health Service Policy on Humane Care and Use of Laboratory Animals. Studies are subjected to retrospective quality assurance audits before they are presented for public review. Draft reports undergo external peer review before they are finalized and published.

The NTP DART Reports are available free of charge on the NTP website and cataloged in PubMed, a free resource developed and maintained by the National Library of Medicine (part of the National Institutes of Health). Data for these studies are included in NTP's Chemical Effects in Biological Systems database.

For questions about the reports and studies, please email NTP or call 984-287-3211. 


\section{Table of Contents}

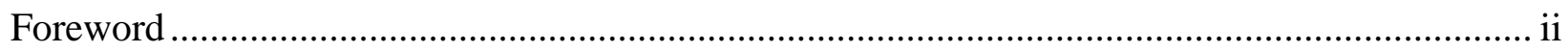

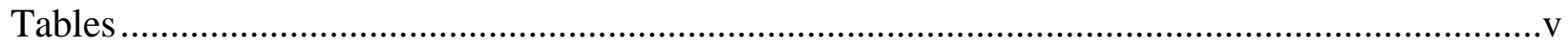

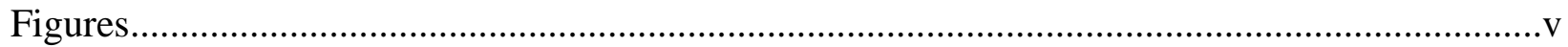

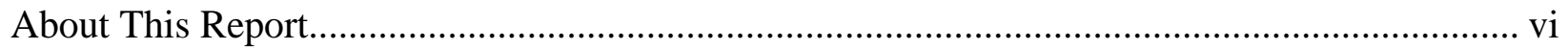

Explanation of Levels of Evidence for Developmental Toxicity ................................................. ix

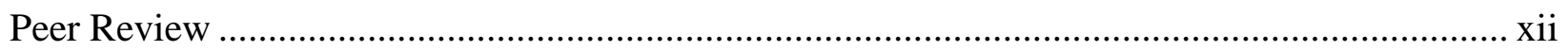

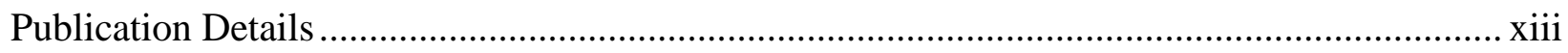

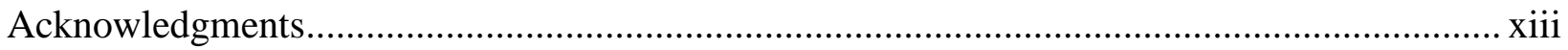

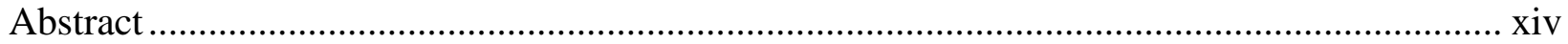

Dose Range-finding Prenatal Developmental Toxicity Study .............................................. xiv

Prenatal Developmental Toxicity Study .......................................................................... xiv

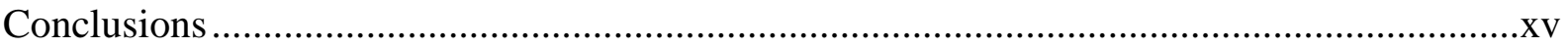

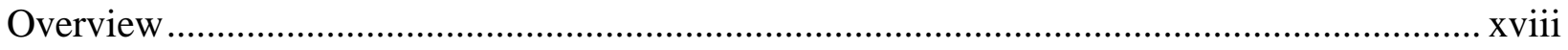

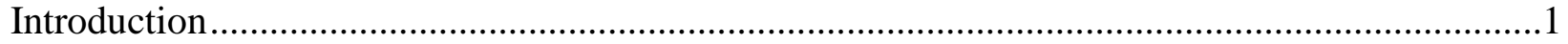

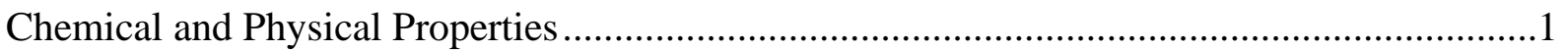

Production, Use, and Human Exposure ..................................................................................

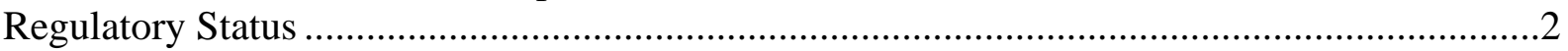

Absorption, Distribution, Metabolism, and Excretion ...............................................................2

Developmental and Reproductive Toxicity …………….....................................................

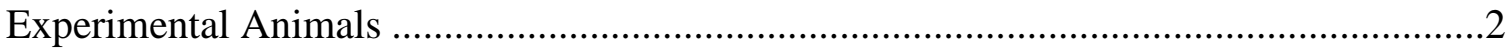

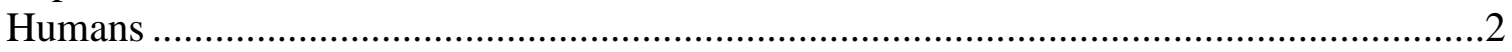

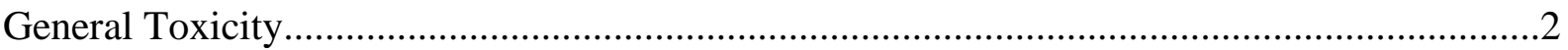

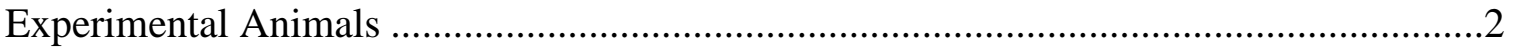

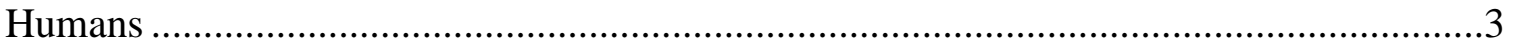

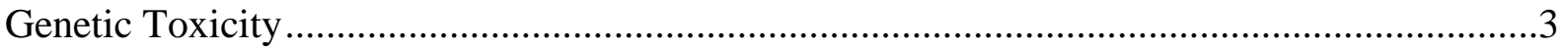

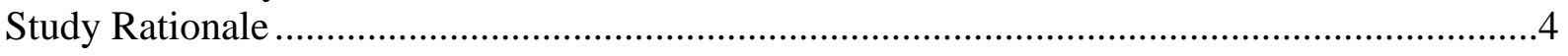

Materials and Methods.......................................................................................................

Overview of Prenatal Developmental Toxicity Study Designs ....................................................5

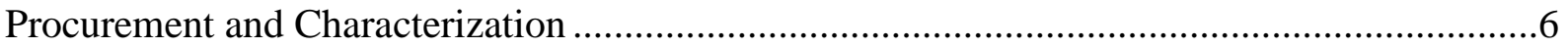

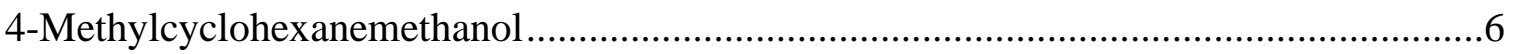

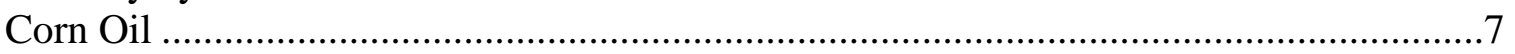

Preparation and Analysis of Dose Formulations.....................................................................

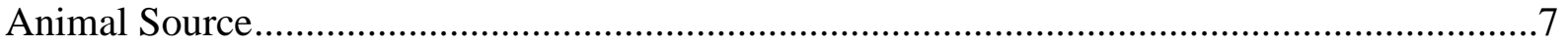

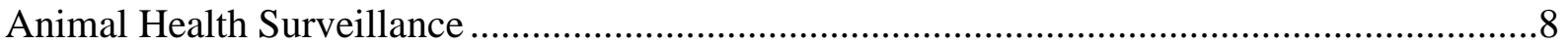

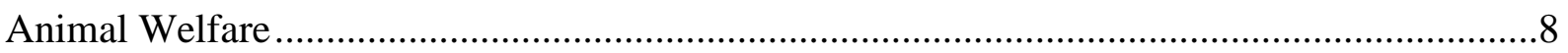

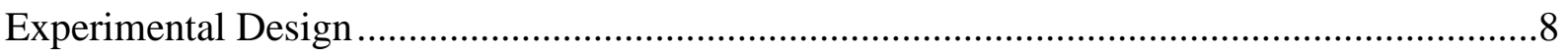

Dose Range-finding Study .........................................................................................

Prenatal Developmental Toxicity Study …………….....................................................

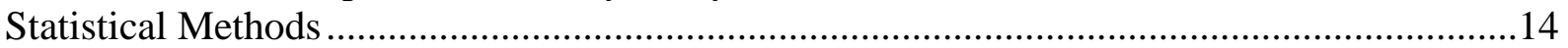


Descriptive Statistics.............................................................................................

Analysis of Maternal Parameters and Uterine Contents .....................................................14

Analysis of Incidences of Gross Pathology and Morphology Findings ............................15

Historical Control Data .............................................................................................15

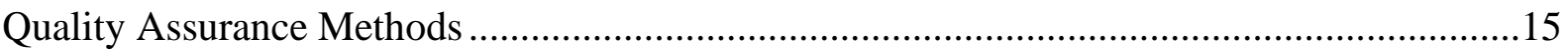

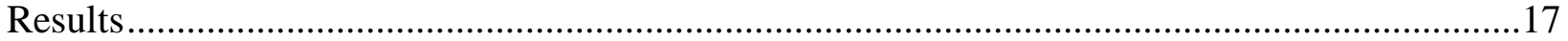

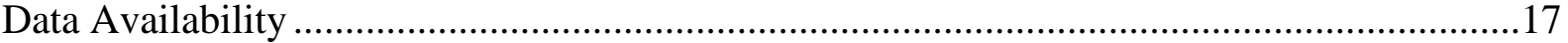

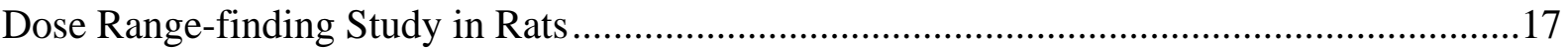

Maternal Findings .....................................................................................................17

Viability and Clinical Observations............................................................................17

Body Weights and Feed Consumption .....................................................................17

Maternal and Litter Observations ...........................................................................19

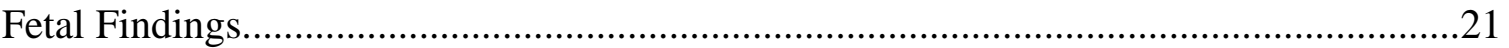

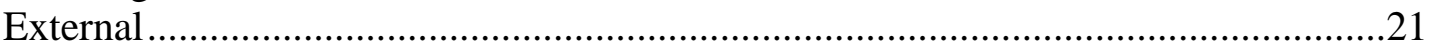

Dose Selection Rationale for the Prenatal Developmental Toxicity Study in

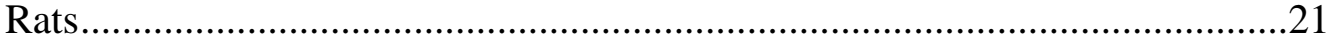

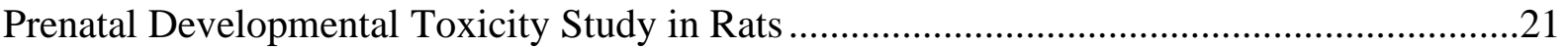

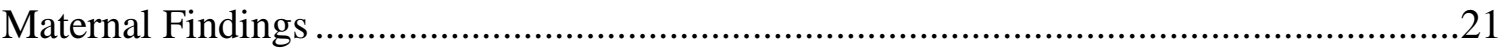

Viability and Clinical Observations.....................................................................21

Body Weights and Feed Consumption ......................................................................21

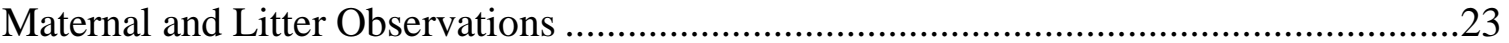

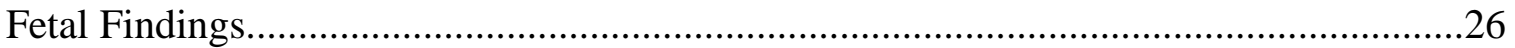

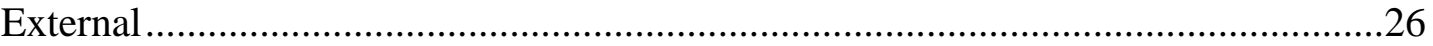

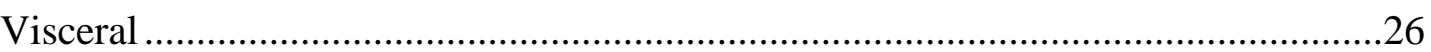

Head 27

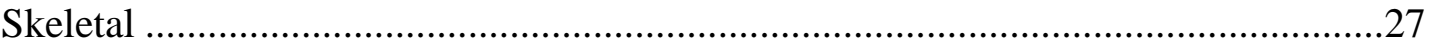

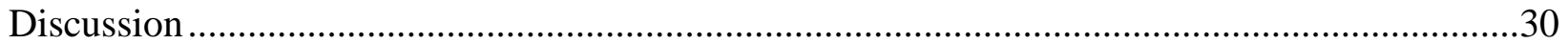

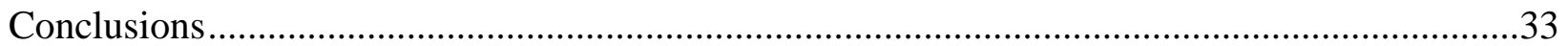

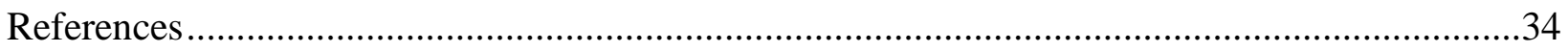

Appendix A. Chemical Characterization and Dose Formulation Studies.................................. A-1

Appendix B. Ingredients, Nutrient Composition, and Contaminant Levels in NIH-07 Rat

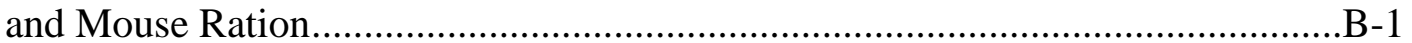

Appendix C. Summary of Peer Review Panel Comments..........................................................

Appendix D. Supplemental Files ......................................................................................... D-1 


\section{Tables}

Summary of Exposure-related Findings in Rats in the Prenatal Developmental Toxicity

Gavage Study of 4-Methylcyclohexanemethanol xvi

Table 1. Experimental Design and Materials and Methods in the Dose Range-finding and Prenatal Developmental Toxicity Gavage Studies of 4-Methylcyclohexanemethanol

Table 2. Maternal Disposition of Rats in the Dose Range-finding Gavage Study of 4-Methylcyclohexanemethanol

Table 3. Summary of Maternal Body Weight Gains of Rats in the Dose Range-finding Gavage Study of 4-Methylcyclohexanemethanol

Table 4. Summary of Maternal Feed Consumption of Rats in the Dose Range-finding

Gavage Study of 4-Methylcyclohexanemethanol

Table 5. Summary of Uterine Content Data for Rats in the Dose Range-finding Gavage Study of 4-Methylcyclohexanemethanol.

Table 6. Maternal Disposition of Rats in the Prenatal Developmental Toxicity Gavage Study of 4-Methylcyclohexanemethanol.

Table 7. Summary of Maternal Body Weight Gains of Rats in the Prenatal Developmental Toxicity Gavage Study of 4-Methylcyclohexanemethanol ${ }^{\mathrm{a}}$

Table 8. Summary of Maternal Feed Consumption of Rats in the Prenatal Developmental Toxicity Gavage Study of 4-Methylcyclohexanemethanol

Table 9. Selected Clinical Chemistry Findings in Rats in the Prenatal Developmental Toxicity Gavage Study of 4-Methylcyclohexanemethanol

Table 10. Summary of Uterine Content Data for Rats in the Prenatal Developmental Toxicity Gavage Study of 4-Methylcyclohexanemethanol

Table 11. Summary of Selected Fetal Visceral Findings in Rats in the Prenatal Developmental Toxicity Gavage Study of 4-Methylcyclohexanemethanol. .26

Table 12. Summary of Selected Fetal Skeletal Findings in Rats in the Prenatal Developmental Toxicity Gavage Study of 4-Methylcyclohexanemethanol.

\section{Figures}

Figure 1. 4-Methylcyclohexanemethanol (CASRN: 34885-03-5; Chemical Formula:

$\mathrm{C}_{8} \mathrm{H}_{16} \mathrm{O}$; Molecular Weight: 128.21) 1

Figure 2. Design of a Dose Range-finding and Prenatal Developmental Toxicity Study in Rats.

Figure 3. Maternal Growth Curves for Pregnant Rats Administered 4-Methylcyclohexanemethanol by Gavage in the Dose Range-finding Study

Figure 4. Maternal Growth Curves for Pregnant Rats Administered 4-Methylcyclohexanemethanol by Gavage in the Prenatal Developmental Toxicity Study 


\section{About This Report}

National Toxicology Program ${ }^{1}$

${ }^{1}$ Division of the National Toxicology Program, National Institute of Environmental Health Sciences, Research Triangle Park, North Carolina, USA

\section{Collaborators}

A.T.D. Watson, S.S. Auerbach, L.J. Betz, C.R. Blystone, S. Brecher, B.J. Collins, M.C. Cora, H.C. Cunny, K.K. Daniels, J.M. Fostel, P.M. Foster, S.F. Harris, C.D. Hébert, M.J. Hooth, S. Iyer, A.P. King-Herbert, G.E. Kissling, J.D. Krause, C.G. Leach, S.A. Masten, B.S. McIntyre, E. Mylchreest, A. Penman, K.R. Ryan, K.A. Shipkowski, K.R. Shockley, M.V. Smith, A.H. Stokes, V.L. Sutherland, V.S. Tharakan, S. Waidyanatha, N.J. Walker

Division of the National Toxicology Program, National Institute of Environmental Health Sciences, Research Triangle Park, North Carolina, USA

Evaluated and interpreted results and reported findings

A.T.D. Watson, Ph.D., Study Scientist

S.S. Auerbach, Ph.D.

C.R. Blystone, Ph.D.

B.J. Collins, M.S.P.H.

M.C. Cora, D.V.M.

H.C. Cunny, Ph.D.

J.M. Fostel, Ph.D.

P.M. Foster, Ph.D. (Retired)

M.J. Hooth, Ph.D.

A.P. King-Herbert, D.V.M.

G.E. Kissling, Ph.D. (Retired)

S.A. Masten, Ph.D.

B.S. McIntyre, Ph.D.

K.R. Ryan, Ph.D.

K.A. Shipkowski, Ph.D.

K.R. Shockley, Ph.D.

V.L. Sutherland, Ph.D.

S. Waidyanatha, Ph.D.

N.J. Walker, Ph.D.

Southern Research, Birmingham, Alabama, USA

Conducted studies and evaluated fetal findings

C.D. Hébert, Ph.D., Principal Investigator

E. Mylchreest, Ph.D., Study Director

K.K. Daniels, Ph.D.

A. Penman, Ph.D.

A.H. Stokes, Ph.D. 
Social \& Scientific Systems, Inc., Research Triangle Park, North Carolina, USA

Provided statistical analyses

M.V. Smith, Ph.D., Principal Investigator

L.J. Betz, M.S.

S.F. Harris, M.S.

J.D. Krause, Ph.D.

C.G. Leach, M.S.

\section{Contributors}

Division of the National Toxicology Program, National Institute of Environmental Health Sciences, Research Triangle Park, North Carolina, USA

Provided oversight of report audit and preparation

G.K. Roberts, Ph.D.

M.K. Vallant, M.S., MT

Provided oversight of external peer review

E.A. Maull, Ph.D.

M.S. Wolfe, Ph.D.

Vistronix, Research Triangle Park, North Carolina, USA

Prepared data for report

P. Brown, B.S.

H. Gong, M.S.

C. Martini, B.S.

C. Myers, M.S.

N. Sayers, B.S.

M. Shaw, B.S.

R. Whittlesey, M.S.

MRI Global, Kansas City, Missouri, USA

Conducted pretest chemistry activities and prepared dose formulations

J. Algaier, Ph.D., Principal Investigator

L. Siemann, B.S.

K. Aillon, Ph.D.

CSS Corporation, Research Triangle Park, North Carolina, USA

Prepared quality assessment audits

S. Brecher, Ph.D., Principal Investigator

S. Iyer, B.S.

V.S. Tharakan, D.V.M.

Biotechnical Services, Inc., Little Rock, Arkansas, USA

Prepared draft report

S.R. Gunnels, M.A., Principal Investigator

K.K. Coker, Ph.D.

B.F. Hall, M.S. 
L.M. Harper, B.S.

D.C. Serbus, Ph.D.

\section{ICF, Durham, North Carolina, USA}

Provided contract oversight, edited and formatted report, and supported peer review D.F. Burch, M.E.M., Contract Manager

S.E. Blaine, B.A.

T.W. Cromer, M.P.S.

L.M. Green, M.P.H.

T. Hamilton, M.S.

B.C. Riley, B.S. 


\section{Explanation of Levels of Evidence for Developmental Toxicity}

The National Toxicology Program (NTP) describes the results of individual studies of chemical agents and other test articles and notes the strength of the evidence for conclusions regarding each study. Generally, each study is confined to a single laboratory animal species, although in some instances, multiple species may be investigated under the purview of a single study report. Negative results, in which the study animals do not exhibit evidence of developmental toxicity, do not necessarily imply that a test article is not a developmental toxicant, but only that the test article is not a developmental toxicant under the specific conditions of the study. Positive results demonstrating that a test article causes developmental toxicity in laboratory animals under the conditions of the study are assumed to be relevant to humans, unless data are available that demonstrate otherwise. In addition, such positive effects should be assumed to be primary effects, unless there is clear evidence that they are secondary consequences of excessive maternal toxicity. Given that developmental events are intertwined in the reproductive process, effects on developmental toxicity may be detected in reproductive studies. Evaluation of such developmental effects should be based on the NTP Criteria for Levels of Evidence for Developmental Toxicity.

It is critical to recognize that the "levels of evidence" statements described herein describe only developmental hazard. The actual determination of risk to humans requires exposure data that are not considered in these summary statements.

Five categories of evidence of developmental toxicity are used to summarize the strength of the evidence observed in each experiment: two categories for positive results (clear evidence and some evidence); one category for uncertain findings (equivocal evidence); one category for no observable effects (no evidence); and one category for experiments that cannot be evaluated because of major design or performance flaws (inadequate study). Application of these criteria requires professional judgment by individuals with ample experience and an understanding of the animal models and study designs employed. For each study, conclusion statements are made using one of the following five categories to describe the findings. These categories refer to the strength of the evidence of the experimental results and not to potency or mechanism.

\section{Levels of Evidence for Evaluating Developmental System Toxicity}

- Clear evidence of developmental toxicity is demonstrated by data that indicate a dose-related effect on one or more of its four elements (embryo-fetal death, structural malformations, growth retardation, or functional deficits) that is not secondary to overt maternal toxicity.

- Some evidence of developmental toxicity is demonstrated by dose-related effects on one or more of its four elements (embryo-fetal death, structural malformations, growth retardation, or functional deficits), but where there are greater uncertainties or weaker relationships with regard to dose, severity, magnitude, incidence, persistence, and/or decreased concordance among affected endpoints.

- Equivocal evidence of developmental toxicity is demonstrated by marginal or discordant effects on developmental parameters that may or may not be related to the test article. 
- No evidence of developmental toxicity is demonstrated by data from a study with appropriate experimental design and conduct that are interpreted as showing no biologically relevant effects on developmental parameters that are related to the test article.

- Inadequate study of developmental toxicity is demonstrated by a study that, because of major design or performance flaws, cannot be used to determine the occurrence of developmental toxicity.

When a conclusion statement for a particular study is selected, consideration must be given to key factors that would support the selection of an individual category of evidence. Such consideration should allow for incorporation of scientific experience and current understanding of developmental toxicity studies in laboratory animals, particularly with respect to interrelationships between endpoints, impact of the change on development, relative sensitivity of endpoints, normal background incidence, and specificity of the effect. For those evaluations that may be on the borderline between two adjacent levels, some factors to consider in selecting the level of evidence of developmental toxicity are given below:

- Increases in severity and/or prevalence (more individuals and/or more affected litters) as a function of dose generally strengthen the level of evidence, keeping in mind that the specific manifestation may be different with increasing dose. For example, malformations may be observed at a lower dose level, but higher doses may produce embryo-fetal death.

- Effects seen in many litters may provide stronger evidence than effects confined to one or a few litters, even if the incidence within those litters is high.

- Because of the complex relationship between maternal physiology and development, evidence for developmental toxicity may be greater for a selective effect on the embryo-fetus or pup.

- Concordant effects (syndromic) may strengthen the evidence of developmental toxicity. Single endpoint changes by themselves may be weaker indicators of effect than concordant effects on multiple endpoints related by a common process or mechanism.

- In order to be assigned a level of "clear evidence” the endpoint(s) evaluated should normally show a statistical increase in the deficit, or syndrome, on a litter basis.

- In general, the more animals affected, the stronger the evidence; however, effects in a small number of animals across multiple, related endpoints should not be discounted, even in the absence of statistical significance for the individual endpoint(s). In addition, rare malformations with low incidence, when interpreted in the context of historical controls, may be biologically important.

- Consistency of effects across generations in a multigenerational study may strengthen the level of evidence. However, if effects are observed in the $\mathrm{F}_{1}$ generation but not in the $F_{2}$ generation (or the effects occur at a lesser frequency in the $F_{2}$ generation), this may be due to survivor selection for resistance to the effect (i.e., if the effect is incompatible with successful reproduction, then the affected individuals will not produce offspring). 
- Transient changes (e.g., pup weight decrements, reduced ossification in fetuses) by themselves may be weaker indicators of an effect than persistent changes.

- Uncertainty about the occurrence of developmental toxicity in one study may be lessened by effects (even if not identical) that are observed in a second species.

- Insights from supportive studies (e.g., toxicokinetics, ADME, computational models, structure-activity relationships) and developmental findings from other in vivo animal studies (NTP or otherwise) should be drawn upon when interpreting the biological plausibility of an effect.

- New assays and techniques need to be appropriately characterized to build confidence in their utility: their usefulness as indicators of effect is increased if they can be associated with changes in traditional endpoints.

For more information visit: http://ntp.niehs.nih.gov/go/10003. 


\section{Peer Review}

An external ad hoc panel was convened at the National Institute of Environmental Health Sciences, Research Triangle Park, NC on July 31, 2019, to peer review the draft NTP Developmental and Reproductive Toxicity Technical Report on the Prenatal Development Studies of 4-Methylcyclohexanemethanol (CASRN 34885-03-5) in Sprague Dawley (Hsd:Sprague Dawley ${ }^{\circledR} S D^{\circledR}$ ) Rats (Gavage Studies). The public could view the proceedings via webcast and there was opportunity for presentation of oral public comment. The selection of panel members and conduct of the peer review were in accordance with Federal policies and regulations. The panel was charged to:

1. Review and evaluate the scientific and technical elements of each study and its presentation.

2. Determine whether each study's experimental design, conduct, and findings support the NTP's conclusion regarding the prenatal developmental toxicity of the substance tested.

NTP carefully considered the panel's recommendations in finalizing the technical report. The peer review report is provided in Appendix C. Other meeting materials are available on the NTP website (https://ntp.niehs.nih.gov/go/meeting).

\section{Peer Reviewers}

George Daston, Ph.D., Chairperson

The Procter and Gamble Company

Cincinnati, Ohio, USA

\section{Cheryl Broussard, Ph.D.}

Centers for Disease Control and Prevention

Atlanta, Georgia, USA

Alan Hoberman, Ph.D.

Charles River Laboratories Preclinical Services

Horsham, Pennsylvania, USA

Linda Roberts, Ph.D.

NapaTox Consulting LLC

San Francisco, California, USA

Mary Alice Smith, Ph.D.

University of Georgia

Athens, Georgia, USA

Kimberley Treinen, Ph.D.

Sunovion Pharmaceuticals, Inc.

Marlborough, Massachusetts, USA 


\section{Publication Details}

Publisher: National Toxicology Program

Publishing Location: Research Triangle Park, NC

ISSN: 2690-2052

DOI: https://doi.org/10.22427/NTP-DART-02

Report Series: NTP Developmental and Reproductive Toxicity Report Series

Report Series Number: 02

Official citation: National Toxicology Program (NTP). 2020. NTP developmental and reproductive toxicity technical report on the prenatal development studies of 4-methylcyclohexanemethanol (CASRN 34885-03-5) in Sprague Dawley (Hsd:Sprague Dawley ${ }^{\circledR} \mathrm{SD}^{\circledR}$ ) rats (gavage studies). Research Triangle Park, NC: National Toxicology Program. DART Report 02.

\section{Acknowledgments}

This work was supported by the Intramural Research Program (ES103316, ES103318, and ES103319) at the National Institute of Environmental Health Sciences, National Institutes of Health and performed for the National Toxicology Program, Public Health Service, U.S. Department of Health and Human Services under contracts HHSN273201800006C, HHSN273201600020C, HHSN273201300010C, HHSN273201300009C, HHSN316201200054W, HHSN273201300004C, and HHSN273201400020C. 


\section{Abstract}

The organic compound 4-methylcyclohexanemethanol (MCHM) is sold as a mixture and is used to reduce impurities in mined coal. On January 9, 2014, an estimated 10,000 gallons of a mixture containing 75\% MCHM leaked into the Elk River upstream of the intake for West Virginia American Water Company's Elk River plant. Upon review of the available toxicity literature for MCHM, the Centers for Disease Control and Prevention and the Agency for Toxic Substances and Disease Registry set a drinking water advisory level of 1 ppm for MCHM and nominated MCHM and other chemicals present in the Elk River spill to the National Toxicology Program (NTP) for toxicity evaluation. Because of the potential for exposure of pregnant women to MCHM and the absence of adequate developmental toxicity data, NTP conducted studies to characterize the toxicity of MCHM in an accepted regulatory in vivo rat model system that assesses the potential harm to the developing conceptus and pregnant rat. Time-mated pregnant Sprague Dawley (Hsd:Sprague Dawley ${ }^{\circledR}$ SD $^{\circledR}$ ) rats received MCHM (99.8\% pure) in corn oil via gavage from implantation on gestation day (GD) 6 to GD 20, the day before expected parturition. The potential for MCHM to induce overt maternal and fetal toxicity was examined in a dose range-finding study followed by a prenatal developmental toxicity study. The guideline prenatal developmental toxicity studies discussed in this report provide important animal data that can be used to address the adequacy of the 1 ppm advisory level in protecting sensitive human populations.

\section{Dose Range-finding Prenatal Developmental Toxicity Study}

Time-mated female rats ( $\mathrm{n}=10$ /dose level) were administered 0, 150, 300, 600, or $900 \mathrm{mg}$ $\mathrm{MCHM} / \mathrm{kg}$ body weight per day (mg/kg/day) in corn oil by gavage $(2 \mathrm{~mL} / \mathrm{kg})$ from GD 6 to GD 20. Control females ( $0 \mathrm{mg} / \mathrm{kg}$ ) received corn oil vehicle.

All dams in the $900 \mathrm{mg} / \mathrm{kg}$ group were euthanized on GD 7 or 8 due to clinical observations indicating overt toxicity (ataxia, cold to touch, clear ocular discharge, excessive salivation, lethargy/hypoactivity, and/or piloerection); three dams from the $600 \mathrm{mg} / \mathrm{kg}$ group displayed similar clinical observations and were removed from study. Body weight gain from GD 6 to 21 in the $600 \mathrm{mg} / \mathrm{kg}$ group was 44\% lower than that of the vehicle control and was associated with a $13 \%$ reduction in feed consumption during the same interval. No signs of maternal toxicity were observed in the 150 or $300 \mathrm{mg} / \mathrm{kg}$ dose groups.

Dams administered $600 \mathrm{mg} / \mathrm{kg}$ displayed higher postimplantation loss (53\%) and lower gravid uterine weight. MCHM exposure did not affect the number of live fetuses per litter or fetal sex ratio; however, fetal weights were $12 \%$ and $39 \%$ lower in the 300 and $600 \mathrm{mg} / \mathrm{kg}$ exposure groups, respectively. No external malformations or variations were attributed to MCHM exposure.

\section{Prenatal Developmental Toxicity Study}

Due to the maternal toxicity observed at 600 and $900 \mathrm{mg} / \mathrm{kg}$ in the dose range-finding study, time-mated female rats ( $\mathrm{n}=25 /$ dose level) were administered $0,50,100,200$, or $400 \mathrm{mg} / \mathrm{kg} / \mathrm{day}$ in corn oil ( $2 \mathrm{~mL} / \mathrm{kg})$ by gavage from GD 6 to GD 20. Vehicle control animals $(0 \mathrm{mg} / \mathrm{kg})$ received corn oil vehicle.

No clinical observations of toxicity were observed in dams in any dose group. Dams administered $400 \mathrm{mg} / \mathrm{kg}$ had significantly lower (11\%) mean body weight gains compared to vehicle control dams. Dams administered MCHM had slightly higher feed consumption. 
Alterations in dam clinical chemistry included reductions in total protein and globulin concentrations that occurred in a dose-related manner in dams administered $\geq 100 \mathrm{mg} / \mathrm{kg}$.

Dams administered $400 \mathrm{mg} / \mathrm{kg}$ exhibited lower gravid uterine weight. No exposure-related effects were found on the number of live fetuses per litter or fetal sex ratio. Fetal body weight was lower (15\%) in the $400 \mathrm{mg} / \mathrm{kg}$ group. Visceral and skeletal examination identified several anomalies that were attributed to MCHM exposure. Misshapen adrenal glands (malformation) and discolored adrenal glands and kidneys (variations) were observed in fetuses in the $400 \mathrm{mg} / \mathrm{kg}$ group. Malformations and variations of the ribs, sternebrae, and vertebrae were also present in the same exposure group. Findings of misaligned costal cartilage (variation); seventh, right costal cartilage not fused to the sternum (malformation); and an increase in short, cervical supernumerary ribs (SNRs) and full, thoracolumbar SNRs (malformations) were significantly higher in the $400 \mathrm{mg} / \mathrm{kg}$ group. Together, the total incidence of all malformations of the ribs, sternebrae, SNRs, and vertebrae were present in $1.0 \%, 1.1 \%, 2.2 \%, 2.8 \%$, and $15.8 \%$ of fetuses from the $0,50,100,200$, and $400 \mathrm{mg} / \mathrm{kg}$ groups; these findings were present in $13 \%, 14 \%, 14 \%$, $26 \%$, and $57 \%$ of litters, respectively.

The maternal no-observed-effect level (NOEL) was $50 \mathrm{mg} / \mathrm{kg}$ based on MCHM-related changes in clinical chemistry at doses $\geq 100 \mathrm{mg} / \mathrm{kg}$, reduced maternal body weight gain at $400 \mathrm{mg} / \mathrm{kg}$, and overt toxicity observed at doses $\geq 600 \mathrm{mg} / \mathrm{kg}$ in the dose range-finding study. The minimal MCHM-related changes in maternal clinical chemistry would not be expected to affect fetal development. MCHM-related effects (lower fetal weight and specific and total axial skeletal malformations) were observed in fetuses exposed to $400 \mathrm{mg} / \mathrm{kg}$, indicating a fetal NOEL of $200 \mathrm{mg} / \mathrm{kg}$. These findings suggest a significant margin of exposure (>1,000-fold) exists between both the maternal and fetal NOELs in the rat and the estimated exposure of $0.04 \mathrm{mg} / \mathrm{kg} / \mathrm{day}$ in pregnant women at the $1 \mathrm{ppm}$ MCHM advisory level.

\section{Conclusions}

Under the conditions of the prenatal study, there was clear evidence $e^{\dagger}$ of developmental toxicity of MCHM in Sprague Dawley (Hsd:Sprague Dawley ${ }^{\circledR}$ SD $^{\circledR}$ ) rats based on reduced fetal weight, adrenal malformations, and increased malformations of the axial skeleton (short cervical SNR, full thoracolumbar SNR, and costal cartilage not fused to the sternum). These findings occurred in fetuses of dams administered $400 \mathrm{mg} / \mathrm{kg}$ and in the absence of overt maternal toxicity.

Synonyms: Cyclohexanemethanol, 4-methyl-; MCHM

${ }^{\dagger}$ See Explanation of Levels of Evidence for Developmental Toxicity. 
Summary of Exposure-related Findings in Rats in the Prenatal Developmental Toxicity Gavage Study of 4-Methylcyclohexanemethanol

\begin{tabular}{|c|c|c|c|c|c|}
\hline & $0 \mathrm{mg} / \mathrm{kg}$ & $50 \mathrm{mg} / \mathrm{kg}$ & $100 \mathrm{mg} / \mathrm{kg}$ & $200 \mathrm{mg} / \mathrm{kg}$ & $400 \mathrm{mg} / \mathrm{kg}$ \\
\hline \multicolumn{6}{|l|}{ Maternal Parameters } \\
\hline Animals on Study & 25 & 25 & 25 & 25 & 25 \\
\hline Number Pregnant & 23 & 21 & 22 & 19 & 21 \\
\hline Number Died or Euthanized Moribund & 0 & 0 & 0 & 0 & 0 \\
\hline Clinical Observations & None & None & None & None & None \\
\hline \multicolumn{6}{|l|}{ Body Weight and Feed Consumption ${ }^{\mathrm{a}}$} \\
\hline Necropsy Body Weight & $370.9 \pm 5.7^{* *}$ & $381.5 \pm 4.3$ & $370.1 \pm 5.8$ & $368.8 \pm 5.6$ & $356.9 \pm 4.9$ \\
\hline Body Weight Change GD 6 to 21 & $131.4 \pm 3.9^{* *}$ & $141.5 \pm 4.3$ & $130.1 \pm 4.8$ & $129.6 \pm 4.9$ & $116.5 \pm 4.1^{*}$ \\
\hline Feed Consumption GD 6 to 21 & $20.7 \pm 0.26^{* *}$ & $21.2 \pm 0.35$ & $21.2 \pm 0.26$ & $21.9 \pm 0.23^{* *}$ & $22.1 \pm 0.29 * *$ \\
\hline Necropsy Observations & None & None & None & None & None \\
\hline \multicolumn{6}{|l|}{ Clinical Pathology } \\
\hline Hematology & None & None & None & None & None \\
\hline Clinical Chemistry & None & None & $\begin{array}{c}\downarrow \text { Total protein } \\
(6 \%) \\
\downarrow \text { Globulin } \\
(10 \%)\end{array}$ & $\begin{array}{c}\downarrow \text { Total protein } \\
(5 \%) \\
\downarrow \text { Globulin } \\
(9 \%)\end{array}$ & $\begin{array}{c}\downarrow \text { Total protein } \\
(8 \%) \\
\downarrow \text { Globulin } \\
(10 \%)\end{array}$ \\
\hline \multicolumn{6}{|l|}{ Developmental/Fetal Parameters } \\
\hline Number of Litters Examined & 23 & 21 & 22 & 19 & 21 \\
\hline Number of Live Fetuses Evaluated & 296 & 283 & 279 & 247 & 254 \\
\hline Number of Live Fetuses per Litter ${ }^{c}$ & $12.87 \pm 0.64$ & $13.48 \pm 0.58$ & $12.68 \pm 0.71$ & $13.00 \pm 0.81$ & $12.10 \pm 0.79$ \\
\hline Number of Early Resorptions ${ }^{\mathrm{b}}$ & 21 & 16 & 12 & 14 & 20 \\
\hline Number of Late Resorptions ${ }^{\mathrm{b}}$ & 1 & 2 & 0 & 0 & 0 \\
\hline Number of Dead Fetuses & 0 & 0 & 0 & 0 & 0 \\
\hline Number of Whole Litter Resorptions ${ }^{\mathrm{b}}$ & 0 & 0 & 1 & 0 & 0 \\
\hline Percent Postimplantation Loss & $8.02 \pm 2.47$ & $6.54 \pm 3.13$ & $8.09 \pm 4.50$ & $5.18 \pm 1.96$ & $7.76 \pm 2.51$ \\
\hline Fetal Body Weight per Litter ${ }^{\mathrm{a}}$ & $5.14 \pm 0.07^{* *}$ & $5.16 \pm 0.08$ & $5.14 \pm 0.07$ & $4.98 \pm 0.09$ & $4.39 \pm 0.09 * *$ \\
\hline Male Fetal Body Weight per Litter & $5.28 \pm 0.06^{* *}$ & $5.30 \pm 0.08$ & $5.28 \pm 0.07$ & $5.12 \pm 0.09$ & $4.46 \pm 0.09 * *$ \\
\hline Female Fetal Body Weight per Litter & $4.99 \pm 0.07 * *$ & $5.00 \pm 0.08$ & $4.98 \pm 0.07$ & $4.82 \pm 0.09$ & $4.34 \pm 0.12^{* *}$ \\
\hline Gravid Uterine Weight $^{\mathrm{a}}$ & $91.76 \pm 4.05^{* *}$ & $96.88 \pm 3.61$ & $90.41 \pm 4.83$ & $88.57 \pm 4.88$ & $75.58 \pm 4.20 * *$ \\
\hline External Findings & None & None & None & None & None \\
\hline \multicolumn{6}{|l|}{ Visceral Findings $^{\mathrm{d}}$} \\
\hline \multicolumn{6}{|l|}{ Abdominal Viscera } \\
\hline \multicolumn{6}{|l|}{ Adrenal, total, discolored - [V] } \\
\hline Fetuses & $0(0.0)^{*}$ & $1(0.4)$ & $0(0.0)$ & $0(0.0)$ & $3(1.2)$ \\
\hline Litters & $0(0.00)^{*}$ & $1(4.76)$ & $0(0.00)$ & $0(0.00)$ & $3(14.29)$ \\
\hline \multicolumn{6}{|l|}{ Adrenal, total, misshapen - [M] } \\
\hline Fetuses & $0(0.0)^{*}$ & $1(0.4)$ & $0(0.0)$ & $0(0.0)$ & $3(1.2)$ \\
\hline Litters & $0(0.00)^{*}$ & $1(4.76)$ & $0(0.00)$ & $0(0.00)$ & $3(14.29)$ \\
\hline
\end{tabular}




\begin{tabular}{lccccc}
\hline & $\mathbf{0 ~} \mathbf{~ m g} / \mathbf{k g}$ & $\mathbf{5 0} \mathbf{~} \mathbf{g g} / \mathbf{k g}$ & $\mathbf{1 0 0} \mathbf{~} \mathbf{~ g} / \mathbf{k g}$ & $\mathbf{2 0 0} \mathbf{~} \mathbf{~ g} / \mathbf{k g}$ & $\mathbf{4 0 0} \mathbf{~} \mathbf{g g} / \mathbf{k g}$ \\
\hline $\begin{array}{l}\text { Urinary Tract } \\
\text { Kidney, total, discolored }-[\mathrm{V}]\end{array}$ & & & & & \\
$\quad$ Fetuses & $0(0.0)^{*}$ & $1(0.4)$ & $0(0.0)$ & $0(0.0)$ & $3(1.2)$ \\
$\quad$ Litters & $0(0.00)^{*}$ & $1(4.76)$ & $0(0.00)$ & $0(0.00)$ & $3(14.29)$
\end{tabular}

\section{Skeletal Findings}

Ribs

Costal cartilage, total, misaligned - [V]

$\begin{array}{lccccc}\text { Fetuses } & 0(0.0)^{* *} & 0(0.0) & 0(0.0) & 0(0.0) & 3(1.2) \\ \text { Litters } & 0(0.00)^{*} & 0(0.00) & 0(0.00) & 0(0.00) & 2(9.52)\end{array}$

Costal cartilage, 7th right, not fused to sternum - [M]

$\begin{array}{lccccc}\text { Fetuses } & 0(0.0)^{* *} & 0(0.0) & 0(0.0) & 2(0.8) & 4(1.6)^{*} \\ \text { Litters } & 0(0.00)^{* *} & 0(0.00) & 0(0.00) & 1(5.26) & 4(19.05)^{*}\end{array}$

Sternebrae

Sternebra, total, unossified or misaligned - [V]

$\begin{array}{lccccc}\text { Fetuses } & 0(0.0)^{* *} & 1(0.4) & 0(0.0) & 0(0.0) & 7(2.8)^{* *} \\ \text { Litters } & 0(0.00)^{* *} & 1(4.76) & 0(0.00) & 0(0.00) & 6(28.57)^{* *}\end{array}$

Vertebrae

Thoracic centrum, total, incomplete ossification or unossified - [V]

$\begin{array}{llcccc}\text { Fetuses } & 0(0.0)^{* *} & 1(0.4) & 0(0.0) & 0(0.0) & 4(1.6)^{*} \\ \text { Litters } & 0(0.00)^{*} & 1(4.76) & 0(0.00) & 0(0.00) & 3(14.29)\end{array}$

Supernumerary Rib

Cervical, total, short - [M]

$\begin{array}{lccccc}\text { Fetuses } & 0(0.0)^{* *} & 0(0.0) & 0(0.0) & 0(0.0) & 6(2.4)^{* *} \\ \text { Litters } & 0(0.00)^{* *} & 0(0.00) & 0(0.00) & 0(0.00) & 3(14.29) \\ \begin{array}{l}\text { Thoracolumbar, total, full }-[\mathrm{M}] \\ \text { Fetuses }\end{array} & 2(0.7)^{* * \#} & 1(0.4) & 6(2.2) & 5(2.0) & 26(10.2)^{* * \# \#} \\ \text { Litters } & 2(8.70)^{* *} & 1(4.76) & 3(14.29) & 4(21.05) & 7(33.33)\end{array}$

Level of Evidence of Developmental Toxicity: Clear Evidence

*Statistically significant ( $\mathrm{p} \leq 0.05)$ trend (denoted in vehicle control column) or pairwise comparison (denoted in dose group column).

${ }^{* *} \mathrm{p} \leq 0.01$.

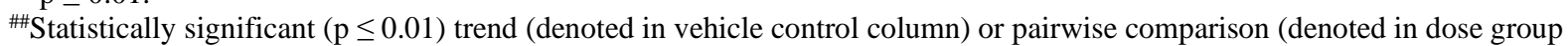
column) in litter-based analysis of fetuses.

$\mathrm{GD}$ = gestation day; $[\mathrm{M}]$ = malformation; $[\mathrm{V}]$ = variation .

${ }^{a}$ Results given in grams. Data are displayed as mean \pm standard error.

${ }^{b}$ No statistical analyses were performed on number of early resorptions, number of late resorptions, or number of whole litter resorptions.

${ }^{\mathrm{c}}$ Data are displayed as mean \pm standard error.

${ }^{\mathrm{d} U p p e r ~ r o w ~ d e n o t e s ~ t h e ~ n u m b e r ~ o f ~ a f f e c t e d ~ f e t u s e s ~ a n d ~(\%) ~ a n d ~ l o w e r ~ r o w ~ t h e ~ n u m b e r ~ o f ~ a f f e c t e d ~ l i t t e r s ~ a n d ~(\%) . ~}$ 


\section{Overview}

The Centers for Disease Control and Prevention and the Agency for Toxic Substances and Disease Registry nominated chemicals associated with the 2014 Elk River spill in West Virginia to the National Toxicology Program (NTP) for toxicology studies. In response, NTP performed research to evaluate the toxicity of 4-methylcyclohexanemethanol and the additional chemical components of crude 4-methylcyclohexanemethanol through various short-term studies. The goals of this research program were to: (1) evaluate the teratogenic, immunotoxic, and genotoxic potential of 4-methylcyclohexanemethanol; (2) identify sensitive biological effects of the spill chemicals and provide additional information about the levels at which there are no adverse effects; and (3) use efficient medium- and high-throughput methods to predict qualitative and quantitative toxicological properties of all chemicals spilled into the Elk River.

These goals were addressed using guideline prenatal developmental toxicity studies in rats, dermal irritation and hypersensitivity studies in mice, short-term toxicogenomic studies in rats, medium-throughput screening assessments in lower animal models, and cell-based highthroughput screening assays. The information and results presented in this report on developmental and reproductive toxicity are specific to the prenatal developmental toxicity studies on 4-methylcyclohexanemethanol; however, further information about the NTP research program related to the Elk River spill in West Virginia is available at https://ntp.niehs.nih.gov/go/wvspill. 


\section{Introduction}

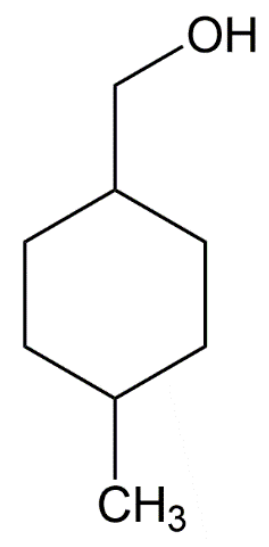

Figure 1. 4-Methylcyclohexanemethanol (CASRN: 34885-03-5; Chemical Formula: $\mathrm{C}_{8} \mathrm{H}_{16} \mathrm{O}$; Molecular Weight: 128.21)

Synonyms: Cyclohexanemethanol, 4-methyl-; MCHM.

\section{Chemical and Physical Properties}

The organic compound 4-methylcyclohexanemethanol (MCHM) has a molecular weight of $128.21 \mathrm{~g} / \mathrm{mol}$ and a density of $0.9074 \mathrm{~g} / \mathrm{cm}^{3}$. MCHM has estimated boiling and melting points of $203.7^{\circ} \mathrm{C}$ and $-12.0^{\circ} \mathrm{C}$, respectively, and a vapor pressure of $0.0588 \mathrm{~mm} \mathrm{Hg}$ at $25^{\circ} \mathrm{C}$. It has a low estimated water solubility of $2.024 \times 10^{3} \mathrm{mg} / \mathrm{L}$ (at $25^{\circ} \mathrm{C}$ ) and an estimated log Kow of 2.55 .

MCHM is a clear, colorless oil and has been reported to have an alcohol or licorice-like odor. ${ }^{1-3}$

\section{Production, Use, and Human Exposure}

The production volume of MCHM is not available, but it is typically sold as a crude mixture for use as a frothing agent to remove impurities during the processing of coal. The crude mixture contains 68-89\% MCHM with other components including 4-(methoxymethyl)cyclohexanemethanol (4-22\%), water (4-10\%), methyl 4-methylcyclohexanecarboxylate (5\%), dimethyl 1,4-cyclohexanedicarboxylate (1\%), methanol (1\%), and 1,4-cyclohexanedimethanol (1-2\%). ${ }^{3}$ Exposure to MCHM can occur via dermal or inhalation routes during the handling or use of the chemical. Of the cis- and trans-isomers, the trans-MCHM is thought to be the dominant source of the licorice odor with an air odor threshold concentration of $0.060 \mathrm{ppb} / \mathrm{v}^{4}$; 5

On January 9, 2014, approximately 10,000 gallons of a mixture of chemicals containing predominantly MCHM leaked into the Elk River upstream of the intake for West Virginia American Water Company's Elk River plant, a municipal water source serving approximately 300,000 people in Charleston, West Virginia. ${ }^{6}$ A number of chemicals were identified in the spill, including crude MCHM (estimated at 88.5\%), propylene glycol ether, and dipropylene glycol phenyl ether. ${ }^{7}$ Of the crude MCHM in the mixture, MCHM alone was estimated to be $75 \%$ of the entire 10,000 -gallon spill. ${ }^{8}$ The spill temporarily contaminated $15 \%$ of the state's tap water, and prior to flushing, concentrations of MCHM in tap water ranged from less than 10 to 420 ppb; levels of the other components of crude MCHM were not measured. ${ }^{9}$ Concentrations of 
MCHM were also measured at the intake (up to $3.35 \mathrm{ppm}$ ) and posttreatment (up to $2.4 \mathrm{ppm}$ ). ${ }^{6}$ Exposure to $2.4 \mathrm{ppm}$ is approximately equivalent to $0.07 \mathrm{mg} / \mathrm{kg}$ body weight per day for an adult (70 kg) consuming $2 \mathrm{~L}$ of water a day, $0.10 \mathrm{mg} / \mathrm{kg} /$ day for a pregnant woman (58 kg) consuming $2.5 \mathrm{~L}$ of water a day, and $0.24 \mathrm{mg} / \mathrm{kg} /$ day for a child $(10 \mathrm{~kg})$ consuming $1 \mathrm{~L}$ of water a day. Levels of the other components of crude MCHM were not measured.

\section{Regulatory Status}

Workplace exposure limits for MCHM are currently unavailable. Immediately following the Elk River spill, the Centers for Disease Control and Prevention (CDC) and the Agency for Toxic Substances and Disease Registry (ATSDR) established a short-term drinking water limit of $1 \mathrm{ppm}$ that was based on the approximate weight $(10 \mathrm{~kg})$ and drinking water intake $(1 \mathrm{~L})$ of a child. ${ }^{8}$ Evaluation of the same data using differing adjustment factors resulted in a calculated health advisory level of 120 ppb. ${ }^{10}$

\section{Absorption, Distribution, Metabolism, and Excretion}

The literature contains no studies on the absorption, distribution, metabolism, or excretion of MCHM in experimental animals or humans.

\section{Developmental and Reproductive Toxicity}

\section{Experimental Animals}

The literature contains no guideline developmental or reproductive toxicity studies of MCHM. In a 28-day repeat oral exposure study, no effects were observed on the histology of the testis or ovaries. ${ }^{11}$ NTP conducted guideline prenatal developmental toxicity studies in alternative models, including the nematode (Caenorhabditis elegans) and zebrafish (Danio rerio). MCHM did not display signs of toxicity in growth, development, feeding, or reproduction in the nematode assay. ${ }^{12}$ In zebrafish, no effects on embryonic and early larval development toxicity were observed following exposure to MCHM at concentrations of up to $100 \mu \mathrm{M}$ (12.8 ppm) for 120 hours. ${ }^{13}$ Some indications of developmental neurotoxicity were identified in the zebrafish model with reduced embryo reaction to light pulses at concentrations of 35 to $100 \mu \mathrm{M} \mathrm{MCHM.}{ }^{14}$

\section{Humans}

The literature contains no studies on the developmental or reproductive toxicity of MCHM in humans.

\section{General Toxicity}

\section{Experimental Animals}

The acute dermal toxicity of MCHM was evaluated in male and female rats [Crl:CD(SD)BR] administered a single topical dose $(0,2,6$, or $20 \mathrm{~mL} / \mathrm{kg}) .{ }^{15}$ A dermal $\mathrm{LD}_{50}$ value of $3.6 \mathrm{~mL} / \mathrm{kg}$ was determined for both males and females. 
Oral $\mathrm{LD}_{50}$ values for MCHM were determined from an acute oral toxicity study in rats [Crl:CD(SD)BR] administered a single dose $(0,625,1,250$, or $2,500 \mathrm{mg} / \mathrm{kg})$ by oral gavage. ${ }^{15}$ $\mathrm{LD}_{50}$ values of 1,768 and $884 \mathrm{mg} / \mathrm{kg}$ were calculated for male and female rats, respectively.

Administration of $0.5 \mathrm{~mL}$ MCHM in a guinea pig dermal irritation study (Crl:[HA]BR Hartley; $\mathrm{n}=5$ ) resulted in strong irritation 24 hours after an occluded single dose. ${ }^{15}$ In the same guinea pig species, a repeated skin test (9 applications over 11 days) of $0.5 \mathrm{~mL}$ MCHM found an increased irritant response with moderate edema, moderate necrosis, and moderate to strong eschars. ${ }^{15}$ MCHM was not found to be a skin sensitizer in the guinea pig $(n=10)$ after application of $0.05 \mathrm{~mL}$ to the footpad and was determined to be a moderate eye irritant in New Zealand white rabbits after a single application of $0.1 \mathrm{~mL} .^{15}$

In skin irritation and sensitization studies by NTP, mild skin irritation was induced in BALB/c mice after 3 days of application of $0 \%, 2 \%, 20 \%$, or 50\% MCHM solution in 4:1 acetone:olive oil (vehicle); hypersensitivity was not induced by the same concentrations. ${ }^{16 ; 17}$

In a preliminary study to determine doses for a 28-day toxicity study, two male and two female rats were orally administered $0,200,400$, or $800 \mathrm{mg} \mathrm{MCHM/kg}$ body weight per day (mg/kg/day) via oral gavage for 5 days. Clinical signs of ataxia and decreased activity were observed in both sexes at $800 \mathrm{mg} / \mathrm{kg}$, and one female rat was euthanized. ${ }^{11}$

Male and female rats exposed to $\operatorname{MCHM}(0,25,100$, or $400 \mathrm{mg} / \mathrm{kg} / \mathrm{day})$ by oral gavage, 5 days per week for 4 weeks exhibited increased liver weights, kidney tubular degeneration, and inflammation at $400 \mathrm{mg} / \mathrm{kg}$. ${ }^{11}$ A no-observed-effect level (NOEL) was set at $100 \mathrm{mg} / \mathrm{kg}$. The results of that study were used by ATSDR to establish the short-term drinking water limit of 1 ppm for MCHM.

MCHM was found to activate a low number of genes associated with gene expression pathways within the rat liver after 5 days of exposure. ${ }^{18}$ Benchmark dose values of these pathways ranged from 107 to $495 \mathrm{mg} / \mathrm{kg} /$ day. In the same study, no significant changes were observed in kidney gene expression. Other effects observed in the 5-day toxicogenomic study included decreases in thymus weight at 300 and $500 \mathrm{mg} / \mathrm{kg} /$ day and an increase in triglycerides and a slight increase in liver weight at $500 \mathrm{mg} / \mathrm{kg} / \mathrm{day}$.

\section{Humans}

No direct studies of MCHM exposure on human health have been conducted. An indirect measurement of potential human health effects following the Elk River spill was conducted via a survey of 498 households and found that 159 households reported an illness related to the spill. ${ }^{19}$ These health effects consisted of rash or skin irritation, nausea or vomiting, diarrhea or abdominal cramps, headache or dizziness, or eye irritation.

\section{Genetic Toxicity}

MCHM was evaluated for genetic toxicity by NTP. It was negative in a micronucleus assay after 5 days of exposure in Sprague Dawley (Hsd:Sprague Dawley ${ }^{\circledR}$ SD $^{\circledR}$ ) rats. $^{20}$ In addition, MCHM was negative up to $1,000 \mu \mathrm{g} /$ plate in two Salmonella typhimurium strains and one Escherichia coli strain. ${ }^{21}$ 


\section{Study Rationale}

The CDC and the ATSDR nominated MCHM and other chemicals associated with the Elk River spill to NTP for toxicity evaluation. In response, NTP conducted a number of studies of relatively short duration to provide information relevant to the potential exposures of the Charleston, West Virginia, residents. Because of the potential exposure to pregnant women and the developing fetus during gestation and concern for potential future exposures, NTP conducted prenatal developmental toxicity studies in rats to assess potential MCHM toxicity. 


\section{Materials and Methods}

\section{Overview of Prenatal Developmental Toxicity Study Designs}

Prenatal developmental toxicity studies are conducted to ascertain if in utero exposure to a test agent results in embryo-fetal death, structural malformations/variations, growth retardation, or functional deficits not secondary to overt maternal toxicity. Overt maternal toxicity has been shown to affect normal embryo-fetal growth and development (e.g., excessively lower maternal body weight gains and lower fetal weights, increased maternal stress in mice, and cleft palate). ${ }^{22-}$ 24 The presence of maternal toxicity, however, should not negate a priori an apparent fetal response. Rather, given the maternal/embryo-fetal interrelationship, maternal responses should be considered when interpreting fetal findings. Pregnant animals should be administered the highest feasible dose levels of test agent (or the limit dose) to achieve maximal dam and fetal exposure and sufficiently challenge the test system to identify potential developmental hazards. ${ }^{25}$

The conduct of a dose range-finding study helps determine dose selection when the potential for test agent-induced maternal toxicity is unknown and can provide preliminary information on embryo-fetal outcomes (e.g., postimplantation loss, changes in fetal weight, external defects) and informs the design for a prenatal developmental toxicity study. In the prenatal developmental toxicity study, fetal examination is expanded to include examination of the fetal viscera, head (soft tissue and skeletal components), and the skeleton for osseous and cartilaginous defects. Abnormalities are categorized in one of two groups: (1) malformations that are permanent structural changes that could adversely affect survival, development, or function; and (2) variations that are a divergence beyond the usual range of structural constitution but might not adversely affect survival or health, ${ }^{23}$ consistent with the descriptions by Makris et al. ${ }^{26}$ The study design for the dose range-finding and prenatal developmental toxicity studies is presented in Figure 2. 


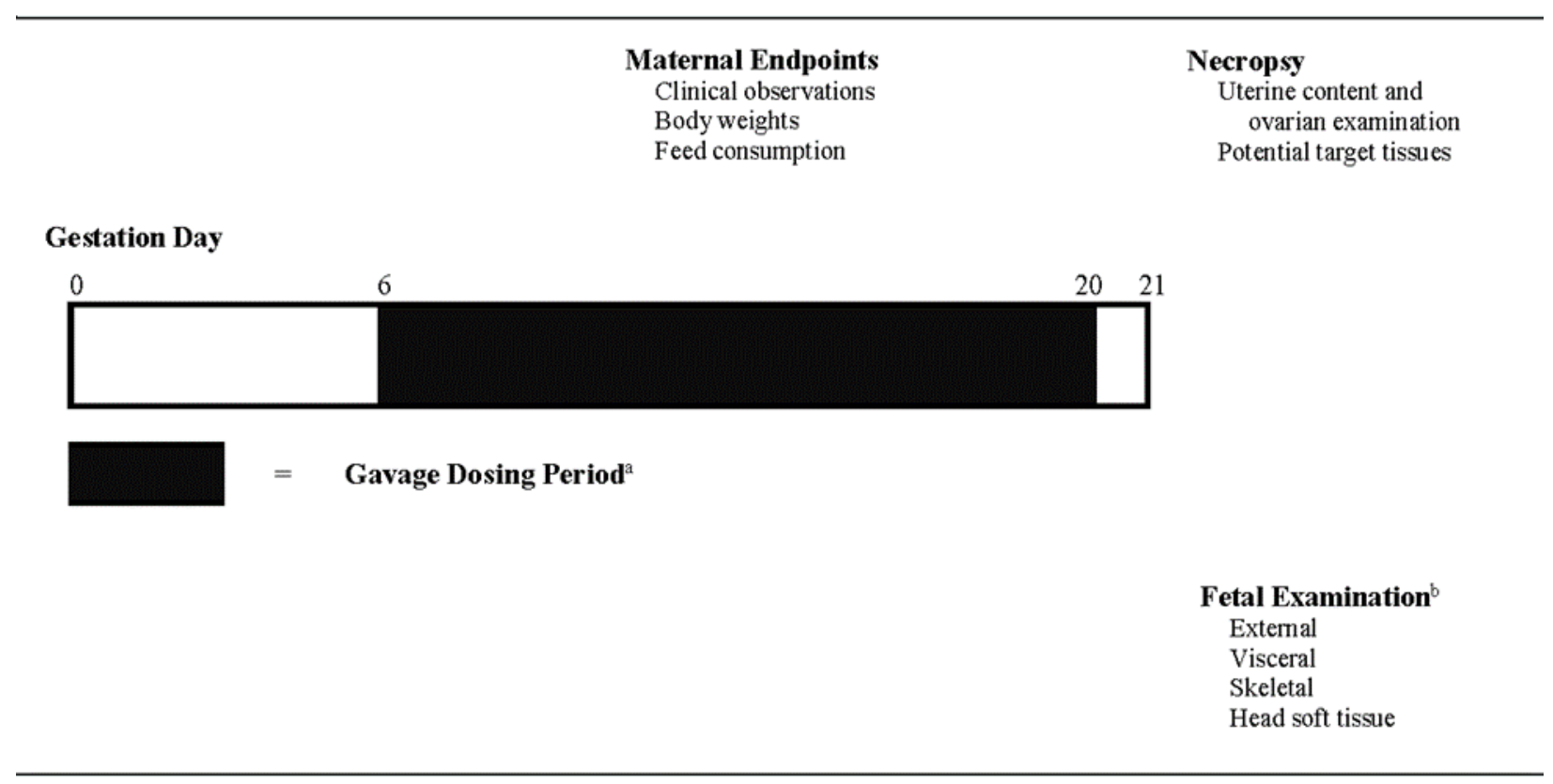

Figure 2. Design of a Dose Range-finding and Prenatal Developmental Toxicity Study in Rats

${ }^{\text {a} A n i m a l s ~ a r e ~ e x p o s e d ~ o n c e ~ d a i l y ~ f r o m ~ g e s t a t i o n ~ d a y ~(G D) ~} 6$ to GD 20 and necropsied on GD 21.

${ }^{b}$ All fetuses are examined externally (including inspection of the oral cavity). Fetuses in the prenatal developmental toxicity study also are examined for visceral and skeletal effects with approximately $50 \%$ of the heads examined for soft tissue alterations.

\section{Procurement and Characterization}

\section{4-Methylcyclohexanemethanol}

4-Methylcyclohexanemethanol (MCHM) was obtained from TCI America (Portland, OR) in one lot (KDY3F). Identity, purity, and stability analyses were conducted by the analytical chemistry laboratory at MRIGlobal (Kansas City, MO) for the study laboratory at Southern Research (Birmingham, AL) (Appendix A).

The chemical, a clear colorless liquid, was identified as MCHM using Fourier transform infrared (FTIR) spectrometry, proton and carbon-13 nuclear magnetic resonance spectroscopy, and gas chromatography (GC) with mass spectrometry detection. In addition, boiling point, density, and octanol:water partition coefficient were determined. Purity of the test article was determined by elemental analyses and GC with flame ionization detection (FID) and two columns with differing polarities.

Karl Fischer titration indicated $0.209 \%$ water. Elemental analyses for carbon, hydrogen, and nitrogen were consistent with the theoretical values for MCHM. GC/FID analysis by one system detected two major peaks with a combined area of $99.97 \%$ of the total peak area and no impurities with areas $\geq 0.05 \%$ of the total peak area. The relative areas of the two major peaks indicated that MCHM consisted of $67.99 \%$ cis- and 31.98\% trans-isomers. GC/FID by a second system detected two major peaks with a combined relative area of $99.83 \%$ (with relative areas of $67.80 \%$ [cis-] and 32.03\% [trans-] isomers), and two minor impurities totaling $0.13 \%$ of the total peak area. The overall purity of lot KDY3F was determined to be greater than or equal to $99.8 \%$. 
Stability studies of the bulk chemical were conducted using GC/FID. These studies indicated that MCHM was stable as a bulk chemical for 2 weeks when stored in amber glass vials under an inert headspace, sealed with aluminum caps with Teflon ${ }^{\circledR}$-lined septa at temperatures up to $60^{\circ} \mathrm{C}$. To ensure stability, the bulk chemical was stored at room temperature under an inert headspace in amber glass bottles. Reanalyses of the bulk chemical were performed using FTIR and GC/FID, and no degradation of the bulk chemical was detected.

\section{Corn Oil}

Corn oil was obtained from Spectrum Laboratory Products, Inc. (Gardena, CA) in two lots (1CK0678 and 2DG0376) that were used as the vehicle in the dose range-finding and prenatal developmental toxicity studies, respectively. A solubility study of MCHM was performed by the analytical chemistry laboratory; after 17 days under refrigerated conditions, the test article remained soluble in corn oil at up to $600 \mathrm{mg} / \mathrm{mL}$ with no remixing required. Both lots contained peroxide levels that were less than the rejection level of 3 milliequivalents (meQ)/kg corn oil.

\section{Preparation and Analysis of Dose Formulations}

The dose formulations were prepared once for the dose range-finding study and once for the prenatal developmental toxicity study by mixing the appropriate amount of MCHM with corn oil. Stability studies of 0.20 and $2.0 \mathrm{mg} / \mathrm{mL}$ formulations were performed by the analytical chemistry laboratory using GC/FID. For the $0.20 \mathrm{mg} / \mathrm{mL}$ formulation, stability was confirmed for at least 42 days during which the formulation was stored under ambient or refrigerated conditions and protected from light, and for 3 hours under simulated animal room conditions. In addition, for the $2.0 \mathrm{mg} / \mathrm{mL}$ formulation, stability was confirmed for at least 44 days during which it was stored under ambient or refrigerated conditions and protected from light.

Analyses of the dose formulations of MCHM were conducted by the analytical chemistry laboratory using GC/FID. During the dose range-finding study, the dose formulations were analyzed once; all four dose formulations were within $10 \%$ of the target concentrations (Table A-3). Animal room samples of these dose formulations were also analyzed; all four animal room samples were within $10 \%$ of the target concentrations. During the prenatal developmental toxicity study, the dose formulations were analyzed once; animal room samples of these dose formulations were analyzed twice (Table A-4). All four dose formulations analyzed were within $10 \%$ of the target concentrations and all eight animal room samples were within $10 \%$ of the target concentrations.

\section{Animal Source}

Female Sprague Dawley (Hsd:Sprague Dawley ${ }^{\circledR} \mathrm{SD}^{\circledR}$ ) rats for use in the dose range-finding and prenatal developmental toxicity studies were obtained from Envigo (formerly Harlan Laboratories, Inc., Indianapolis, IN). Sexually mature (12 to 13 weeks old) females were timemated overnight at the vendor and were received on gestation day (GD) 1 or 2 for both the dose range-finding and prenatal developmental toxicity studies. GD 0 was defined as the day positive evidence of mating was observed. 


\section{Animal Health Surveillance}

Disease screening was not conducted at the laboratory in the rats; however, rats were obtained from a commercial colony free of the following rat pathogens: Sendai virus, pneumonia virus of mice, sialodacryoadenitis virus, Kilham rat virus, Toolan's H1 virus, rat minute virus, reovirus, rat theilovirus, lymphocytic choriomeningitis virus, hantavirus, mouse adenovirus, rat parvovirus, Mycoplasma pulmonis, and Pneumocystis carinii.

\section{Animal Welfare}

Animal care and use are in accordance with the Public Health Service Policy on Humane Care and Use of Animals. All animal studies were conducted in an animal facility accredited by AAALAC International. Studies were approved by the Southern Research Animal Care and Use Committee and conducted in accordance with all relevant National Institutes of Health (NIH) and National Toxicology Program (NTP) animal care and use policies and applicable federal, state, and local regulations and guidelines.

\section{Experimental Design}

In the dose range-finding and prenatal developmental toxicity studies, time-mated rats were housed individually, provided NIH-07 feed and water ad libitum, and observed at least twice daily for viability (morning and afternoon, with at least 6 hours between observations). Clinical observations were recorded at least once from GD 3 through GD 5 and then daily during dosing (GD 6 through GD 20) until removal (1 to 3 hours after dosing). Dams were weighed daily from GD 3 through GD 21 (dose range-finding study) or on arrival, on GD 3, and daily from GD 6 through GD 21 (prenatal developmental toxicity study). Feed consumption was recorded for GD 3 to 6, GD 6 to 9, GD 9 to 12, GD 12 to 15, GD 15 to 18, and GD 18 to 21. Details of the study design - including animal source and identification, diet, water, husbandry, environmental conditions, euthanasia, necropsy, and fetal evaluations-are summarized in Table 1. Information on feed composition and contaminants is provided in Appendix B.

On GD 21, dams were weighed, euthanized with $\mathrm{CO}_{2}$, and examined for gross lesions of the thoracic and abdominal cavities. The gravid uterus and ovaries were excised and weighed (organs for prenatal developmental toxicity study only), and any placental findings were recorded. The numbers of uterine implantation sites and corpora lutea visible on the surface of each ovary were recorded. Uterine contents were examined for pregnancy status, and the numbers and locations of all live and dead fetuses (a live fetus is defined as one that responds to stimuli; a dead fetus is defined as a term fetus that does not respond to stimuli and is not markedly autolyzed) and resorptions were recorded.

Resorptions were classified as early or late. Early resorptions included a conceptus characterized by a grossly necrotic mass that had no recognizable fetal form and presence of nidation sites (“pregnant by stain”). Late resorptions were characterized by grossly necrotic but recognizable fetal form with placental remnants visible. ${ }^{27 ; 28}$ Postimplantation loss was calculated as the number of dead and resorbed conceptuses divided by the total number of implantations (multiplied by 100). For each uterus with no macroscopic evidence of implantation, the uterus was stained with $10 \%$ (v/v) ammonium sulfide to visualize any possible implantation sites. ${ }^{29}$ In the dose range-finding study, the left and right kidney and liver were also weighed. 
Adult females that were euthanized moribund, delivered early, or found dead received a gross necropsy that included an examination of the thoracic and abdominal viscera for evidence of dosing trauma or toxicity. The uterus of each female was examined and stained, if necessary, to determine pregnancy status. Dams were not retained for further examination.

\section{Dose Range-finding Study}

Time-mated rats were individually identified by tail marking and randomized by GD 3 body weight stratification into five treatment groups using the Instem ${ }^{\mathrm{TM}}$ Provantis $^{\circledR}$ (version 8) electronic data collection system.

Groups of 10 time-mated female rats were administered 0 (vehicle control), 150, 300, 600, or $900 \mathrm{mg}$ MCHM/kg body weight per day (mg/kg/day) (based on the most recent body weight) in corn oil by gavage from GD 6 to GD 20. The top dose of $900 \mathrm{mg}$ MCHM/kg per day was selected consistent with the limited data available for MCHM, which includes a 5-day oral gavage study of doses up to $800 \mathrm{mg} / \mathrm{kg} /$ day ( $\mathrm{n}=2$ animals/sex/dose) that was used to select doses for a subsequent 28-day subchronic study. ${ }^{11}$ Vehicle control animals received the corn oil vehicle alone; the dosing volume was $2 \mathrm{~mL} / \mathrm{kg}$ body weight.

On GD 21, fetuses were removed from the uterus, individually weighed (live fetuses only), and examined externally for morphological alterations, including inspection of the oral cavity for cleft palate. Live fetuses were euthanized by intraperitoneal injection of a commercially available solution of sodium pentobarbital followed by bilateral pneumothorax and/or decapitation. External findings were recorded as developmental variations or malformations. Fetuses were not retained following completion of the external examination.

\section{Prenatal Developmental Toxicity Study}

On receipt (GD 1 or 2), time-mated rats were individually identified by tail marking and were randomized by GD 3 body weight stratification into five treatment groups using the Instem ${ }^{\mathrm{TM}}$ Provantis ${ }^{\circledR}$ (version 8) electronic data collection system.

Groups of 25 time-mated female rats were administered 0 (vehicle control), 50, 100, 200, or $400 \mathrm{mg} \mathrm{MCHM} / \mathrm{kg}$ per day (based on the most recent body weight) in corn oil by gavage from GD 6 to GD 20. Vehicle control animals received corn oil vehicle alone; the dosing volume was $2 \mathrm{~mL} / \mathrm{kg}$.

On GD 21, fetuses were removed from the uterus, and live fetuses individually weighed. The uteri of animals that did not appear pregnant were examined for nidations (implantation sites) by staining with $0.5 \%$ ammonium sulfide. ${ }^{29 ; 30}$ All fetuses were examined externally for alterations, including inspection of the oral cavity for cleft palate. Live fetuses were subsequently euthanized by intraperitoneal injection of sodium pentobarbital. Fetal sex was confirmed by inspection of gonads in situ. All fetuses were examined for soft tissue alterations under a stereomicroscope. ${ }^{31}$; 32 The heads were removed from approximately half of the fetuses in each litter and fixed in Bouin's solution and subsequently examined by free-hand sectioning. ${ }^{33}$ This technique precludes skeletal evaluations of the skull; therefore, remaining heads and all fetuses were eviscerated, fixed in ethanol, macerated in potassium hydroxide, stained with alcian blue and alizarin red, and examined for subsequent cartilage and osseous alterations. ${ }^{30 ;} 34$ External, visceral, and skeletal fetal alterations were recorded as developmental variations or malformations. 
Additionally, blood was collected by cardiac puncture from the dams at the time of euthanasia for clinical pathology. Blood was collected into tubes containing potassium EDTA as the anticoagulant for hematology or no anticoagulant for clinical chemistry samples. The contents of the tubes containing anticoagulant were mixed by gentle inversion and maintained at room temperature. Samples obtained for hematology and clinical chemistry were analyzed on the day the samples were collected. Hematology analyses were performed on an Advia 120 analyzer (Siemens Healthcare Diagnostics, Tarrytown, NJ), except manual hematocrit determinations were performed using a microcentrifuge. Platelet, leukocyte, and erythrocyte morphology and nucleated erythrocytes were assessed using smears stained with a Romanowsky-type aqueous stain in a HemaTek Slide Stainer (Siemens Healthcare Diagnostics, Tarrytown, NJ). Serum samples for clinical chemistry analyses were centrifuged, the serum harvested, and analyses performed on a Cobas c501 analyzer (Roche Diagnostic Corp., Indianapolis, IN). The parameters measured are listed in Table 1. 
Table 1. Experimental Design and Materials and Methods in the Dose Range-finding and Prenatal Developmental Toxicity Gavage Studies of 4-Methylcyclohexanemethanol

\begin{tabular}{|c|c|}
\hline Dose Range-finding Study & Prenatal Developmental Toxicity Study \\
\hline \multicolumn{2}{|l|}{ Study Laboratory } \\
\hline Southern Research (Birmingham, AL) & Southern Research (Birmingham, AL) \\
\hline \multicolumn{2}{|l|}{ Strain and Species } \\
\hline Sprague Dawley (Hsd:Sprague Dawley ${ }^{\circledR} \mathrm{SD}^{\circledR}$ ) rats & Sprague Dawley (Hsd:Sprague Dawley ${ }^{\circledR} \mathrm{SD}^{\circledR}$ ) rats \\
\hline \multicolumn{2}{|l|}{ Animal Source } \\
\hline $\begin{array}{l}\text { Envigo (formerly Harlan Laboratories, Inc., } \\
\text { Indianapolis, IN) }\end{array}$ & $\begin{array}{l}\text { Envigo (formerly Harlan Laboratories, Inc., } \\
\text { Indianapolis, IN) }\end{array}$ \\
\hline \multicolumn{2}{|l|}{ Day of Arrival } \\
\hline GD 1 or 2 (August 20, 2014) & GD 1 or 2 (November 12, 14, or 19, 2014) \\
\hline \multicolumn{2}{|l|}{ Average Age on Arrival } \\
\hline 13 weeks & 12 to 13 weeks \\
\hline \multicolumn{2}{|l|}{ Weight Range at Randomization } \\
\hline 206.7 to 266.2 g on GD 3 & 218.6 to 271.9 g on GD 3 \\
\hline \multicolumn{2}{|l|}{ Calendar Day of First Dose (GD 6) and Last Dose (GD 20) } \\
\hline $\begin{array}{l}\text { GD } 6 \text { (August } 24 \text { or 25, 2014) and GD } 20 \text { (September } 7 \\
\text { or 8, 2014); staggered start }\end{array}$ & $\begin{array}{l}\text { GD } 6 \text { (November } 16,17,18,19 \text {, or } 23,2014 \text { ) and } \\
\text { GD } 20 \text { (November } 30 \text { or December 1, 2, 3, or 7, 2014); } \\
\text { staggered start }\end{array}$ \\
\hline \multicolumn{2}{|l|}{ Duration of Dosing } \\
\hline GD 6 to 20, once daily & GD 6 to 20, once daily \\
\hline \multicolumn{2}{|l|}{ Size of Study Groups } \\
\hline 10 time-mated females & 25 time-mated females \\
\hline \multicolumn{2}{|l|}{ Method of Randomization and Identification } \\
\hline $\begin{array}{l}\text { Time-mated animals were uniquely identified on day of } \\
\text { receipt by ink tail marking and assigned to exposure } \\
\text { group by body weight stratified randomization of GD } 3 \\
\text { body weights using Instem Provantis }{ }^{\circledR} \text { (version } 8 \text { ) } \\
\text { electronic data collection system. }\end{array}$ & Same as dose range-finding study \\
\hline \multicolumn{2}{|l|}{$\begin{array}{l}\text { Each animal was assigned a unique animal number in } \\
\text { Provantis. This number was linked to the respective } \\
\text { marking and all data collected during the study was } \\
\text { associated with the Provantis animal number. }\end{array}$} \\
\hline \multicolumn{2}{|l|}{ Animals per Cage } \\
\hline 1 & 1 \\
\hline \multicolumn{2}{|l|}{ Diet } \\
\hline $\begin{array}{l}\text { Irradiated NIH-07 pelleted diet (Zeigler Brothers, Inc., } \\
\text { Gardners, PA), available ad libitum, changed at least } \\
\text { weekly }\end{array}$ & Same as dose range-finding study \\
\hline
\end{tabular}




\begin{tabular}{cc}
\hline Dose Range-finding Study & Prenatal Developmental Toxicity Study \\
\hline Water
\end{tabular}

\section{Water}

Tap water (Birmingham, AL, municipal supply) via automatic watering system (Edstrom Industries, Inc., Waterford, WI), available ad libitum

\section{Cages}

Solid bottom polycarbonate (Lab Products, Seaford, DE), changed weekly

Same as dose range-finding study

\section{Bedding}

Certified irradiated Sani-Chips ${ }^{\circledR}$ hardwood cage bedding Same as dose range-finding study (P.J. Murphy Forest Products Corporation, Montville, NJ), changed weekly

\section{Cage Filters}

Reemay ${ }^{\circledR}$ spunbonded polyester (Andico, Birmingham, Same as dose range-finding study $A L)$, changed every 2 weeks

\section{Racks}

Stainless steel (Lab Products, Inc.), changed every 2 weeks

\section{Animal Room Environment}

Temperature: $72^{\circ} \mathrm{F} \pm 3^{\circ} \mathrm{F}$

Relative humidity: $50 \% \pm 15 \%$

Room fluorescent light: 12 hours/day

Room air changes: at least 17/hour

\section{Doses}

0, 150, 300, 600, or $900 \mathrm{mg} / \mathrm{kg}$ in corn oil (dosing volume $2 \mathrm{~mL} / \mathrm{kg}$ )

\section{Type and Frequency of Observation of Dams}

Observed for viability (cageside) twice daily from GD 3 through GD 20. Clinical observations (out of cage) were recorded at least once from GD 3 through GD 5 and then daily beginning GD 6 at 1 to 3 hours post dose, and at the end of the study. Animals were weighed daily beginning on GD 3. Feed consumption was recorded at 3-day intervals from GD 3 through GD 21.

Same as dose range-finding study

Temperature: $72^{\circ} \mathrm{F} \pm 3^{\circ} \mathrm{F}$

Relative humidity: $50 \% \pm 15 \%$

Room fluorescent light: 12 hours/day

Room air changes: at least 19/hour

$0,50,100,200$, or $400 \mathrm{mg} / \mathrm{kg}$ in corn oil (dosing volume $2 \mathrm{~mL} / \mathrm{kg}$ )

Observed for viability (cageside) at least twice daily from GD 3 through GD 20. Clinical observations (out of cage) were recorded at least once from GD 3 through GD 5 and then daily beginning GD 6 at 1 to 3 hours post dose, and at the end of the study. Animals were weighed on the day of arrival, on GD 3, and daily beginning on GD 6. Feed consumption was recorded at 3-day intervals from GD 3 through GD 21.

\section{Primary Method of Euthanasia}

$100 \% \mathrm{CO}_{2}$ (dams) or intraperitoneal injection of solution Same as dose range-finding study containing sodium pentobarbital followed by bilateral pneumothorax and/or decapitation (fetuses GD $\geq 15$ ) 


\begin{tabular}{l} 
Dose Range-finding Study \\
\hline Necropsy and Postmortem Evaluation of Females \\
On GD 21, terminal body weights, kidney and liver \\
weights, and gravid uterine weights were recorded, and \\
the uterine contents examined. The number of corpora \\
lutea on each ovary was recorded. The number and \\
location of all fetuses (live or dead) and resorptions \\
(early or late) and the total number of implantation sites \\
were recorded; if no macroscopic evidence of \\
pregnancy, the uterus was stained with a 10\% aqueous \\
solution of ammonium sulfide to visualize potential \\
evidence of implantation sites. \\
For early removals, gross necropsy including an \\
examination of the thoracic and abdominal viscera was \\
performed. The uterus of each dam was examined to \\
determine pregnancy status, or, if no evidence of \\
pregnancy, stained with a 10\% aqueous solution of \\
ammonium sulfide to visualize possible early \\
implantation sites.
\end{tabular}

\section{Clinical Pathology}

None

\section{Fetal Evaluation}

Live fetuses were counted, sexed, weighed, and examined for external morphological abnormalities that included inspection of the oral cavity for cleft palate.
Prenatal Developmental Toxicity Study

On GD 21, terminal body weights and gravid uterine weights were recorded, and the uterine contents examined. The number of corpora lutea on each ovary was recorded. The number and location of all fetuses (live or dead) and resorptions (early or late) and the total number of implantation sites were recorded; if no macroscopic evidence of pregnancy, the uterus was stained with a $10 \%$ aqueous solution of ammonium sulfide to visualize potential evidence of implantation sites.

There were no early removals.

Blood was collected from surviving dams by cardiac puncture at the time of euthanasia for hematology and clinical chemistry analyses.

Hematology: hematocrit; hemoglobin concentration; erythrocyte, reticulocyte, platelet, and nucleated erythrocyte counts; mean cell volume; mean cell hemoglobin; mean cell hemoglobin concentration; and leukocyte count and differentials

Clinical Chemistry: urea nitrogen, creatinine, glucose, calcium, phosphorus, total protein, albumin, globulin, albumin/globulin ratio, total bilirubin, direct bilirubin, cholesterol, triglycerides, alanine aminotransferase, alkaline phosphatase, aspartate aminotransferase, and creatine kinase

Live fetuses were counted, sexed, weighed, and examined for external morphological abnormalities that included inspection of the oral cavity for cleft palate. Placental morphology was also evaluated.

Live fetuses were euthanized and then examined for visceral morphological abnormalities by fresh dissection. The sex of each fetus was confirmed by internal examination. The heads from approximately one-half of the fetuses in each litter were fixed, sectioned, and examined. All fetuses were eviscerated, fixed, stained, and examined for skeletal developmental variations, malformations, or other morphological findings.

GD = gestation day. 


\section{Statistical Methods}

In both the dose range-finding study and the main study, statistical analyses were performed on data from pregnant females that survived until the end of the study and were examined on GD 21 and from live fetuses. Statistical analyses were performed using SAS 9.3 (SAS Institute, Cary, NC).

\section{Descriptive Statistics}

Maternal Parameters: Maternal body weights were measured daily starting at GD 3 and reported as means. Terminal maternal body weights at GD 21 were adjusted for gravid uterine weight by subtracting the gravid uterine weight from the dam's body weight. Body weight gains were calculated over each 3-day interval and from GD 6 to GD 21. Daily feed consumption was averaged over each 3-day interval and from GD 6 to GD 21. These continuous variables, in addition to gravid uterine weights, other organ weights, hematology, and clinical chemistry were summarized with means and standard errors.

Placental and Fetal Parameters: Data on uterine contents are reported as means and standard errors of counts per dam/litter (corpora lutea, implants, resorptions, dead fetuses) and as total numbers of occurrences (resorptions, dead fetuses). Data from females that were not pregnant or that did not survive to the end of the study were not included. Postimplantation loss is calculated as a percentage of the number of implants per dam. Fetal findings are reported as means and standard errors of counts per litter (numbers of live fetuses, male fetuses, female fetuses), means and standard errors of litter means (fetal weight, male fetal weight, female fetal weight), and total numbers of occurrences (total number of live fetuses). In addition, several calculated variables are reported, including the percentage of live male and female fetuses per litter.

Incidences of morphological findings from the gross, external, visceral, skeletal, and head examinations of pathology of placentae and fetuses are presented as number and percentage of affected fetuses and as number and percentage of affected litters.

\section{Analysis of Maternal Parameters and Uterine Contents}

Maternal organ and body weight data, which historically have approximately normal distributions, were analyzed with the parametric multiple comparison procedures of Dunnett ${ }^{35}$ and Williams. ${ }^{36 ; 37}$ Non-normally distributed variables, such as food consumption, hematology, clinical chemistry, and uterine content endpoints, were analyzed using the nonparametric multiple comparison methods of Shirley ${ }^{38}$ (as modified by Williams ${ }^{39}$ ) and Dunn. ${ }^{40}$ For normally distributed and non-normally distributed variables, the Jonckheere test ${ }^{41}$ was used to assess the significance of dose-related trends at $\mathrm{p}<0.01$ to determine whether a trend-sensitive test (the Williams or Shirley test) was more appropriate than a test that does not assume a monotonic dose-related trend (the Dunnett or Dunn test). Prior to statistical analysis, extreme values identified by the outlier test of Dixon and Massey ${ }^{42}$ were examined by NTP personnel, and implausible values were eliminated from the analysis.

Fetal body weights were analyzed using mixed-effects linear models, with litter as a random effect to account for potential within-litter correlations. To test for a linear trend, dose was entered into the model as its numeric value and its significance was evaluated. For pairwise comparisons with the control group, a second mixed-effects model with dose entered into the 
model as a categorical variable was estimated, followed by the Dunnett ${ }^{35}$ and $\mathrm{Hsu}^{43}$ multiple comparisons tests.

\section{Analysis of Incidences of Gross Pathology and Morphology Findings}

Incidences of gross findings, malformations, and variations in the fetuses were summarized and analyzed as number of litters affected and as number of fetuses affected. Incidences of gross findings, malformations, and numbers of litters affected were analyzed using the CochranArmitage trend test ${ }^{44}$ and the Fisher exact test. ${ }^{45}$ Numbers of fetuses affected were analyzed using mixed-effects logistic regression in which the litter was a random effect to account for potential litter effects. ${ }^{46-48}$ For each fetal finding, an initial mixed-effects logistic regression model used the numerical value of the dose to assess the significance of an exposure-related trend; a subsequent logistic regression model incorporated dose as a categorical variable to compare each dose group with the control group. To conduct the mixed-effects logistic regression analyses, at least one finding was required per dose group and the correlation matrix describing the relationship between litters was required to be "positive definite.” If the mixedeffects logistic regression failed to converge or did not meet the specified criteria, two separate analyses were used to bracket the true $\mathrm{p}$ value. The Cochran-Armitage trend test and the Fisher exact test were used with the litter as the experimental unit to calculate the upper limit for the true $\mathrm{p}$ value and with the fetus as the experimental unit to calculate the lower limit for the true $\mathrm{p}$ value.

\section{Historical Control Data}

The concurrent control group is the most valid comparison to the treated groups and is the only control group analyzed statistically in NTP developmental and reproductive toxicity studies. Historical control data are often helpful, however, in interpreting potential exposure-related effects, particularly for uncommon fetal findings that occur at a very low incidence. For meaningful comparisons, the conditions for studies in the historical control database must be generally similar. Factors that might affect the background incidences of fetal findings at a variety of anatomical sites are diet, sex, strain/stock, route of exposure, study type, and/or laboratory that conducted the study. The NTP historical control database for teratology studies contains all fetal evaluations (e.g., teratology studies or modified one-generation studies) for each laboratory. In general, the historical control database for a given study includes studies using the same route of administration and study design. Historical control data for rats in this NTP Developmental and Reproductive Toxicity Technical Report are from gavage studies conducted at Southern Research. The concurrent controls are included in the historical control data set. NTP historical controls are available online at https://ntp.niehs.nih.gov/go/historical_controls.

\section{Quality Assurance Methods}

The dose range-finding and prenatal developmental toxicity studies were conducted in compliance with Food and Drug Administration Good Laboratory Practice Regulations (21 CFR, Part 58). ${ }^{49}$ Records from these studies were submitted to the NTP Archives. The prenatal developmental toxicity study was audited retrospectively by an independent quality assessment contractor. Separate audits covered completeness and accuracy of the final study data tables for the dose range-finding and prenatal developmental toxicity studies and a draft of this NTP 
Developmental and Reproductive Toxicity Technical Report. Audit procedures and findings are presented in the reports and are on file at the NIEHS. The audit findings were reviewed and assessed by NTP staff, and all comments were resolved or otherwise addressed during the preparation of this report. 


\section{Results}

\section{Data Availability}

The National Toxicology Program (NTP) evaluated all study data. Data relevant for evaluating toxicological findings are presented here. All study data are available in the NTP Chemical Effects in Biological Systems (CEBS) database: https://doi.org/10.22427/NTP-DATA-DART-02. ${ }^{50}$

\section{Dose Range-finding Study in Rats}

\section{Maternal Findings}

\section{Viability and Clinical Observations}

Dose-related mortality and clinical observations of toxicity occurred in dams in the 600 and $900 \mathrm{mg} / \mathrm{kg}$ groups (Table 2; Appendix $\mathrm{D}^{50}$ ). The $900 \mathrm{mg} / \mathrm{kg}$ group was euthanized by gestation day (GD) 8 due to overt toxicity. Clinical observations in these animals included ataxia, cold to touch, clear ocular discharge, excessive salivation, lethargy/hypoactivity, and/or piloerection. Additionally, three animals in the $600 \mathrm{mg} / \mathrm{kg}$ group were euthanized on GD 9 to 10 with clinical observations similar to those that were observed in the $900 \mathrm{mg} / \mathrm{kg}$ group. No clinical observations of toxicity occurred in dams administered $300 \mathrm{mg} / \mathrm{kg}$ or less.

Table 2. Maternal Disposition of Rats in the Dose Range-finding Gavage Study of 4-Methylcyclohexanemethanol

\begin{tabular}{lccccc}
\hline & $\mathbf{0 ~} \mathbf{~} \mathbf{g} / \mathbf{k g}$ & $\mathbf{1 5 0} \mathbf{~} \mathbf{g} / \mathbf{k g}$ & $\mathbf{3 0 0} \mathbf{~} \mathbf{g} / \mathbf{k g}$ & $\mathbf{6 0 0} \mathbf{~} \mathbf{g} / \mathbf{k g}$ & $\mathbf{9 0 0} \mathbf{~} \mathbf{g} / \mathbf{k g}$ \\
\hline Time-mated Females & 10 & 10 & 10 & 10 & 10 \\
Pregnant (on GD 21) & 9 & 9 & 8 & 7 & 0 \\
Euthanized Moribund - Pregnant & 0 & 0 & 0 & $3^{\mathrm{a}}$ & $2^{\mathrm{b}}$ \\
Group Removal & 0 & 0 & 0 & 0 & $8^{\mathrm{c}}$ \\
Delivered Early & 0 & 1 & 1 & 0 & 0 \\
Nonpregnant (on GD 21) & 1 & 0 & 1 & 0 & 0 \\
\hline
\end{tabular}

GD = gestation day.

${ }^{a}$ Dams were euthanized on GD 9 and GD 10.

${ }^{\mathrm{b}}$ Dams were euthanized on GD 8.

${ }^{\mathrm{c} R e m a i n i n g ~ d a m s ~ f r o m ~ t h e ~} 900 \mathrm{mg} / \mathrm{kg}$ group were removed on GD 7 or 8 .

\section{Body Weights and Feed Consumption}

Average body weights of the 600 and $900 \mathrm{mg} / \mathrm{kg}$ groups were $9 \%$ and 14\% lower than those of the vehicle controls on GD 8, respectively (Appendix $\mathrm{D}^{50}$ ). Maternal body weight gain (GD 6 to 21) was $44 \%$ lower than that in the vehicle controls in dams administered $600 \mathrm{mg} / \mathrm{kg}$ that were necropsied on GD 21 (Figure 3 and Table 3). This lower weight gain was associated with the body weight loss that occurred on GD 6 to 9 and toward the end of gestation (Table 3; Appendix $\mathrm{D}^{50}$ ). Body weights and body weight gains of the 150 and $300 \mathrm{mg} / \mathrm{kg}$ groups were similar to those of the vehicle control groups throughout gestation. When adjusted for gravid uterine weight (at necropsy), maternal body weight was 4\% and 2\% higher in 150 and $300 \mathrm{mg} / \mathrm{kg}$ groups, respectively, and 5\% lower in the $600 \mathrm{mg} / \mathrm{kg}$ group than that of the vehicle controls (Table 5) 
Mean feed consumption from GD 6 to 21 was 13\% less than that of the vehicle control groups in dams administered $600 \mathrm{mg} / \mathrm{kg}$. This overall reduction was due to a $52 \%$ lower feed consumption during GD 6 to 9, which was associated with lower body weights and negative weight gains during that interval (Table 3 and Table 4). Feed consumption in the 150 and $300 \mathrm{mg} / \mathrm{kg}$ groups was similar to or greater than that of the vehicle controls throughout gestation.

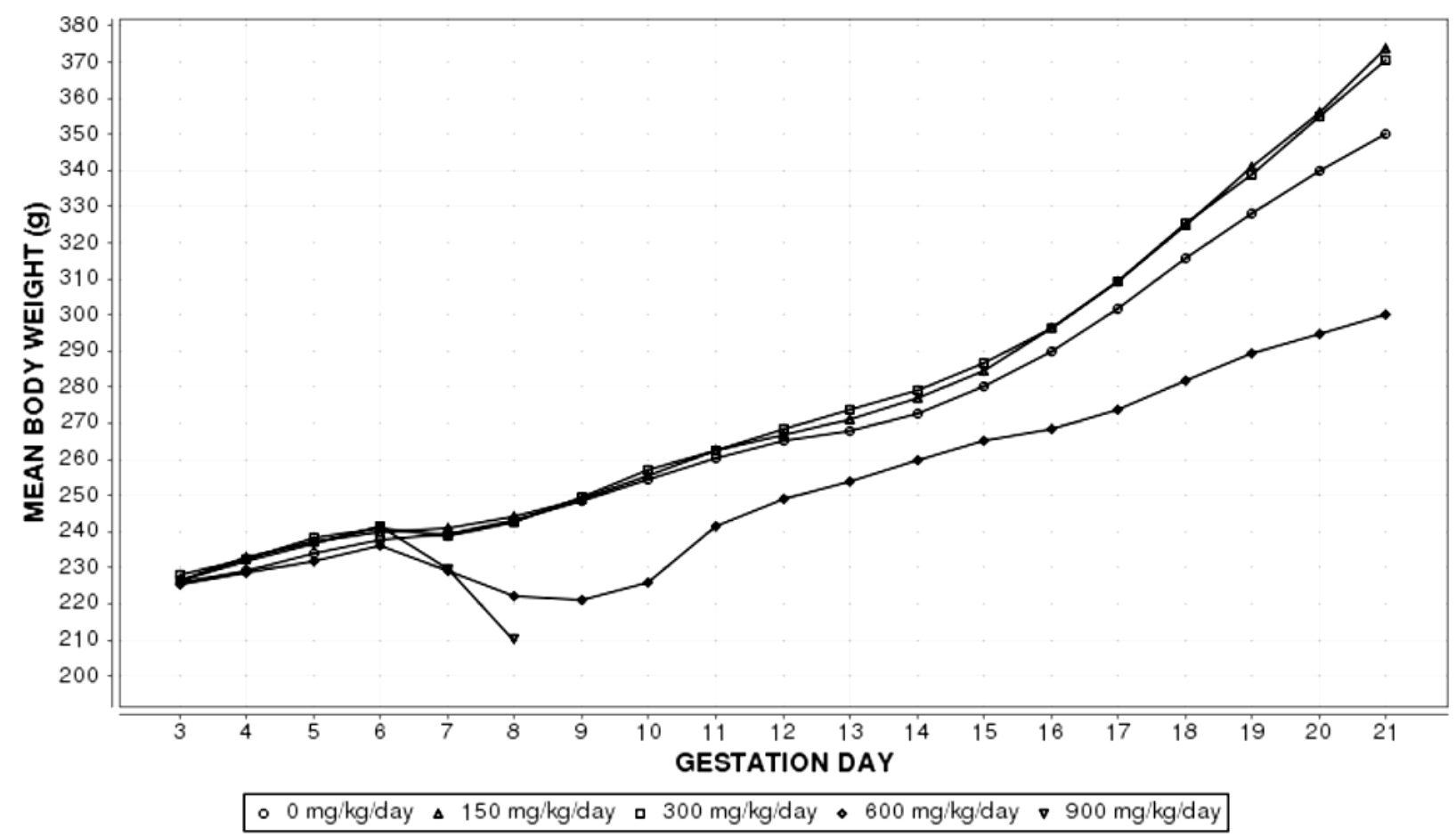

Figure 3. Maternal Growth Curves for Pregnant Rats Administered 4-Methylcyclohexanemethanol by Gavage in the Dose Range-finding Study

Information for statistical significance in maternal weights is provided in Table 3 and Appendix D. ${ }^{50}$

Table 3. Summary of Maternal Body Weight Gains of Rats in the Dose Range-finding Gavage Study of 4-Methylcyclohexanemethanol ${ }^{\mathrm{a}}$

\begin{tabular}{cccccc}
\hline $\begin{array}{c}\text { Gestation Day } \\
\text { Interval }\end{array}$ & $\mathbf{0 ~} \mathbf{~ m g} / \mathbf{k g}$ & $\mathbf{1 5 0} \mathbf{~ m g / k g}$ & $\mathbf{3 0 0} \mathbf{~ m g / k g}$ & $\mathbf{6 0 0} \mathbf{~ m g} / \mathbf{k g}$ & $\mathbf{9 0 0} \mathbf{~ m g / k g}$ \\
\hline $6-21$ & $112.1 \pm 9.4(9)$ & $132.2 \pm 7.8(9)$ & $129.6 \pm 5.0(9)$ & $63.1 \pm 16.8^{* *}(7)$ & - \\
$3-6$ & $11.8 \pm 0.7(9)$ & $13.7 \pm 1.8(10)$ & $12.9 \pm 1.5(9)$ & $10.7 \pm 1.1(10)$ & $14.9 \pm 1.4(9)$ \\
$6-9$ & $10.5 \pm 0.8^{* *}(9)$ & $9.2 \pm 1.2(10)$ & $8.6 \pm 1.4(9)$ & $-14.9 \pm 5.2^{* *}(10)$ & - \\
$9-12$ & $16.9 \pm 0.9(9)$ & $18.0 \pm 1.0(10)$ & $19.1 \pm 1.1(9)$ & $18.0 \pm 2.4(7)$ & - \\
$12-15$ & $15.2 \pm 2.1(9)$ & $17.4 \pm 1.8(10)$ & $18.3 \pm 0.7(9)$ & $16.2 \pm 3.1(7)$ & - \\
$15-18$ & $35.0 \pm 3.7(9)$ & $40.5 \pm 2.4(10)$ & $38.6 \pm 2.3(9)$ & $16.4 \pm 5.1^{* *}(7)$ & - \\
$18-21$ & $34.5 \pm 3.8(9)$ & $49.1 \pm 2.9(9)$ & $45.1 \pm 2.4(9)$ & $18.4 \pm 8.0^{*}(7)$ & - \\
\hline
\end{tabular}

*Statistically significant ( $\leq 0.05$ ) trend (by the Jonckheere test) or pairwise comparison (by the Williams or Dunnett test). A significant trend test is indicated in the vehicle control column. A significant pairwise comparison with the vehicle control group is indicated in the dose group column.

$* * \mathrm{p} \leq 0.01$.

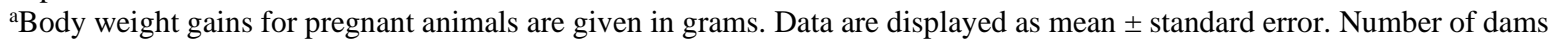
weighed is given in parentheses. 
Table 4. Summary of Maternal Feed Consumption of Rats in the Dose Range-finding Gavage Study of 4-Methylcyclohexanemethanol ${ }^{\mathrm{a}}$

\begin{tabular}{|c|c|c|c|c|c|}
\hline $\begin{array}{l}\text { Gestation Day } \\
\text { Interval }\end{array}$ & 0 mg/kg & $150 \mathrm{mg} / \mathrm{kg}$ & $300 \mathrm{mg} / \mathrm{kg}$ & $600 \mathrm{mg} / \mathrm{kg}$ & $900 \mathrm{mg} / \mathrm{kg}$ \\
\hline $6-21$ & $19.5 \pm 0.33(9)$ & $20.8 \pm 0.56(9)$ & $21.8 \pm 0.51 *(9)$ & $17.0 \pm 1.07(7)$ & - \\
\hline $3-6$ & $17.8 \pm 0.27(9)$ & $18.6 \pm 0.58(10)$ & $18.6 \pm 0.48$ (9) & $17.0 \pm 0.38(10)$ & $17.8 \pm 0.40$ \\
\hline $6-9$ & $17.7 \pm 0.37^{* *}(9)$ & $17.7 \pm 0.47(10)$ & $17.4 \pm 0.57(9)$ & $8.4 \pm 1.67^{* *}(10)$ & - \\
\hline $9-12$ & $18.8 \pm 0.32(9)$ & $19.7 \pm 0.44(10)$ & $21.3 \pm 0.66^{*}(9)$ & $16.2 \pm 0.97(7)$ & - \\
\hline $12-15$ & $18.6 \pm 0.45^{*}(9)$ & $19.5 \pm 0.44(9)$ & $22.0 \pm 0.63^{* *}(9)$ & $18.7 \pm 1.37(7)$ & - \\
\hline 15-18 & $21.5 \pm 0.68(9)$ & $23.3 \pm 0.76(10)$ & $24.3 \pm 0.65 *(9)$ & $20.2 \pm 1.28(7)$ & - \\
\hline 18-21 & $20.9 \pm 0.63(9)$ & $23.4 \pm 0.70(9)$ & $24.1 \pm 0.84 *(9)$ & $19.1 \pm 1.33(7)$ & - \\
\hline
\end{tabular}

*Statistically significant ( $\leq 0.05)$ trend (by the Jonckheere test) or pairwise comparison (by the Shirley or Dunn test). A significant trend test is indicated in the vehicle control column. A significant pairwise comparison with the vehicle control group is indicated in the dose group column.

$* * \mathrm{p} \leq 0.01$.

${ }^{\text {a}}$ Feed consumption for pregnant females is given in grams/day. Data are displayed as mean \pm standard error. Number of dams with feed consumption measured is given in parentheses.

\section{Maternal and Litter Observations}

Gross observations in the $600 \mathrm{mg} / \mathrm{kg}$ group at necropsy consisted of stomachs distended with food and were considered dose related (this occurred in three moribund euthanasia animals and in two animals at scheduled euthanasia on GD 21) (Appendix $\mathrm{D}^{50}$ ). One moribund $600 \mathrm{mg} / \mathrm{kg}$ animal was observed to have a dilated bladder; it is not clear if this was related to chemical administration. Increased relative kidney and liver weights in the $600 \mathrm{mg} / \mathrm{kg}$ group were considered to be secondary to the decreased body weights of dams in this group (Appendix $\mathrm{D}^{50}$ ).

The number of pregnant females and the mean numbers of corpora lutea and implantation sites were similar across the dose groups (Table 5). One $150 \mathrm{mg} / \mathrm{kg}$ dam delivered on GD 20, and one $300 \mathrm{mg} / \mathrm{kg}$ dam delivered in the morning of GD 21 shortly before scheduled necropsy; these early deliveries were considered incidental and not related to chemical exposure (Table 2 and Table 5).

There was an exposure-related effect on percent postimplantation loss as a result of an increase in the number of early and late resorptions and dead fetuses noted in the $600 \mathrm{mg} / \mathrm{kg}$ group (Table 5). The numbers of live and dead fetuses and early and late resorptions in the 150 and $300 \mathrm{mg} / \mathrm{kg}$ groups were similar to those in the vehicle controls. The fetal sex ratios were similar across the dose groups.

There was an exposure-related effect on fetal weights at doses of 300 and $600 \mathrm{mg} / \mathrm{kg}$ (Table 5). Compared to the vehicle controls, mean fetal weights per litter were decreased $12 \%$ and $39 \%$ in the 300 and $600 \mathrm{mg} / \mathrm{kg}$ groups, respectively, and the magnitudes of these effects were similar in male and female fetuses. In the $150 \mathrm{mg} / \mathrm{kg}$ group, mean fetal weight per litter was marginally less (4\%) than that in the vehicle controls. 
Table 5. Summary of Uterine Content Data for Rats in the Dose Range-finding Gavage Study of 4Methylcyclohexanemethanol

\begin{tabular}{|c|c|c|c|c|c|}
\hline & $0 \mathrm{mg} / \mathrm{kg}$ & $150 \mathrm{mg} / \mathrm{kg}$ & $300 \mathrm{mg} / \mathrm{kg}$ & $600 \mathrm{mg} / \mathrm{kg}$ & $900 \mathrm{mg} / \mathrm{kg}$ \\
\hline \multicolumn{6}{|l|}{ Pregnancy Summary } \\
\hline Mated females & 10 & 10 & 10 & 10 & 10 \\
\hline Pregnant females & 9 & 10 & 9 & 10 & 9 \\
\hline $\begin{array}{l}\text { Pregnant females examined } \\
\text { on GD } 21^{\mathrm{a}}\end{array}$ & $9 *$ & 9 & 8 & 7 & 0 \\
\hline Corpora lutea per female ${ }^{\mathrm{b}}$ & $16.67 \pm 1.24(9)$ & $16.20 \pm 0.47(10)$ & $16.22 \pm 0.94(9)^{\mathrm{c}}$ & $15.71 \pm 0.75(7)$ & \\
\hline Implantations per female ${ }^{\mathrm{b}}$ & $11.67 \pm 1.67(9)$ & $13.56 \pm 0.94(9)$ & $14.50 \pm 0.82(8)$ & $15.00 \pm 0.79(7)$ & \\
\hline $\begin{array}{l}\text { Percent postimplantation } \\
\text { loss }^{\mathrm{b}}\end{array}$ & $9.81 \pm 2.71(9)$ & $5.68 \pm 3.36(9)$ & $2.08 \pm 1.40(8)$ & $53.34 \pm 17.46(7)$ & \\
\hline Total resorptions per litter ${ }^{b}$ & $1.22 \pm 0.40(9)$ & $0.56 \pm 0.29(9)$ & $0.25 \pm 0.16(8)$ & $8.00 \pm 2.86(7)$ & \\
\hline Early resorptions per litter ${ }^{\mathrm{b}}$ & $1.11 \pm 0.42(9)$ & $0.56 \pm 0.29(9)$ & $0.13 \pm 0.13(8)$ & $7.57 \pm 2.92(7)$ & \\
\hline Late resorptions per litter ${ }^{b}$ & $0.11 \pm 0.11(9)$ & $0.00 \pm 0.00(9)$ & $0.13 \pm 0.13(8)$ & $0.43 \pm 0.30(7)$ & \\
\hline Dead fetuses per litter ${ }^{\mathrm{b}}$ & $0.00 \pm 0.00(9)$ & $0.00 \pm 0.00(9)$ & $0.00 \pm 0.00(8)$ & $0.29 \pm 0.29(7)$ & \\
\hline Number of early resorptions & 10 & 5 & 1 & 53 & \\
\hline Number of late resorptions & 1 & 0 & 1 & 3 & \\
\hline Number of dead fetuses & 0 & 0 & 0 & 2 & \\
\hline $\begin{array}{l}\text { Number of whole litter } \\
\text { resorptions }^{\mathrm{a}}\end{array}$ & $0 *$ & 0 & 0 & 2 & \\
\hline
\end{tabular}

\section{Live Fetuses $^{\mathrm{b}}$}

Number of live fetuses

Live fetuses per litter

Live male fetuses per litter

Live female fetuses per litter

Percent live male fetuses per litter

\footnotetext{
Fetal Weight (g) ${ }^{\mathrm{d}}$

Fetal weight per litter

$5.34 \pm 0.16(9)^{* *} \quad 5.11 \pm 0.11(9) \quad 4.72 \pm 0.07(8)^{*} \quad 3.28 \pm 0.37(5)^{* *}$

Male weight per litter

$5.38 \pm 0.17(8) * * \quad 5.26 \pm 0.11(9) \quad 4.79 \pm 0.08(8) * * \quad 3.71 \pm 0.30(4)^{* *}$

Female weight per litter

$5.25 \pm 0.17(9)^{* *} \quad 4.98 \pm 0.09(9) \quad 4.64 \pm 0.08(8)^{*} \quad 3.23 \pm 0.37(5)^{* *}$

Gravid Uterine Weight (g)

Gravid uterine weight

$75.88 \pm 10.09(9) \quad 88.80 \pm 7.15(9) \quad 92.78 \pm 4.70(8) \quad 40.59 \pm 14.31(7) *$

Terminal body weight

$349.9 \pm 11.9$ (9) $\quad 373.9 \pm 11.5(9) \quad 370.5 \pm 8.1(9) \quad 300.0 \pm 16.1(7) *$

Adjusted body weight

$274.06 \pm 2.81$ (9) $285.06 \pm 5.93$ (9) $280.16 \pm 6.02$ (8) $259.40 \pm 5.77$ (7)

Values are reported per litter as mean \pm standard error (n) and do not include nonpregnant animals or those that did not survive to end of study.

*Statistically significant $(\mathrm{p} \leq 0.05)$ trend (denoted in vehicle control column) or pairwise comparison (denoted in dose group column).

$* * \mathrm{p} \leq 0.01$.

GD = gestation day.

${ }^{\text {a}}$ Statistical analysis performed by the Cochran-Armitage (trend) and Fisher exact (pairwise) tests.

bStatistical analysis on number per litter performed by the Jonckheere (trend) and Shirley or Dunn (pairwise) tests.

'One dam in the $300 \mathrm{mg} / \mathrm{kg}$ group delivered early on GD 21, shortly before scheduled necropsy, and was examined for corpora lutea.

${ }^{\text {d} S t a t i s t i c a l ~ a n a l y s i s ~ p e r f o r m e d ~ u s i n g ~ a ~ m i x e d-e f f e c t s ~ l i n e a r ~ m o d e l ~ w i t h ~ l i t t e r ~ a s ~ a ~ r a n d o m ~ e f f e c t ~(t r e n d ~ a n d ~ p a i r w i s e) . ~}$

eStatistical analysis performed by the Jonckheere (trend) and William or Dunnett (pairwise) tests; adjusted body weight $=$ terminal body weight minus gravid uterine weight.
} 


\section{Fetal Findings}

\section{External}

No external morphological abnormalities were attributed to MCHM administration at 150, 300, or $600 \mathrm{mg} / \mathrm{kg}$ (Appendix $\mathrm{D}^{50}$ ).

\section{Dose Selection Rationale for the Prenatal Developmental Toxicity Study in Rats}

Due to overt maternal toxicity in dams administered 600 or $900 \mathrm{mg} / \mathrm{kg}$ and lack of significant maternal toxicity in those dosed with $300 \mathrm{mg} / \mathrm{kg}$ in the dose range-finding study, a high dose of $400 \mathrm{mg} / \mathrm{kg}$ was selected for the subsequent prenatal developmental toxicity study. The dose of $400 \mathrm{mg} / \mathrm{kg}$ was estimated to induce minimal maternal toxicity. A low dose of $50 \mathrm{mg} / \mathrm{kg}$ was included to extend the dose-response assessment. Thus, dose concentrations of $0,50,100,200$, and $400 \mathrm{mg} / \mathrm{kg}$ were selected for the prenatal developmental toxicity gavage study.

\section{Prenatal Developmental Toxicity Study in Rats}

\section{Maternal Findings}

\section{Viability and Clinical Observations}

No animals were removed from the study prior to scheduled necropsy (Table 6). No clinical observations of toxicity were observed in dams at any dose (Appendix $\mathrm{D}^{50}$ ).

Table 6. Maternal Disposition of Rats in the Prenatal Developmental Toxicity Gavage Study of 4-Methylcyclohexanemethanol

\begin{tabular}{lccccc}
\hline & $\mathbf{0 ~} \mathbf{~ m g} / \mathbf{k g}$ & $\mathbf{5 0} \mathbf{~} \mathbf{g} / \mathbf{k g}$ & $\mathbf{1 0 0} \mathbf{~} \mathbf{g} / \mathbf{k g}$ & $\mathbf{2 0 0} \mathbf{~} \mathbf{~ g} \mathbf{k g}$ & $\mathbf{4 0 0} \mathbf{~} \mathbf{g} / \mathbf{k g}$ \\
\hline Time-mated Females & 25 & 25 & 25 & 25 & 25 \\
Pregnant (on GD 21) & 23 & 21 & 22 & 19 & 21 \\
Nonpregnant (on GD 21) & 2 & 4 & 3 & 6 & 4 \\
\hline
\end{tabular}

GD = gestation day.

\section{Body Weights and Feed Consumption}

There was no effect on absolute body weight from GD 6 to 21. Overall maternal weight gain from GD 6 to 21 was 11\% lower than that of vehicle controls in dams in administered $400 \mathrm{mg} / \mathrm{kg}$ (Figure 4 and Table 7). The overall decrease in $400 \mathrm{mg} / \mathrm{kg}$ dams reflects lower (41\%) weight gains over the GD 6 to 9 interval, a rebound (25\% increase) from GD 9 to 12, and lower (18\%) weight gain over the GD 18 to 21 interval. The lower weight gain in late gestation in dams exposed to $400 \mathrm{mg} / \mathrm{kg}$ was associated with lower gravid uterine weight. Mean adjusted body weight at necropsy (minus gravid uterine weight) was unaffected with MCHM administration.

Overall feed consumption (GD 6 to 21) was marginally increased 6-7\% in the 200 and $400 \mathrm{mg} / \mathrm{kg}$ groups, respectively, compared to the vehicle control group (Table 8). Dams in the $400 \mathrm{mg} / \mathrm{kg}$ group displayed an increase in feed consumption (11\%) from GD 9 to 12, which corresponds to the increased weight gain observed over the same interval. 


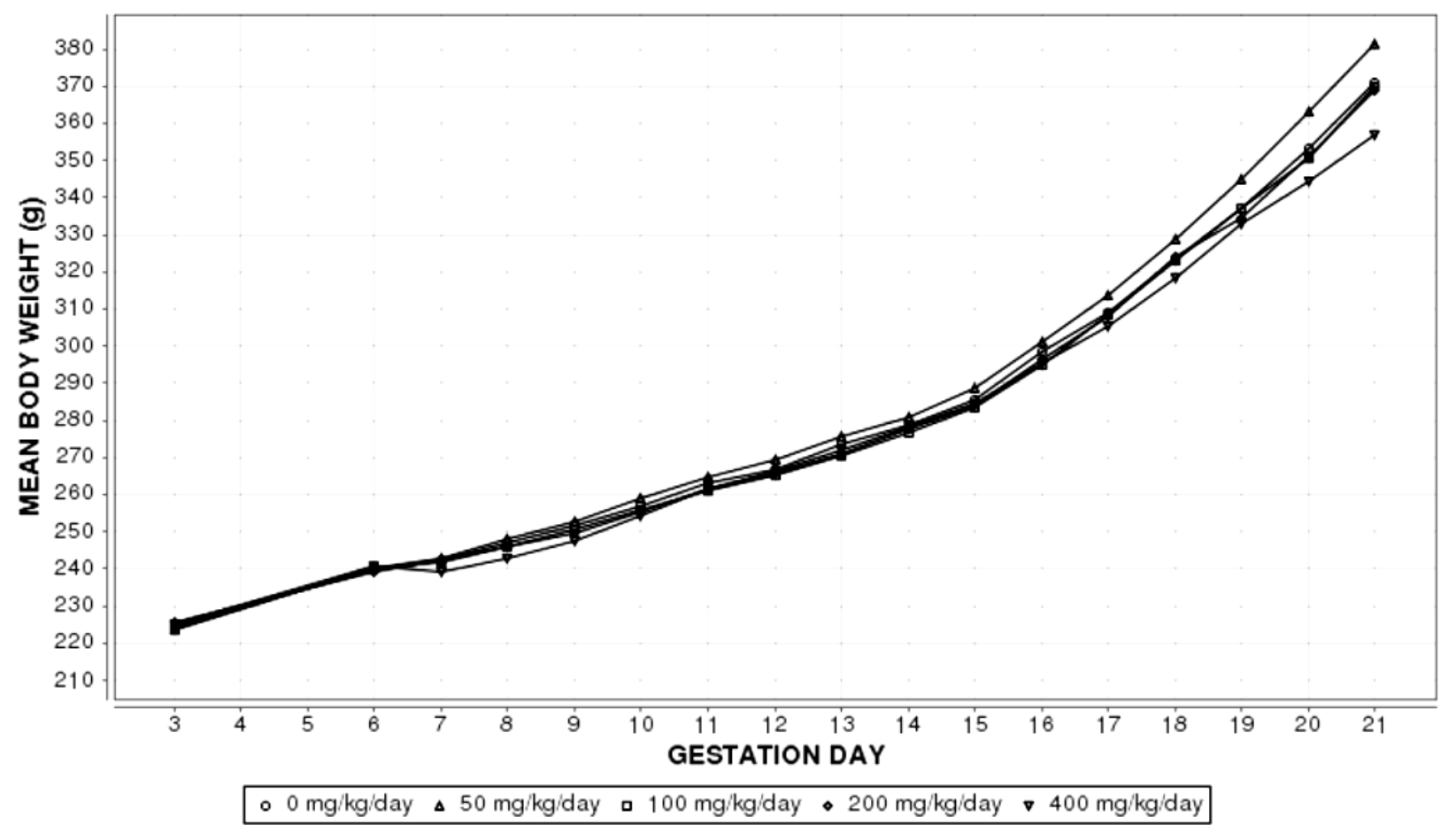

Figure 4. Maternal Growth Curves for Pregnant Rats Administered 4-Methylcyclohexanemethanol by Gavage in the Prenatal Developmental Toxicity Study

Information for statistical significance in maternal weights is provided in Table 7 and Appendix D. ${ }^{50}$

Table 7. Summary of Maternal Body Weight Gains of Rats in the Prenatal Developmental Toxicity Gavage Study of 4-Methylcyclohexanemethanol ${ }^{\mathrm{a}}$

\begin{tabular}{|c|c|c|c|c|c|}
\hline $\begin{array}{c}\text { Gestation Day } \\
\text { Interval }\end{array}$ & $0 \mathrm{mg} / \mathrm{kg}$ & $50 \mathrm{mg} / \mathrm{kg}$ & $100 \mathrm{mg} / \mathrm{kg}$ & $200 \mathrm{mg} / \mathrm{kg}$ & $400 \mathrm{mg} / \mathrm{kg}$ \\
\hline $6-21$ & $131.4 \pm 3.9 * *(23)$ & $141.5 \pm 4.3(21)$ & $130.1 \pm 4.8(22)$ & $129.6 \pm 4.9$ (19) & $116.5 \pm 4.1 *(21)$ \\
\hline $3-6$ & $15.1 \pm 2.2(23)$ & $16.3 \pm 2.1(21)$ & $16.0 \pm 2.3(22)$ & $13.8 \pm 1.2(19)$ & $15.2 \pm 1.9(21)$ \\
\hline $6-9$ & $12.3 \pm 0.6^{* *}(23)$ & $12.9 \pm 1.0(21)$ & $10.8 \pm 0.5(22)$ & $10.2 \pm 0.9$ (19) & $7.2 \pm 0.9 * *(21)$ \\
\hline $9-12$ & $14.9 \pm 0.6^{* *}(23)$ & $16.7 \pm 0.7(21)$ & $14.5 \pm 0.6(22)$ & $16.1 \pm 1.0(19)$ & $18.6 \pm 0.7^{* *}(21)$ \\
\hline $12-15$ & $18.8 \pm 0.8(23)$ & $19.3 \pm 0.5(21)$ & $18.4 \pm 1.6(22)$ & $18.5 \pm 1.8(19)$ & $18.2 \pm 0.8(21)$ \\
\hline $15-18$ & $38.3 \pm 1.4(23)$ & $39.9 \pm 3.0(21)$ & $39.5 \pm 1.9(22)$ & $39.8 \pm 2.1$ (19) & $33.9 \pm 1.6(21)$ \\
\hline $18-21$ & $47.1 \pm 1.9 * *(23)$ & $52.8 \pm 2.7(21)$ & $47.0 \pm 2.4(22)$ & $44.9 \pm 2.7$ (19) & $38.6 \pm 2.5^{*}(21)$ \\
\hline
\end{tabular}

*Statistically significant ( $\leq 0.05$ ) trend (by the Jonckheere test) or pairwise comparison (by the Williams or Dunnett test). A significant trend test is indicated in the vehicle control column. A significant pairwise comparison with the vehicle control group is indicated in the dose group column.

$* * \mathrm{p} \leq 0.01$.

aBody weight gains for pregnant animals are given in grams. Data are displayed as mean \pm standard error. Number of dams is given in parentheses. 
Table 8. Summary of Maternal Feed Consumption of Rats in the Prenatal Developmental Toxicity Gavage Study of 4-Methylcyclohexanemethanol ${ }^{a}$

\begin{tabular}{|c|c|c|c|c|c|}
\hline $\begin{array}{l}\text { Gestation Day } \\
\text { Interval }\end{array}$ & $0 \mathrm{mg} / \mathrm{kg}$ & $50 \mathrm{mg} / \mathrm{kg}$ & $100 \mathrm{mg} / \mathrm{kg}$ & $200 \mathrm{mg} / \mathrm{kg}$ & $400 \mathrm{mg} / \mathrm{kg}$ \\
\hline $6-21$ & $20.7 \pm$ & 21.2 & 21.2 & 21.9 & 22.1 \\
\hline $3-6$ & $19.0 \pm 0.34(23)$ & $18.6 \pm 0.37(21)$ & $18.9 \pm 0.24(22)$ & $19.1 \pm 0.33(19)$ & $19.5 \pm 0.40(21)$ \\
\hline $6-9$ & $19.0 \pm 0.31(23)$ & $18.9 \pm 0.40(21)$ & $19.0 \pm 0.31(22)$ & $.52(19)$ & $0.45(21)$ \\
\hline $9-12$ & $19.5 \pm 0.35^{* *}(23)$ & $20.3 \pm 0.37(21)$ & $19.8 \pm 0.31(22)$ & $20.3 \pm 0.30$ (19) & $21.7 \pm 0.37 * *(21)$ \\
\hline $12-15$ & $20.2 \pm 0.29 * *$ & $20.3 \pm 0.47(21)$ & $20.4 \pm 0.33(22)$ & $21.1 \pm 0.27$ (19) & $22.2 \pm 0.36^{* *}(21)$ \\
\hline $15-18$ & $22.6 \pm 0.40^{* *}(23)$ & $22.6 \pm 0.59(21)$ & $23.5 \pm 0.47(22)$ & $24.5 \pm 0.39 * *(19)$ & $24.9 \pm 0.52^{* *}(21)$ \\
\hline $18-21$ & $22.4 \pm 0.38 *(23)$ & $23.7 \pm 0.49(21)$ & $23.3 \pm 0.54(22)$ & $23.7 \pm 0.54(19)$ & $23.8 \pm 0.61(21)$ \\
\hline
\end{tabular}

*Statistically significant ( $\leq 0.05$ ) trend (by the Jonckheere test) or pairwise comparison (by the Shirley or Dunn test). A significant trend test is indicated in the vehicle control column. A significant pairwise comparison with the vehicle control group is indicated in the dose group column.

$* * \mathrm{p} \leq 0.01$.

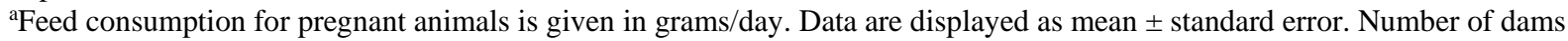
with feed consumption measured is given in parentheses.

\section{Maternal and Litter Observations}

There were no maternal gross observations at any dose level (Appendix $\mathrm{D}^{50}$ ).

Because of the influence of pregnancy status on hematology and clinical chemistry, these data are presented only for pregnant animals (Appendix $\mathrm{D}^{50}$ ). Total protein concentrations were decreased $(\leq 10 \%)$ in the 100,200 , and $400 \mathrm{mg} / \mathrm{kg}$ groups; this change was driven by a $10 \%$ decrease in the globulin concentrations in the same dose groups (Table 9). A mild decrease (6\%) in calcium concentration was observed in the $400 \mathrm{mg} / \mathrm{kg}$ group. Calcium is mainly bound to albumin in circulation; therefore, decreases in albumin result in decreases in serum total calcium concentrations (versus serum ionized calcium). Although there was not a significant decrease in albumin concentration in the $400 \mathrm{mg} / \mathrm{kg}$ group, there was a significant downward trend with albumin $7 \%$ lower in the $400 \mathrm{mg} / \mathrm{kg}$ group compared to the vehicle control group. 
Table 9. Selected Clinical Chemistry Findings in Rats in the Prenatal Developmental Toxicity Gavage Study of 4-Methylcyclohexanemethanol

\begin{tabular}{|c|c|c|c|c|c|}
\hline & $0 \mathrm{mg} / \mathrm{kg}$ & $50 \mathrm{mg} / \mathrm{kg}$ & $100 \mathrm{mg} / \mathrm{kg}$ & $200 \mathrm{mg} / \mathrm{kg}$ & $400 \mathrm{mg} / \mathrm{kg}$ \\
\hline Urea Nitrogen (mg/dL) & $17.9 \pm 0.6^{* *}(23)$ & $17.7 \pm 0.5(21)$ & $17.5 \pm 0.5(22)$ & $18.7 \pm 1.0(19)$ & $20.8 \pm 0.6^{* *}(21)$ \\
\hline Glucose (mg/dL) & $181.2 \pm 10.3^{* *}(23)$ & $153.9 \pm 7.4(21)$ & $176.0 \pm 11.1(22)$ & $150.6 \pm 10.6 *(19)$ & $141.3 \pm 9.3 * *(21)$ \\
\hline Calcium (mg/dL) & $12.2 \pm 0.2 *(22)$ & $11.7 \pm 0.2(21)$ & $11.8 \pm 0.2(22)$ & $11.7 \pm 0.2(19)$ & $11.4 \pm 0.3^{*}(20)$ \\
\hline Total Protein (g/dL) & $5.17 \pm 0.11 * *(23)$ & $4.93 \pm 0.10(21)$ & $4.84 \pm 0.10 *(22)$ & $4.91 \pm 0.15 *(19)$ & $4.74 \pm 0.14 * *(21)$ \\
\hline Albumin (g/dL) & $3.07 \pm 0.09 *(23)$ & $2.93 \pm 0.07(21)$ & $2.95 \pm 0.10(22)$ & $3.01 \pm 0.12(19)$ & $2.85 \pm 0.13(21)$ \\
\hline Globulin (g/dL) & $2.10 \pm 0.05 * *(23)$ & $2.01 \pm 0.06(21)$ & $1.89 \pm 0.04^{* *}(22)$ & $1.90 \pm 0.04^{* *}(19)$ & $1.89 \pm 0.06^{* *}(21)$ \\
\hline Triglycerides (mg/dL) & $145.5 \pm 21.0^{* *}(23)$ & $114.8 \pm 18.0(21)$ & $94.6 \pm 12.6(22)$ & $108.4 \pm 14.0(19)$ & $194.6 \pm 31.8^{*}(21)$ \\
\hline Alkaline Phosphatase (IU/L) & $138.4 \pm 6.9(23)$ & $142.0 \pm 4.7(21)$ & $131.7 \pm 4.2(22)$ & $134.9 \pm 5.4(19)$ & $157.0 \pm 6.2 *(21)$ \\
\hline
\end{tabular}

Glucose concentrations were decreased in the $200 \mathrm{mg} / \mathrm{kg}$ (17\%) and $400 \mathrm{mg} / \mathrm{kg}$ (22\%) groups, and triglyceride concentrations were increased (34\%) in the $400 \mathrm{mg} / \mathrm{kg}$ group (Table 9).

Although the mechanism is not known, these changes could indicate alterations in carbohydrate and lipid metabolism or might be due to differences in feed consumption relative to control animals. Blood urea nitrogen (BUN) was mildly increased (16\%) in the $400 \mathrm{mg} / \mathrm{kg}$ group, whereas creatinine concentration was unchanged. A common cause of mildly increased BUN levels is decreased water intake (dehydration); although no other hematological or biochemical changes support this and water consumption was not assessed, a decrease in water intake was considered the most likely reason for this finding.

Alkaline phosphatase (ALP) activity was elevated (13\%) in the $400 \mathrm{mg} / \mathrm{kg}$ group (Table 9). This hepatic enzyme could increase as a result of cholestasis; however, bilirubin was unchanged and the increase in ALP was minimal. The intestinal isoenzyme of ALP (along with the osseous isoenzyme) is the dominant form of serum ALP in rats and food intake is known to have a pronounced effect on serum ALP activity in rats. ${ }^{51 ; 52}$ Thus, the minimal increases in ALP activity in the $400 \mathrm{mg} / \mathrm{kg}$ group could be due to increased feed consumption that was observed in this dose group during gestation, or alternatively, could represent normal biological variability.

The number of corpora lutea, implantation sites, and fetuses per litter were similar across the dose groups (Table 10). There was no effect on embryo-fetal viability with exposure to MCHM. The fetal sex ratios were similar across the dose groups.

The mean numbers of live fetuses and early/late resorptions were similar across the dose groups. There was a significant decrease (15\%) in fetal weights (males and females combined) in the $400 \mathrm{mg} / \mathrm{kg}$ group. There was no effect of MCHM exposure on fetal weights in the 50, 100, and $200 \mathrm{mg} / \mathrm{kg}$ groups. 
Table 10. Summary of Uterine Content Data for Rats in the Prenatal Developmental Toxicity Gavage Study of 4-Methylcyclohexanemethanol

\begin{tabular}{|c|c|c|c|c|c|}
\hline & $0 \mathrm{mg} / \mathrm{kg}$ & $50 \mathrm{mg} / \mathrm{kg}$ & $100 \mathrm{mg} / \mathrm{kg}$ & $200 \mathrm{mg} / \mathrm{kg}$ & $400 \mathrm{mg} / \mathrm{kg}$ \\
\hline \multicolumn{6}{|l|}{ Pregnancy Summary } \\
\hline Mated females & 25 & 25 & 25 & 25 & 25 \\
\hline Pregnant females & 23 & 21 & 22 & 19 & 21 \\
\hline $\begin{array}{l}\text { Pregnant females examined on } \\
\text { GD } 21^{\mathrm{a}}\end{array}$ & 23 & 21 & 22 & 19 & 21 \\
\hline Corpora lutea per female ${ }^{b}$ & $17.17 \pm 0.43(23)$ & $16.67 \pm 0.85(21)$ & $17.50 \pm 0.70(22)$ & $18.47 \pm 1.11$ & $16.81 \pm 0.63(21)$ \\
\hline Implantations per female ${ }^{b}$ & $13.83 \pm 0.55(23)$ & $14.33 \pm 0.37(21)$ & $13.23 \pm 0.69(22)$ & $13.74 \pm 0.80$ & $13.05 \pm 0.74(21)$ \\
\hline Percent postimplantation loss ${ }^{\mathrm{b}}$ & $8.02 \pm 2.47(23)$ & $6.54 \pm 3.13(21)$ & $8.09 \pm 4.50(22)$ & $5.18 \pm 1.96(19)$ & $7.76 \pm 2.51(21)$ \\
\hline Total resorptions per litter ${ }^{\mathrm{b}}$ & $0.96 \pm 0.20(23)$ & $0.86 \pm 0.36(21)$ & $0.55 \pm 0.14(22)$ & $0.74 \pm 0.27(19)$ & $0.95 \pm 0.30(21)$ \\
\hline Early resorptions per litter ${ }^{\mathrm{b}}$ & $0.91 \pm 0.21(23)$ & $0.76 \pm 0.28(21)$ & $0.55 \pm 0.14(22)$ & $0.74 \pm 0.27(19)$ & $0.95 \pm 0.30(21)$ \\
\hline Late resorptions per litter ${ }^{\mathrm{b}}$ & $0.04 \pm 0.04(23)$ & $0.10 \pm 0.10(21)$ & $0.00 \pm 0.00(22)$ & $0.00 \pm 0.00(19)$ & $0.00 \pm 0.00(21)$ \\
\hline Dead fetuses per litter ${ }^{\mathrm{b}}$ & $0.00 \pm 0.00(23)$ & $0.00 \pm 0.00$ & $0.00 \pm 0.00(22)$ & $0.00 \pm 0.00$ & $0.00 \pm 0.00(21)$ \\
\hline Number of early resorptions ${ }^{c}$ & 21 & 16 & 12 & 14 & 20 \\
\hline Number of late resorptions ${ }^{\mathrm{c}}$ & 1 & 2 & 0 & 0 & 0 \\
\hline Number of dead fetuses & 0 & 0 & 0 & 0 & 0 \\
\hline $\begin{array}{l}\text { Number of whole litter } \\
\text { resorptions }{ }^{\mathrm{c}}\end{array}$ & 0 & 0 & 1 & 0 & 0 \\
\hline \multicolumn{6}{|l|}{ Live Fetuses $^{\mathrm{b}}$} \\
\hline Number of live fetuses & 296 & 283 & 279 & 247 & 254 \\
\hline Live fetuses per litter & $12.87 \pm 0.64(23)$ & $13.48 \pm 0.58(21)$ & $12.68 \pm 0.71(22)$ & $13.00 \pm 0.81$ & $12.10 \pm 0.79(21)$ \\
\hline Live male fetuses per litter & $6.26 \pm 0.41(23)$ & $7.14 \pm 0.59(21)$ & $7.05 \pm 0.67(22)$ & $6.26 \pm 0.64(19)$ & $6.05 \pm 0.49(21)$ \\
\hline Live female fetuses per litter & $6.61 \pm 0.42(23)$ & $6.33 \pm 0.51(21)$ & $5.64 \pm 0.51(22)$ & $6.74 \pm 0.58(19)$ & $6.05 \pm 0.56(21)$ \\
\hline $\begin{array}{l}\text { Percent live male fetuses per } \\
\text { litter }\end{array}$ & 49.89 & 51.95 & 54.80 & 49.29 & 51.02 \\
\hline
\end{tabular}

Fetal Weight $^{\mathrm{d}}(\mathrm{g})$

Fetal weight per litter

$5.14 \pm 0.07(23)^{* *} 5.16 \pm 0.08(21) \quad 5.14 \pm 0.07(21) \quad 4.98 \pm 0.09$ (19) $4.39 \pm 0.09(21)^{* *}$

Male weight per litter

$5.28 \pm 0.06(23)^{* *} 5.30 \pm 0.08$ (21) $5.28 \pm 0.07$ (21) $5.12 \pm 0.09$ (19) $4.46 \pm 0.09$ (21)**

Female weight per litter

$4.99 \pm 0.07(22)^{* *} 5.00 \pm 0.08(21) \quad 4.98 \pm 0.07$ (21) $4.82 \pm 0.09$ (18) $4.34 \pm 0.12(21)^{* *}$

Gravid Uterine Weight ${ }^{\mathrm{e}}$ (g)

Gravid uterine weight

Terminal body weight

$91.76 \pm 4.05$

$96.88 \pm 3.61(21) 90.41 \pm 4.83$

(22) $88.57 \pm 4.88(19)$

$75.58 \pm 4.20$

$(23) * *$

$(21)^{* *}$

Adjusted body weight

$370.9 \pm 5.7(23)^{* *} 381.5 \pm 4.3(21) \quad 370.1 \pm 5.8(22) \quad 368.8 \pm 5.6(19) \quad 356.9 \pm 4.9$ (21)

$279.10 \pm 2.70(23) \quad 284.61 \pm 2.55 \quad 279.65 \pm 2.61 \quad 280.23 \pm 2.47 \quad 281.34 \pm 3.23(21)$

(21)

(22)

(19)

Values are reported per litter as mean \pm standard error (n) and do not include nonpregnant animals or those that did not survive to end of study.

**Statistically significant ( $\mathrm{p} \leq 0.01$ ) trend (denoted in vehicle control column) or pairwise comparison (denoted in dose group column).

GD = gestation day.

${ }^{\text {aS }}$ tatistical analysis performed by the Cochran-Armitage (trend) and Fisher exact (pairwise) tests.

bStatistical analysis performed by the Jonckheere (trend) and Shirley or Dunn (pairwise) tests.

${ }^{\mathrm{c}}$ No statistical analyses were performed on number of early resorptions, number of late resorptions, or number of whole litter resorptions.

${ }^{\text {d} S t a t i s t i c a l ~ a n a l y s i s ~ p e r f o r m e d ~ u s i n g ~ a ~ m i x e d-e f f e c t s ~ l i n e a r ~ m o d e l ~ w i t h ~ l i t t e r ~ a s ~ a ~ r a n d o m ~ e f f e c t ~(t r e n d ~ a n d ~ p a i r w i s e) . ~}$

'Statistical analysis performed by the Jonckheere (trend) and Williams or Dunnett (pairwise) tests; adjusted body weight = total terminal body weight minus gravid uterine weight. 


\section{Fetal Findings}

\section{External}

Low incidences of malformations (one to two fetuses) of absent anus and thread-like tail (occurred in the same fetus), bent tail, and omphalocele were noted. With the exception of bent tail in two fetuses from two litters in the $50 \mathrm{mg} / \mathrm{kg}$ group, these malformations were observed in fetuses in the $400 \mathrm{mg} / \mathrm{kg}$ group but were not considered to be a result of MCHM administration (Appendix $\mathrm{D}^{50}$ ).

\section{Visceral}

Visceral malformations and variations were limited to findings in the adrenal glands and kidneys at $400 \mathrm{mg} / \mathrm{kg}$. These findings included misshapen and discolored adrenal glands (glands appeared grossly necrotic) and discolored kidneys (Table 11; Appendix $\mathrm{D}^{50}$ ). These three findings occurred together in one $50 \mathrm{mg} / \mathrm{kg}$ fetus and in each of three $400 \mathrm{mg} / \mathrm{kg}$ fetuses from three different litters (Table 11; Appendix $\mathrm{D}^{50}$ ). No other visceral findings were considered to be related to MCHM treatment.

Table 11. Summary of Selected Fetal Visceral Findings in Rats in the Prenatal Developmental Toxicity Gavage Study of 4-Methylcyclohexanemethanol

\begin{tabular}{|c|c|c|c|c|c|}
\hline & $0 \mathrm{mg} / \mathrm{kg}$ & $50 \mathrm{mg} / \mathrm{kg}$ & $100 \mathrm{mg} / \mathrm{kg}$ & $200 \mathrm{mg} / \mathrm{kg}$ & $400 \mathrm{mg} / \mathrm{kg}$ \\
\hline Total Number of Fetuses & 296 & 283 & 279 & 247 & 254 \\
\hline Number of Fetuses Examined & 296 & 283 & 279 & 247 & 254 \\
\hline Number of Litters Examined & 23 & 21 & 21 & 19 & 21 \\
\hline \multicolumn{6}{|l|}{ Abdominal Viscera } \\
\hline \multicolumn{6}{|c|}{ Adrenal, total, discolored $-[\mathrm{V}]^{\mathrm{a}}$} \\
\hline Fetuses $^{\mathrm{b}}$ & $0(0.0)^{*}$ & $1(0.4)$ & $0(0.0)$ & $0(0.0)$ & $3(1.2)$ \\
\hline Litters & $0(0.00)^{*}$ & $1(4.76)$ & $0(0.00)$ & $0(0.00)$ & $3(14.29)$ \\
\hline \multicolumn{6}{|c|}{ Adrenal, total, misshapen - $[\mathrm{M}]^{\mathrm{a}}$} \\
\hline Fetuses & $0(0.0)^{*}$ & $1(0.4)$ & $0(0.0)$ & $0(0.0)$ & $3(1.2)$ \\
\hline Litters & $0(0.00)^{*}$ & $1(4.76)$ & $0(0.00)$ & $0(0.00)$ & $3(14.29)$ \\
\hline \multicolumn{6}{|l|}{ Urinary Tract } \\
\hline \multicolumn{6}{|l|}{ Kidney, total, discolored $-[\mathrm{V}]^{\mathrm{a}}$} \\
\hline Fetuses & $0(0.0)^{*}$ & $1(0.4)$ & $0(0.0)$ & $0(0.0)$ & $3(1.2)$ \\
\hline Litters & $0(0.00)^{*}$ & $1(4.76)$ & $0(0.00)$ & $0(0.00)$ & 3 (14.29) \\
\hline
\end{tabular}

Upper row denotes number of affected fetuses (\%); lower row the number of affected litters (\%).

*Statistically significant $(\mathrm{p} \leq 0.05$ ) trend according to the Cochran-Armitage (trend) test. None of the pairwise comparisons to the control group were statistically significant by the Fisher exact test. A significant trend test is indicated in the vehicle control column. A significant pairwise comparison with the vehicle control group is indicated in the dose group column.

$[\mathrm{M}]=$ malformation; $[\mathrm{V}]$ = variation .

${ }^{a}$ Historical incidence for prenatal developmental toxicity gavage studies: fetuses: 0/1,326 (0\%); litters 0/104 (0\%).

bStatistical analysis of fetuses performed by mixed-effects logistic regression models with litter-based adjustments found no statistically significant trend or pairwise comparison. 


\section{Head}

No chemical-related increases were found in the incidences of variations or malformations of the skull in exposed fetuses (Appendix $\mathrm{D}^{50}$ ).

\section{Skeletal}

Several skeletal anomalies were observed in fetuses in the $400 \mathrm{mg} / \mathrm{kg}$ group. These variations and malformations occurred along the axial skeleton and included anomalies in the costal cartilage, sternebrae, and the presence of cervical and thoracolumbar supernumerary ribs (SNRs).

The incidence of the seventh, right costal cartilage not fusing to the sternum was increased in the $400 \mathrm{mg} / \mathrm{kg}$ group (Table 12; Appendix $\mathrm{D}^{50}$ ). Additionally, misaligned costal cartilage was observed in the fourth and fifth right ribs in one fetus and in multiple sites in two fetuses from different litters. When combined, there was a significant increase in the total litter incidences of misaligned costal cartilage in three fetuses from two litters in the $400 \mathrm{mg} / \mathrm{kg}$ group.

Increases in the number of unossified second, fifth, and sixth sternebrae were observed in the $400 \mathrm{mg} / \mathrm{kg}$ group; in one fetus, this occurred in multiple sites (Table 12; Appendix $\mathrm{D}^{50}$ ). In addition, there was an increase in the total incidences of unossified (first thoracic) or incompletely ossified (12th and 13th thoracic) vertebrae of the thoracic centrum due to the occurrence in four fetuses from three litters in the $400 \mathrm{mg} / \mathrm{kg}$ group. The sternal and vertebral ossification delays were consistent with the small size of the affected fetuses and with the reduced fetal weight at this exposure level.

There was an increase in the number of full thoracolumbar and short cervical SNRs. These malformations were significantly increased in the $400 \mathrm{mg} / \mathrm{kg}$ group (Table 12; Appendix $\mathrm{D}^{50}$ ).

Overall, the total incidences of skeletal malformations of the axial skeleton (ribs, sternebrae, SNRs, and vertebrae) were increased in an exposure-dependent manner. These malformations exceeded the historical control incidences (both fetal- and litter-based) observed in NTP prenatal developmental toxicity studies (Table 12; Appendix $\mathrm{D}^{50}$ ).

Table 12. Summary of Selected Fetal Skeletal Findings in Rats in the Prenatal Developmental Toxicity Gavage Study of 4-Methylcyclohexanemethanol

\begin{tabular}{|c|c|c|c|c|c|}
\hline & $0 \mathrm{mg} / \mathrm{kg}$ & $50 \mathrm{mg} / \mathrm{kg}$ & $100 \mathrm{mg} / \mathrm{kg}$ & $200 \mathrm{mg} / \mathrm{kg}$ & $400 \mathrm{mg} / \mathrm{kg}$ \\
\hline Total Number of Fetuses & 296 & 283 & 279 & 247 & 254 \\
\hline Number of Fetuses Examined & 296 & 283 & 279 & 247 & 254 \\
\hline Number of Litters Examined & 23 & 21 & 21 & 19 & 21 \\
\hline \multicolumn{6}{|l|}{ Ribs } \\
\hline \multicolumn{6}{|c|}{ Costal cartilage, 4th right, misaligned - [V] } \\
\hline Fetuses & $0(0.0)$ & $0(0.0)$ & $0(0.0)$ & $0(0.0)$ & $1(0.4)$ \\
\hline Litters & $0(0.00)$ & $0(0.00)$ & $0(0.00)$ & $0(0.00)$ & $1(4.76)$ \\
\hline \multicolumn{6}{|c|}{ Costal cartilage, 5th right, misaligned - [V] } \\
\hline Fetuses & $0(0.0)$ & $0(0.0)$ & $0(0.0)$ & $0(0.0)$ & $1(0.4)$ \\
\hline Litters & $0(0.00)$ & $0(0.00)$ & $0(0.00)$ & $0(0.00)$ & $1(4.76)$ \\
\hline
\end{tabular}




\begin{tabular}{|c|c|c|c|c|c|}
\hline & $0 \mathrm{mg} / \mathrm{kg}$ & $50 \mathrm{mg} / \mathrm{kg}$ & $100 \mathrm{mg} / \mathrm{kg}$ & $200 \mathrm{mg} / \mathrm{kg}$ & $400 \mathrm{mg} / \mathrm{kg}$ \\
\hline \multicolumn{6}{|c|}{ Costal cartilage, multiple sites, misaligned - [V] } \\
\hline Fetuses & $0(0.0)^{*}$ & $0(0.0)$ & $0(0.0)$ & $0(0.0)$ & $2(0.8)$ \\
\hline Litters & $0(0.00)$ & $0(0.00)$ & $0(0.00)$ & $0(0.00)$ & $1(4.76)$ \\
\hline \multicolumn{6}{|c|}{ Costal cartilage, total, misaligned - [V] } \\
\hline Fetuses & $0(0.0)^{* *}$ & $0(0.0)$ & $0(0.0)$ & $0(0.0)$ & $3(1.2)$ \\
\hline Litters & $0(0.00)^{*}$ & $0(0.00)$ & $0(0.00)$ & $0(0.00)$ & $2(9.52)$ \\
\hline \multicolumn{6}{|c|}{ Costal cartilage, 7th right, not fused to sternum $-[\mathrm{M}]^{\mathrm{a}}$} \\
\hline Fetuses & $0(0.0)^{* *}$ & $0(0.0)$ & $0(0.0)$ & $2(0.8)$ & $4(1.6)^{*}$ \\
\hline Litters & $0(0.00)^{* *}$ & $0(0.00)$ & $0(0.00)$ & $1(5.26)$ & $4(19.05)^{*}$ \\
\hline \multicolumn{6}{|l|}{ Sternebrae } \\
\hline \multicolumn{6}{|c|}{ Sternebra, 2nd, unossified - [V] } \\
\hline Fetuses & $0(0.0)^{* *}$ & $1(0.4)$ & $0(0.0)$ & $0(0.0)$ & $4(1.6)^{*}$ \\
\hline Litters & $0(0.00)^{* *}$ & $1(4.76)$ & $0(0.00)$ & $0(0.00)$ & $4(19.05)^{*}$ \\
\hline \multicolumn{6}{|c|}{ Sternebra, 5th, unossified - [V] } \\
\hline Fetuses & $0(0.0)$ & $1(0.4)$ & $0(0.0)$ & $0(0.0)$ & $2(0.8)$ \\
\hline Litters & $0(0.00)$ & $1(4.76)$ & $0(0.00)$ & $0(0.00)$ & $2(9.52)$ \\
\hline \multicolumn{6}{|c|}{ Sternebra, 6th, unossified - [V] } \\
\hline Fetuses & $0(0.0)$ & $1(0.4)$ & $0(0.0)$ & $0(0.0)$ & $2(0.8)$ \\
\hline Litters & $0(0.00)$ & $1(4.76)$ & $0(0.00)$ & $0(0.00)$ & $2(9.52)$ \\
\hline \multicolumn{6}{|c|}{ Sternebra, multiple sites, unossified - [V] } \\
\hline Fetuses & $0(0.0)$ & $0(0.0)$ & $0(0.0)$ & $0(0.0)$ & $1(0.4)$ \\
\hline Litters & $0(0.00)$ & $0(0.00)$ & $0(0.00)$ & $0(0.00)$ & $1(4.76)$ \\
\hline \multicolumn{6}{|c|}{ Sternebra, total, unossified - [V] } \\
\hline Fetuses & $0(0.0)^{* *}$ & $1(0.4)$ & $0(0.0)$ & $0(0.0)$ & $6(2.4)^{* *}$ \\
\hline Litters & $0(0.00)^{* *}$ & $1(4.76)$ & $0(0.00)$ & $0(0.00)$ & $5(23.81)^{*}$ \\
\hline \multicolumn{6}{|c|}{ Sternebra, 4th, misaligned - [V] } \\
\hline Fetuses & $0(0.0)^{*}$ & $0(0.0)$ & $0(0.0)$ & $0(0.0)$ & $2(0.8)$ \\
\hline Litters & $0(0.00)^{*}$ & $0(0.00)$ & $0(0.00)$ & $0(0.00)$ & $2(9.52)$ \\
\hline \multicolumn{6}{|c|}{ Sternebra, total, unossified or misaligned - [V] } \\
\hline Fetuses & $0(0.0)^{* *}$ & $1(0.4)$ & $0(0.0)$ & $0(0.0)$ & $7(2.8)^{* *}$ \\
\hline Litters & $0(0.00)^{* *}$ & $1(4.76)$ & $0(0.00)$ & $0(0.00)$ & $6(28.57)^{* *}$ \\
\hline \multicolumn{6}{|l|}{ Vertebrae } \\
\hline \multicolumn{6}{|c|}{ Thoracic centrum, total, incomplete ossification - [V] } \\
\hline Fetuses & $0(0.0)^{*}$ & $1(0.4)$ & $0(0.0)$ & $0(0.0)$ & $3(1.2)$ \\
\hline Litters & $0(0.00)$ & $1(4.76)$ & $0(0.00)$ & $0(0.00)$ & $2(9.52)$ \\
\hline
\end{tabular}




\begin{tabular}{|c|c|c|c|c|c|}
\hline & $0 \mathrm{mg} / \mathrm{kg}$ & $50 \mathrm{mg} / \mathrm{kg}$ & $100 \mathrm{mg} / \mathrm{kg}$ & $200 \mathrm{mg} / \mathrm{kg}$ & $400 \mathrm{mg} / \mathrm{kg}$ \\
\hline \multicolumn{6}{|c|}{ Thoracic centrum, total, incomplete ossification or unossified - [V] } \\
\hline Fetuses & $0(0.0)^{* *}$ & $1(0.4)$ & $0(0.0)$ & $0(0.0)$ & $4(1.6)^{*}$ \\
\hline Litters & $0(0.00)^{*}$ & $1(4.76)$ & $0(0.00)$ & $0(0.00)$ & $3(14.29)$ \\
\hline \multicolumn{6}{|c|}{ Supernumerary Rib } \\
\hline \multicolumn{6}{|c|}{ Cervical, total, short $-[\mathrm{M}]^{\mathrm{b}}$} \\
\hline Fetuses & $0(0.0)^{* *}$ & $0(0.0)$ & $0(0.0)$ & $0(0.0)$ & $6(2.4)^{* *}$ \\
\hline Litters & $0(0.00)^{* *}$ & $0(0.00)$ & $0(0.00)$ & $0(0.00)$ & $3(14.29)$ \\
\hline \multicolumn{6}{|c|}{ Thoracolumbar, total, short $-[\mathrm{V}]$} \\
\hline Fetuses & $76(25.8)^{* *}$ & $56(19.8)$ & $79(28.3)$ & $87(35.2)^{*}$ & $77(30.3)$ \\
\hline Litters & $21(91.30)$ & $19(90.48)$ & 17 (80.95) & $17(89.47)$ & 19 (90.48) \\
\hline \multicolumn{6}{|c|}{ Thoracolumbar, total, full $-[\mathrm{M}]^{\mathrm{c}}$} \\
\hline Fetuses & $2(0.7)^{* * \# \#}$ & $1(0.4)$ & $6(2.2)$ & $5(2.0)$ & $26(10.3)^{* * \# \#}$ \\
\hline Litters & $2(8.70)^{* *}$ & $1(4.76)$ & $3(14.29)$ & $4(21.05)$ & $7(33.33)^{*}$ \\
\hline \multicolumn{6}{|c|}{ Ribs, Sternebrae, Supernumerary Rib, or Vertebrae, Total } \\
\hline \multicolumn{6}{|c|}{ Incomplete Ossification or Unossified, Total - [V] } \\
\hline Fetuses & $0(0.0)^{* *}$ & $2(0.7)$ & $0(0.0)$ & $0(0.0)$ & $9(3.6)^{* *}$ \\
\hline Litters & $0(0.00)^{* *}$ & $2(9.52)$ & $0(0.00)$ & $0(0.00)$ & $7(33.33)^{* *}$ \\
\hline \multicolumn{6}{|c|}{ Malformation, total $-[\mathrm{M}]^{\mathrm{d}}$} \\
\hline Fetuses & $3(1.0)^{* * \# \#}$ & $3(1.1)$ & $6(2.2)$ & $7(2.8)$ & $40(15.8)^{* * \#+\#}$ \\
\hline Litters & $3(13.04)^{* *}$ & 3 (14.29) & 3 (14.29) & $5(26.32)$ & $12(57.14)^{* *}$ \\
\hline
\end{tabular}

Upper row denotes number of affected fetuses (\%); lower row the number of affected litters (\%).

*Statistically significant $(\mathrm{p} \leq 0.05)$ trend according to the Cochran-Armitage (trend) or Fisher exact (pairwise) tests. A significant trend test is indicated in the vehicle control column. A significant pairwise comparison with the vehicle control group is indicated in the dose group column.

$* * \mathrm{p} \leq 0.01$.

\# Statistically significant $(\mathrm{p} \leq 0.01)$ according to mixed-effects logistic regression with litter-based adjustments. A significant trend test is indicated in the vehicle control column. A significant pairwise comparison with the vehicle control group is indicated in the dose group column.

$[\mathrm{M}]=$ malformation; $[\mathrm{V}]$ = variation .

Historical incidence for gavage studies:

aFetuses: 2/1,324 (0.15\%), range 0-0.41\%; litters 2/104 (1.92\%), range 0-5.56\%.

betuses: $1 / 1,324(0.08 \%)$, range $0-0.35 \%$; litters $1 / 104(0.96 \%)$, range $0-4.35 \%$.

'Fetuses: 14/1,324 (1.06\%), range 0.34-3.35\%; litters 13/104 (12.5\%), range 4.76-31.6\%.

dFetuses: 18/1,324 (1.36\%), range 0.68-3.35\%; litters 17/104 (16.3\%), range 9.5-31.6\%. 


\section{Discussion}

4-Methylcyclohexanemethanol (MCHM) is sold as a crude mixture (containing 68-89\% MCHM) and is used to remove impurities during the processing of coal. ${ }^{53}$ On January 9, 2014, an estimated 10,000 gallons of a mixture containing 75\% MCHM leaked into the Elk River upstream of the intake for the West Virginia American Water Company's Elk River plant. ${ }^{6}$ In response, the Centers for Disease Control and Prevention (CDC) and the Agency for Toxic Substances and Disease Registry recommended a 1 ppm drinking water health advisory level that was based on the available toxicity data and nominated MCHM and other chemicals present in the Elk River spill for toxicological evaluation by NTP. Because of the potential for exposure of pregnant women to MCHM and the absence of developmental toxicity data, NTP conducted toxicity studies in Hsd:Sprague Dawley ${ }^{\circledR}$ SD $^{\circledR}$ rats to evaluate the potential effects of MCHM on pregnant rats and fetal development. The guideline prenatal developmental toxicity studies discussed in this report provide important animal data that can be used to address the adequacy of the 1 ppm advisory level in protecting sensitive human populations.

MCHM dose levels selected for the range-finding study were $0,150,300,600$, and $900 \mathrm{mg} / \mathrm{kg}$ body weight per day (mg/kg/day). All dams in the $900 \mathrm{mg} / \mathrm{kg}$ group and three dams in the $600 \mathrm{mg} / \mathrm{kg}$ group displayed clinical signs of overt toxicity and were euthanized moribund and/or removed from the study by gestational day (GD) 10. The remaining $600 \mathrm{mg} / \mathrm{kg}$ dams experienced reduced body weight gain during gestation and reduced gravid uterine weight compared to vehicle control dams. Increased postimplantation loss was also observed at this dose, and although not statistically significant, this finding indicates test article-related toxicity to dams and/or pups. No signs of maternal toxicity were present at $300 \mathrm{mg} / \mathrm{kg}$; however, exposure to MCHM resulted in lower fetal body weights in the 300 and $600 \mathrm{mg} / \mathrm{kg}$ groups. Therefore, because maternal toxicity occurred at or above $600 \mathrm{mg} / \mathrm{kg}$ in the dose range-finding study, $400 \mathrm{mg} / \mathrm{kg}$ was selected as the high dose for the prenatal developmental toxicity study.

In the prenatal developmental toxicity study, no signs of overt toxicity were evident in dams following daily gavage of $0,50,100,200$, or $400 \mathrm{mg} / \mathrm{kg}$. Total protein concentrations were decreased in dams administered $100 \mathrm{mg} / \mathrm{kg}$ or greater, which was driven by a decrease in globulin concentrations in the same dams. Several serum proteins comprise the globulin fraction and include proteins produced by both B-lymphocytes (immunoglobulins) and hepatocytes (e.g., haptoglobulin, complement, C-reactive protein); however, the mechanism of the decreased globulins in this study is not known and the toxicological significance of these changes is unclear. Increased triglycerides (400 mg/kg) and decreased glucose levels (200 and $400 \mathrm{mg} / \mathrm{kg}$ ) were also observed. It is possible that differences in feed consumption might be responsible for these changes; however, toxicogenomic data from MCHM-treated adult male Sprague Dawley (Hsd:Sprague Dawley ${ }^{\circledR} \mathrm{SD}^{\circledR}$ ) rats could provide additional context. In addition to the minor alterations in triglyceride and glucose levels, exposure to MCHM altered the expression of several genes in the liver involved in pathways known to modulate fatty acid metabolism and cholesterol homeostasis. ${ }^{20}$ These findings suggest that MCHM might affect lipid and/or carbohydrate metabolism; however, the mechanism underlying these changes is not known.

Exposure to MCHM significantly affected embryo-fetal development. Fetal body weight was decreased in an exposure-dependent manner in both the dose range-finding and prenatal developmental toxicity studies with lower fetal body weight observed at levels greater than or 
equal to $300 \mathrm{mg} / \mathrm{kg}$. Reduced fetal body weight is a common toxicological response following in utero exposure and is responsible for lowest-observable-adverse-effect levels (LOAELs) in 75\% of NTP prenatal developmental toxicity studies conducted in rats. ${ }^{54}$ Fetal body weight reductions might also be associated with lower maternal body weight and body weight gain. Such a finding could be secondary to maternal stress and/or toxicity as maternal feed restriction studies in the rat and rabbit demonstrate a relationship between reduced maternal weight gain and lower fetal body weights. ${ }^{55}$ The present study, however, demonstrated that the MCHM-related reduction in fetal body weight occurred at exposure levels where the adjusted maternal body weight remained unaffected in the 300 and $400 \mathrm{mg} / \mathrm{kg}$ dams.

Examination of visceral organs revealed exposure-related increases in kidney variations as well as adrenal variations and malformations, with glands appearing grossly necrotic (histopathology was not performed in this study). One $50 \mathrm{mg} / \mathrm{kg}$ fetus and a total of three fetuses from three litters in the $400 \mathrm{mg} / \mathrm{kg}$ group had misshapen and discolored adrenals and discolored kidneys. In addition, one $400 \mathrm{mg} / \mathrm{kg}$ fetus also had findings of a misshapen (malformation) and discolored left ovary. Although the etiology of these findings is uncertain, MCHM-related effects on the kidney were previously observed in a 28-day gavage study in adult Sprague Dawley rats. Both males and females displayed proximal tubular degeneration at $400 \mathrm{mg} / \mathrm{kg} / \mathrm{day}$ and males displayed slight increases in relative kidney weights at 25, 100, and $400 \mathrm{mg} / \mathrm{kg} / \mathrm{day} .{ }^{11}$ Despite the low incidences of adrenal and kidney findings, these occurred at rates greater than those observed in the historical controls for the Sprague Dawley (Hsd:Sprague Dawley ${ }^{\circledR}$ SD $^{\circledR}$ ) rat used by NTP in prenatal developmental toxicity studies.

MCHM-related teratogenicity was also evidenced by increased incidences of skeletal malformations. These included exposure-related increases in the incidences of cartilage not fused to the sternum and full thoracolumbar supernumerary ribs (SNRs); the latter demonstrating a statistically significant increase in fetuses exposed to $400 \mathrm{mg} / \mathrm{kg}$. Full thoracolumbar SNRs were observed in 10\% and 33\% of fetuses and litters, respectively, in the $400 \mathrm{mg} / \mathrm{kg}$ group. Both measures were significantly higher than those in concurrent vehicle controls and exceeded the historical control incidence in fetuses (0.3-3.5\%) and litters (5-32\%) observed in Sprague Dawley (Hsd:Sprague Dawley ${ }^{\circledR} \mathrm{SD}^{\circledR}$ ) rats used in prenatal developmental toxicity studies conducted by NTP.

Despite varying levels of background incidence, an increase in thoracolumbar SNRs is a common finding following in utero exposure to a range of test articles in the rat and mouse model. Notable examples include methanol, ${ }^{56}$ tri-n-butyltin acetate, ${ }^{57}$ nitrous oxide,${ }^{58}$ sodium salicylate, ${ }^{59}$ retinoic acid, valproic acid, and bromoxynil. ${ }^{56 ; 60}$ An increased incidence of SNRs has been attributed to alterations of the underlying mechanisms responsible for anteriorization/posteriorization patterning of the axial skeleton. ${ }^{60-63}$ Alternatively, an increase in SNRs has been attributed to maternal stress; however, this effect may be species-dependent as maternal restraint induced an elevated incidence of SNRs in mice but not in rats. ${ }^{64}$ Given the absence of overt maternal stress or toxicity in dams administered $400 \mathrm{mg} / \mathrm{kg}$ MCHM, the observed increase in SNRs at this dose is likely due to MCHM treatment; however, the underlying mechanism(s) responsible for the increase in SNRs cannot be ascertained under the conditions of this study. The exposure-related increase in full thoracolumbar SNRs in this study is biologically significant. Full thoracolumbar SNRs have been shown to persist through postnatal development following sodium salicylate exposure to Sprague Dawley dams on GD 9 and longitudinal assessment of pups from postnatal day (PND) 1 to PND $54 .{ }^{65}$ A similar finding 
was observed in bromoxynil- ${ }^{66}$ and acetazolamide-induced SNRs in mice. ${ }^{67}$ Therefore, the exposure-related increase of full thoracolumbar SNRs in the present study might represent a permanent structural change that is unlikely to be remodeled and resolved with continued growth.

MCHM also resulted in exposure-related increases in other skeletal anomalies including misaligned costal cartilage and unossified or incomplete ossification of the sternebrae and thoracic centra. Although these variations might not represent adverse functional deficits per se, it is important to note their incidence in conjunction with other endpoints associated with developmental delay. The overall delays in ossification and reduction in fetal body weight suggest that MCHM exposure results in an overall growth retardation. Several studies demonstrate a similar relationship between fetal body weight and ossification delays ${ }^{68 ; 69}$; however, some delays in ossification resolve during subsequent postnatal development as shown in rats exposed to ethylene glycol in utero. ${ }^{34}$

Taken together, the data from the range-finding and prenatal developmental toxicity studies demonstrate the potential for MCHM to adversely affect fetal development in the Sprague Dawley rat. A maternal NOEL of $50 \mathrm{mg} / \mathrm{kg}$ was identified based on changes in clinical chemistry observed at doses $\geq 100 \mathrm{mg} / \mathrm{kg}$, as well as reduced weight gain at $400 \mathrm{mg} / \mathrm{kg}$ and overt toxicity observed at 600 and $900 \mathrm{mg} / \mathrm{kg}$ in the dose range-finding study. The minimal alterations in clinical chemistry would not be expected to affect fetal development. A fetal NOEL of $200 \mathrm{mg} / \mathrm{kg}$ was based on findings of reduced fetal body weight and increased incidence of skeletal malformations at $400 \mathrm{mg} / \mathrm{kg}$.

These data provide important context to address the recommended $1 \mathrm{ppm}$ health advisory level for drinking water set by the CDC. Consumption of drinking water containing $1 \mathrm{ppm} \mathrm{MCHM}$ represents an equivalent exposure of $0.03 \mathrm{mg} / \mathrm{kg}$ in adults (70 kg adult consuming $2 \mathrm{~L}$ per day), $0.04 \mathrm{mg} / \mathrm{kg} /$ day in pregnant women (58 kg female consuming $2.5 \mathrm{~L}$ per day), and $0.1 \mathrm{mg} / \mathrm{kg} / \mathrm{day}$ in children (10 kg child consuming $1 \mathrm{~L}$ per day). Thus, a significant margin of exposure ( $>1000$ fold) exists between the fetal NOEL of $200 \mathrm{mg} / \mathrm{kg}$ identified in the present study and the estimated human exposure at the 1 ppm screening level for MCHM. In addition, a review of hospital records from Charleston, West Virginia, and the surrounding area, did not find an association between adverse birth outcomes and exposure to MCHM or other chemicals present in the spill..$^{70 ;} 71$ 


\section{Conclusions}

Under the conditions of this prenatal study, there was clear evidence of developmental toxicity of MCHM in Hsd:Sprague Dawley ${ }^{\circledR} \mathrm{SD}^{\circledR}$ rats based on reduced fetal weight, adrenal malformations, and increased malformations of the axial skeleton (short cervical SNRs, full thoracolumbar SNRs, and costal cartilage not fused to the sternum). These findings occurred in fetuses of dams administered $400 \mathrm{mg} / \mathrm{kg}$ and in the absence of overt maternal toxicity. 


\section{References}

1. Lide DR, Milne GWA. Handbook of data on organic compounds, 3rd ed., Vol. 1, No. 2228. Boca Raton, FL: CRC Press. 1994.

2. U.S. Environmental Protection Agency (USEPA). Estimation Programs Interface Suite ${ }^{\mathrm{TM}}$ for Microsoft Windows $^{\circledR}$, Ver. 4.1. Washington, DC: U.S. Environmental Protection Agency; 2014. https://www.epa.gov/tsca-screening-tools/estimation-program-interface-epi-suite-tm-program$\underline{\text { modifications-new-features }}$

3. Eastman Chemical Company. Safety Data Sheet: Crude MCHM. Version 3.0. Kingsport, TN: Eastman Chemical Company; 2015.

4. Foreman WT, Rose DL, Chambers DB, Crain AS, Murtagh LK, Thakellapalli H, Wang KK. Determination of (4-methylcyclohexyl) methanol isomers by heated purge-and-trap GC/MS in water samples from the 2014 Elk River, West Virginia, chemical spill. Chemosphere. 2015; 131:217-224. http://dx.doi.org/10.1016/j.chemosphere.2014.11.006

5. Gallagher DL, Phetxumphou K, Smiley E, Dietrich AM. Tale of two isomers: Complexities of human odor perception for cis-and trans-4-methylcyclohexane methanol from the chemical spill in West Virginia. Environ Sci Technol. 2015; 49(3):1319-1327.

http://dx.doi.org/10.1021/es5049418

6. West Virginia Office of the Governor. After action review: Emergency response to January 9, 2014, Freedom Industries chemical leak. Charleston, WV: State of West Virginia Office of the Governor; Homeland Security and Emergency Management; and West Virginia National Guard; 2015. http://www.governor.wv.gov/Documents/After\%20Action\%20Review.PDF [Accessed: September 21, 2016]

7. West Virginia Poison Center (WVPC). Factsheet: Freedom Industries, Elk River chemical spill, February 10, 2014. Washington, DC: West Virginia Poison Center; and Georgetown University, Mid-Atlantic Center for Children’s Health and the Environment; 2014.

http://www.legis.state.wv.us/legisdocs/2014/committee/interim/water/Documents/Bureau\%20for \%20Public\%20Health\%20Packet.pdf [Accessed: September 21, 2016]

8. Centers for Disease Control and Prevention (CDC). Summary report of short-term screening level calculation and analysis of available animal studies for MCHM. Atlanta, GA: U.S. Department of Health and Human Services, Centers for Disease Control and Prevention; 2014. http://emergency.cdc.gov/chemical/MCHM/westvirginia2014/mchm.asp

9. Whelton AJ, McMillan L, Connell M, Kelley KM, Gill JP, White KD, Gupta R, Dey R, Novy C. Residential tap water contamination following the Freedom Industries chemical spill:

Perceptions, water quality, and health impacts. Environ Sci Technol. 2015; 49(2):813-823. http://dx.doi.org/10.1021/es5040969

10. Toxicology Excellence for Risk Assessment (TERA). Report of expert panel review of screening levels for exposure to chemicals from the January 2014 Elk River spill. Charleston, WV: West Virginia Division of Homeland Security and Emergency Management, West Virginia Testing Assessment Project; 2014. 
11. Eastman Kodak Company. Four-week oral toxicity study of 4-methylcyclohexane methanol in the rat. Rochester, NY: Eastman Kodak Company, Health and Environment Laboratories, Toxicological Sciences Laboratory; 1990. TX-89-296; HAEL No. 89-0081; Accession. No. 907670. http://www.eastman.com/Literature_Center/Misc/Pure_Distilled_MCHM-28-

Day_Oral_Feeding_Study.pdf

12. National Toxicology Program (NTP). West Virginia chemical spill: Nematode (caenorhabditis elegans) toxicity study. March 2015 update. Research Triangle Park, NC: U.S. Department of Health and Human Services, National Institutes of Health, National Toxicology Program; 2015.

https://ntp.niehs.nih.gov/ntp/research/areas/wvspill/celegans_wvupdate_march2015_508.pdf

13. National Toxicology Program (NTP). West Virginia chemical spill: Zebrafish developmental toxicity study. June 2015 update. Research Triangle Park, NC: U.S. Department of Health and Human Services, National Institutes of Health, National Toxicology Program; 2015. https://ntp.niehs.nih.gov/ntp/research/areas/wvspill/zebrafish_update_june2015_508.pdf

14. National Toxicology Program (NTP). West Virginia chemical spill: Zebrafish photomotor response study. August 2015 update. Research Triangle Park, NC: U.S. Department of Health and Human Services, National Institutes of Health, National Toxicology Program; 2015. https://ntp.niehs.nih.gov/ntp/research/areas/wvspill/zebrafish_update_aug2015_508.pdf

15. Eastman Kodak Company. Acute toxicity of 4-methylcyclohexane methanol. Rochester, NY: Eastman Kodak Company, Health and Environment Laboratories, Toxicological Sciences Laboratory; 1990. TX-90-5; HAEL No. 89 0081; Accession No. 907670. http://www.eastman.com/Literature_Center/Misc/Pure_Distilled_MCHMAcute_Toxicity_Battery_Containing_5_Study_Reports.pdf

16. National Toxicology Program (NTP). West Virginia chemical spill: Mouse dermal irritation and hypersensitivity study. June 2015 update. Research Triangle Park, NC: U.S. Department of Health and Human Services, National Institutes of Health, National Toxicology Program; 2015. https://ntp.niehs.nih.gov/ntp/research/areas/wvspill/mouse_dermal_wvupdate_508.pdf

17. National Toxicology Program (NTP). NTP technical report on the dermal hypersensitivity and irritancy studies of 4-methylcyclohexanemethanol (CAS No. 34885-03-5) and crude 4methylcyclohexanemethanol administered topically to female BALB/c mice [In Preparation]. Research Triangle Park, NC: U.S. Department of Health and Human Services, National Institutes of Health, National Toxicology Program; 2019.

18. National Toxicology Program (NTP). West Virginia chemical spill: 5-day rat toxicogenomic studies. July 2016 update. Research Triangle Park, NC: U.S. Department of Health and Human Services, National Institutes of Health, National Toxicology Program; 2016. https://ntp.niehs.nih.gov/ntp/research/areas/wvspill/tgmx_update_july2016_508.pdf

19. Schade CP, Wright N, Gupta R, Latif DA, Jha A, Robinson J. Self-reported household impacts of large-scale chemical contamination of the public water supply, Charleston, West Virginia, USA. PLoS One. 2015; 10(5):e0126744. http://dx.doi.org/10.1371/journal.pone.0126744 
20. National Toxicology Program (NTP). West Virginia chemical spill: 5-day toxicogenomic studies: In vivo micronucleus assay component. February 2015 update. Research Triangle Park, NC: U.S. Department of Health and Human Services, National Institutes of Health, National Toxicology Program; 2015. https://ntp.niehs.nih.gov/ntp/research/areas/wvspill/micronucleus_wvfeb2015_508.pdf

21. National Toxicology Program (NTP). West Virginia chemical spill: Bacterial mutagenicity study. July 2015 update. Research Triangle Park, NC: U.S. Department of Health and Human Services, National Institutes of Health, National Toxicology Program; 2015. https://ntp.niehs.nih.gov/ntp/research/areas/wvspill/bacterial_mutagenesis_july2015_508.pdf

22. Chernoff N, Setzer RW, Miller DB, Rosen MB, Rogers JM. Effects of chemically induced maternal toxicity on prenatal development in the rat. Teratology. 1990; 42(6):651-658. http://dx.doi.org/10.1002/tera.1420420610

23. U.S. Environmental Protection Agency (USEPA). Guidelines for developmental toxicity risk assessment. Washington, DC: U.S. Environmental Protection Agency, Risk Assessment Forum; 1991. EPA Document No. EPA/600/FR-91/001.

24. Tyl RW. Commentary on the role of maternal toxicity on developmental toxicity. Birth Defects Res B: Dev Reprod Toxicol. 2012; 95(3):262-266. http://dx.doi.org/10.1002/bdrb.21015

25. Organisation for Economic Co-operation and Development (OECD). OECD guideline for the testing of chemicals, test no. 44, prenatal developmental toxicity study. Paris, France:

Organisation for Economic Co-operation and Development; 2001.

26. Makris SL, Solomon HM, Clark R, Shiota K, Barbellion S, Buschmann J, Ema M, Fujiwara M, Grote K, Hazelden KP. Terminology of developmental abnormalities in common laboratory mammals (version 2). Congenit Anom. 2009; 49(3):123-246. http://dx.doi.org/10.1111/j.17414520.2009.00239.x

27. Suckow MA, Weisbroth SH, Franklin CL. The laboratory rat, 2nd ed. Amsterdam, Netherlands: Elsevier; 2006.

28. Hayes AW, Kruger CL. Hayes’ principles and methods of toxicology, 6th ed., pp. 16701672. Boca Raton, FL: CRC Press; 2014.

29. Salewski E. Färbemethode zum makroskopischen nachweis von implantationsstellen am uterus der ratte. Naunyn-Schmiedeberg's Arch Pharmacol. 1964; 247(4):367.

http://dx.doi.org/10.1007/BF02308461

30. Tyl RW, Marr MC. Developmental toxicity texting - methodology. Developmental and Reporductive Toxicology. 2nd ed. New York, NY: Taylor and Francis Group; 2006. p. 201-261.

31. Staples RE. Detection of visceral alterations in mammalian fetuses. Teratology. 1974; 9:A37A38.

32. Stuckhardt JL, Poppe SM. Fresh visceral examination of rat and rabbit fetuses used in teratogenicity testing. Teratog Carcinog Mutagen. 1984; 4(2):181-188. http://dx.doi.org/10.1002/tcm.1770040203 
33. Thompson RF. Basic neuroanatomy. Foundations of Physiological Psychology. New York, NY: Harper and Row Publishers; 1967. p. 79-82.

34. Marr MC, Price CJ, Myers CB, Morrissey RE. Developmental stages of the $\mathrm{CD}^{\circledR}($ SpragueDawley) rat skeleton after maternal exposure to ethylene glycol. Teratology. 1992; 46(2):169181. http://dx.doi.org/10.1002/tera.1420460210

35. Dunnett CW. A multiple comparison procedure for comparing several treatments with a control. J Am Stat Assoc. 1955; 50(272):1096-1121.

http://dx.doi.org/10.1080/01621459.1955.10501294

36. Williams DA. A test for differences between treatment means when several dose levels are compared with a zero dose control. Biometrics. 1971; 27:103-117.

http://dx.doi.org/10.2307/2528930

37. Williams DA. The comparison of several dose levels with a zero dose control. Biometrics. 1972; 28:519-531. http://dx.doi.org/10.2307/2556164

38. Shirley E. A non-parametric equivalent of Williams' test for contrasting increasing dose levels of a treatment. Biometrics. 1977; 33:386-389. http://dx.doi.org/10.2307/2529789

39. Williams DA. A note on Shirley's nonparametric test for comparing several dose levels with a zero-dose control. Biometrics. 1986; 42:183-186. http://dx.doi.org/10.2307/2531254

40. Dunn OJ. Multiple comparisons using rank sums. Technometrics. 1964; 6(3):241-252. http:// dx.doi.org/10.1080/00401706.1964.10490181

41. Jonckheere AR. A distribution-free k-sample test against ordered alternatives. Biometrika. 1954; 41(1/2):133-145. http://dx.doi.org/10.2307/2333011

42. Dixon WJ, Massey FJ, Jr. Introduction to statistical analysis, 2nd ed., pp. 276-278, 412. New York, NY: McGraw-Hill Book Company, Inc; 1957. http://dx.doi.org/10.2307/2332898

43. Hsu JC. The factor analytic approach to simultaneous inference in the general linear model. J Comput Graph Stat. 1992; 1(2):151-168.

44. Armitage P. Tests for linear trends in proportions and frequencies. Biometrics. 1955; 11(3):375-386. http://dx.doi.org/10.2307/3001775

45. Gart JJ, Chu KC, Tarone RE. Statistical issues in interpretation of chronic bioassay tests for carcinogenicity. J Natl Cancer Inst. 1979; 62(4):957-974.

46. Zorrilla EP. Multiparous species present problems (and possibilities) to developmentalists. Dev Psychobiol. 1997; 30(2):141-150. https://doi.org/10.1002/ (SICI)1098-2302(199703)30:2<141::A $\overline{\text { ID-DEV5>3.0.CO;2-Q }}$

47. Pendergast JF, Gagne SJ, Lindstrom MJ. Correlated binary data In: Encyclopedia of Biostatistics. London, UK: John Wiley and Sons; 2005.

http://dx.doi.org/10.1002/0470011815.b2a10018 
48. Li B, Lingsma HF, Steyerberg EW, Lesaffre E. Logistic random effects regression models: A comparison of statistical packages for binary and ordinal outcomes. BMC Med Res Methodol. 2011; 11(1):77. http://dx.doi.org/10.1186/1471-2288-11-77

49. Code of Federal Regulations (CFR). 21:Part 58.

50. National Toxicology Program (NTP). DART-02: Growth and clinical finding tables (I), pathology tables (PA), developmental and reproductive tables (R) from NTP developmental and reproductive toxicity studies. Research Triangle Park, NC. 2019.

http://dx.doi.org/10.22427/NTP-DATA-DART-02

51. Pickering RG, Pickering CE. Studies of rat alkaline phosphatase. II. Some applications of the methods for detecting the isoenzymes of plasma alkaline phosphatase in rats. Arch Toxicol.

1978; 39(4):267-287. http://dx.doi.org/10.1007/BF00296387

52. Waner T, Nyska A. The influence of fasting on blood glucose, triglycerides, cholesterol, and alkaline phosphatase in rats. Vet Clin Pathol. 1994; 23(3):78-80.

http://dx.doi.org/10.1111/j.1939-165X.1994.tb00683.x

53. Eastman Chemical Company. Safety Data Sheet: Crude MCHM. Version 3.1. Kingsport, TN: Eastman Chemical Company; 2016.

54. Chernoff N, Rogers EH, Gage MI, Francis BM. The relationship of maternal and fetal toxicity in developmental toxicology bioassays with notes on the biological significance of the “no observed adverse effect level”. Reprod Toxicol. 2008; 25(2):192-202. http://dx.doi.org/10.1016/j.reprotox.2007.12.001

55. Nitzsche D. Effect of maternal feed restriction on prenatal development in rats and rabbits-A review of published data. Regul Toxicol Pharm. 2017; 90:95-103.

http://dx.doi.org/10.1016/j.yrtph.2017.08.009

56. Rogers JM, Francis BM, Barbee BD, Chernoff N. Developmental toxicity of bromoxynil in mice and rats. Fundam Appl Toxicol. 1991; 17(3):442-447. http://dx.doi.org/10.1016/0272$\underline{0590(91) 90195-A}$

57. Tsutomu N, Shigeru M, Tetsuo Y, Mitsuru S, Tomoko N, Minoru S, Akio Y. Teratogenicity study of tri-n-butyltin acetate in rats by oral administration. Toxicol Lett. 1991; 55(1):109-115. http://dx.doi.org/10.1016/0378-4274(91)90032-2

58. Fujinaga M, Baden JM, Mazze RI. Susceptible period of nitrous oxide teratogenicity in Sprague-Dawley rats. Teratology. 1989; 40(5):439-444.

http://dx.doi.org/10.1002/tera.1420400505

59. Foulon O, Girard H, Pallen C, Urtizberea M, Repetto-Larsay M, Blacker AM. Induction of supernumerary ribs with sodium salicylate. Reprod Toxicol. 1999; 13(5):369-374. http://dx.doi.org/10.1016/S0890-6238(99)00029-5

60. Kawanishi CY, Hartig P, Bobseine KL, Schmid J, Cardon M, Massenburg G, Chernoff N. Axial skeletal and Hox expression domain alterations induced by retinoic acid, valproic acid, and bromoxynil during murine development. J Biochem Mol Toxicol. 2003; 17(6):346-356.

http://dx.doi.org/10.1002/jbt.10098 
61. Branch S, Rogers JM, Brownie CF, Chernoff N. Supernumerary lumbar rib: Manifestation of basic alteration in embryonic development of ribs. J Appl Toxicol. 1996; 16(2):115-119. http://dx.doi.org/10.1002/(SICI)1099-1263(199603)16:2<115::AID-JAT309>3.0.CO;2-H

62. Connelly LE, Rogers JM. Methanol causes posteriorization of cervical vertebrae in mice. Teratology. 1997; 55(2):138-144. http://dx.doi.org/10.1002/ (SICI) 1096-9926(199702)55:2<138::AID-TERA4>3.0.CO;2-\%23

63. Wéry N, Narotsky MG, Pacico N, Kavlock RJ, Picard JJ, Gofflot F. Defects in cervical vertebrae in boric acid-exposed rat embryos are associated with anterior shifts of hox gene expression domains. Birth Defects Res Part A: Clin Mol Teratol. 2003; 67(1):59-67. http://dx.doi.org/10.1002/bdra.10031

64. Beyer PE, Chernoff N. The induction of supernumerary ribs in rodents: Role of the maternal stress. Teratog Carcinog Mutagen. 1986; 6(5):419-429.

http://dx.doi.org/10.1002/tcm.1770060508

65. Foulon O, Jaussely C, Repetto M, Urtizberea M, Blacker AM. Postnatal evolution of supernumerary ribs in rats after a single administration of sodium salicylate. J Appl Toxicol. 2000; 20(3):205-209. http://dx.doi.org/10.1002/(SICI)1099-1263(200005/06)20:3<205::AIDJAT635>3.0.CO;2-G

66. Chernoff N, Rogers JM, Turner CI, Francis BM. Significance of supernumerary ribs in rodent developmental toxicity studies: Postnatal persistence in rats and mice. Toxicol Sci. 1991; 17(3):448-453. http://dx.doi.org/10.1016/0272-0590(91)90196-B

67. Beck SL. Assessment of adult skeletons to detect prenatal exposure to trypan blue in mice. Teratology. 1983; 28(2):271-285. http://dx.doi.org/10.1002/tera.1420280217

68. Khera KS. Common fetal aberrations and their teratologic significance: A review. Toxicol Sci. 1981; 1(1):13-18. http://dx.doi.org/10.1093/toxsci/1.1.13

69. Daston GP, Seed J. Skeletal malformations and variations in developmental toxicity studies: Interpretation issues for human risk assessment. Birth Defects Res B: Dev Reprod Toxicol. 2007; 80(6):421-424. http://dx.doi.org/10.1002/bdrb.20135

70. Benson SM, Ruestow P, Keeton KA, Novick RM, Marsh GM, Paustenbach DJ. The 2014 crude 4-methylcyclohexanemethanol chemical release and birth outcomes in West Virginia. Arch Environ Occup Health. 2018; 73(5):292-301.

http://dx.doi.org/10.1080/19338244.2017.1350132

71. Sanders S. Analysis of birthweight after the January 9, 2014 chemical spill in Charleston, West Virginia. Charleston, WV: West Virginia Department of Health and Human Resources, Office of Maternal, Child and Family Health; 2016. https://www.wvdhhr.org/mcfh/files/birthweightanalysis.pdf

72. Advanced Chemistry Development (ACD). SciFinder ${ }^{\circledR}$ Spectrum ID 34885035-HNMR. Predicted NMR data calculated using Advanced Chemistry Development, Inc., Software V11.01. Toronto, Ontario, Canada: ACD Labs; 1994. 
73. National Institute of Standards and Technology (NIST). Mass Spectral Library, Version d.OF; trans, ID 18215, cis, ID 18228. Gaithersburg, MD: National Institute of Standards and Technology; 2008.

74. American Chemical Society (ACS). SciFinder ${ }^{\circledR}$ Spectrum ID BR08924. 2014.

75. American Chemical Society (ACS). SciFinder ${ }^{\circledR}$ Spectrum ID NC_05067. 2014.

76. Allen CFH, Ball WL, Young DM. Dihydro-p-tolualdehyde. Can J Res. 1933; 9(2):169-174. http://dx.doi.org/10.1139/cjr33-078 


\section{Appendix A. Chemical Characterization and Dose Formulation Studies}

\section{Table of Contents}

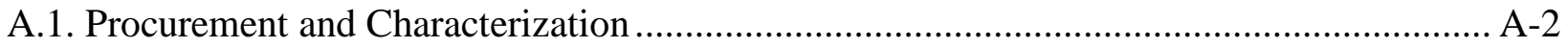

A.2. Preparation and Analysis of Dose Formulations...................................................... A-3

\section{Tables}

Table A-1. Gas Chromatography Systems Used in the Gavage Studies of

4-Methylcyclohexanemethanol

Table A-2. Preparation and Storage of Dose Formulations in the Gavage Studies of

4-Methylcyclohexanemethanol

Table A-3. Results of Analyses of Dose Formulations Administered to Female Rats in the

Dose Range-Finding Gavage Study of 4-Methylcyclohexanemethanol

Table A-4. Results of Analyses of Dose Formulations Administered to Female Rats in the

Prenatal Developmental Toxicity Gavage Study of

4-Methylcyclohexanemethanol

\section{Figures}

Figure A-1. Fourier Transform Infrared Absorption Spectrum of

4-Methylcyclohexanemethanol

Figure A-2. Fourier Transform Proton Nuclear Magnetic Resonance Spectrum of

4-Methylcyclohexanemethanol 


\section{A.1. Procurement and Characterization}

\section{A.1.1. 4-Methylcyclohexanemethanol}

4-Methylcyclohexanemethanol (MCHM) was obtained from TCI America (Portland, OR) in one lot (KDY3F) that was used in the dose range-finding study and the prenatal developmental toxicity study. Identity, purity, and stability analyses were conducted by the analytical chemistry laboratory at MRIGlobal (Kansas City, MO) for the study laboratory at Southern Research (Birmingham, AL). Reports on analyses performed in support of the MCHM studies are on file at the National Institute of Environmental Health Sciences.

Lot KDY3F of the test chemical, a clear colorless liquid, was identified as MCHM using Fourier transform infrared (FTIR), proton and carbon-13 nuclear magnetic resonance (NMR) spectroscopy, and gas chromatography (GC) with mass spectrometry (MS) detection. In addition, boiling point, density, and octanol:water partition coefficient were measured. All spectra were consistent with isomers of the proposed structure and literature spectra of MCHM. ${ }^{72-75}$ Two components tentatively identified as cis- and trans-isomers of MCHM were observed for the test article using GC/MS. Representative FTIR and FT proton NMR spectra are presented in Figure A-1 and Figure A-2, respectively. The boiling point of the test chemical was $199.4^{\circ} \mathrm{C}$ (consistent with a literature reference value of $202^{\circ} \mathrm{C}^{76}$ ), the relative density was $0.9203 \mathrm{~g} / \mathrm{mL}$, and the octanol:water partition coefficient was 353 (resulting in a $\log \mathrm{P}$ of 2.55).

The moisture content of lot KDY3F was determined using Karl Fischer titration. Elemental analyses for carbon, hydrogen, and nitrogen were conducted by Galbraith Laboratories, Inc. (Knoxville, TN). The purity profile was determined using GC with flame ionization detection (FID) and two columns with differing polarities.

For lot KDY3F, Karl Fischer titration indicated 0.209\% water. Elemental analyses for carbon, hydrogen, and nitrogen were consistent with the theoretical values for MCHM. GC/FID analysis by system A (Table A-1) detected two major peaks with a combined area of $99.97 \%$ of the total peak area and no impurities with areas $\geq 0.05 \%$ of the total peak area. The relative areas of the two major peaks indicated that MCHM consisted of $67.99 \%$ cis- and $31.98 \%$ trans-isomers. GC/FID by system B detected two major peaks with a combined relative area of $99.83 \%$ (with relative areas of $67.80 \%$ [cis-] and 32.03\% [trans-] isomers), and two minor impurities totaling $0.13 \%$ of the total peak area. The overall purity of lot KDY3F was determined to be greater than or equal to $99.8 \%$.

Stability studies of the bulk chemical were conducted using GC/FID by a system similar to system A. These studies indicated that MCHM was stable as a bulk chemical for 2 weeks when stored in amber glass vials under an inert headspace, sealed with aluminum caps with Teflon ${ }^{\circledR}$ lined septa at temperatures up to $60^{\circ} \mathrm{C}$. To ensure stability, the bulk chemical was stored at room temperature under an inert headspace in amber glass bottles. Reanalyses of the bulk chemical were performed during the animal studies by the analytical chemistry laboratory using FTIR and GC/FID by system $\mathrm{C}$ and no degradation of the bulk chemical was detected.

\section{A.1.2. Corn Oil}

Corn oil was obtained from Spectrum Laboratory Products, Inc. (Gardena, CA), in two lots (ICK0678 and 2DG0376) that were used as the vehicle in the dose range-finding and prenatal 
developmental toxicity studies, respectively. A solubility study of MCHM was performed by the analytical chemistry laboratory; after 17 days under refrigerated conditions, the test article remained soluble in corn oil at up to $600 \mathrm{mg} / \mathrm{mL}$ with no remixing required. Both lots contained peroxide levels less than the rejection level of $3 \mathrm{meQ} / \mathrm{kg}$ corn oil.

\section{A.2. Preparation and Analysis of Dose Formulations}

The dose formulations were prepared once for the dose range-finding study and once for the prenatal developmental toxicity study by mixing the appropriate amount of MCHM with corn oil to give the required concentrations (Table A-2). The dose formulations were stored at room temperature in amber glass bottles with Teflon-lined caps, protected from light, for up to 27 days (dose range-finding study) or 39 days (prenatal developmental toxicity study).

Stability studies of 0.20 and $2.0 \mathrm{mg} / \mathrm{mL}$ formulations were performed by the analytical chemistry laboratory with GC/FID by system C (Table A-1). For the $0.2 \mathrm{mg} / \mathrm{mL}$ formulation, stability was confirmed for at least 42 days during which the formulation was stored under ambient or refrigerated conditions and protected from light, and for 3 hours under simulated animal room conditions. In addition, for the $2.0 \mathrm{mg} / \mathrm{mL}$ formulation, stability was confirmed for at least 44 days during which it was stored under ambient or refrigerated conditions and protected from light.

Analyses of the dose formulations of MCHM were conducted by the analytical chemistry laboratory using GC/FID by system C. During the dose range-finding study, the dose formulations were analyzed once; all four dose formulations were within $10 \%$ of the target concentrations (Table A-3). Animal room samples of these dose formulations were also analyzed; all four animal room samples were within $10 \%$ of the target concentrations. During the prenatal developmental toxicity study, the dose formulations were analyzed once; animal room samples of these dose formulations were analyzed twice (Table A-4). All four dose formulations analyzed were within $10 \%$ of the target concentrations and all eight animal room samples were within $10 \%$ of the target concentrations. 


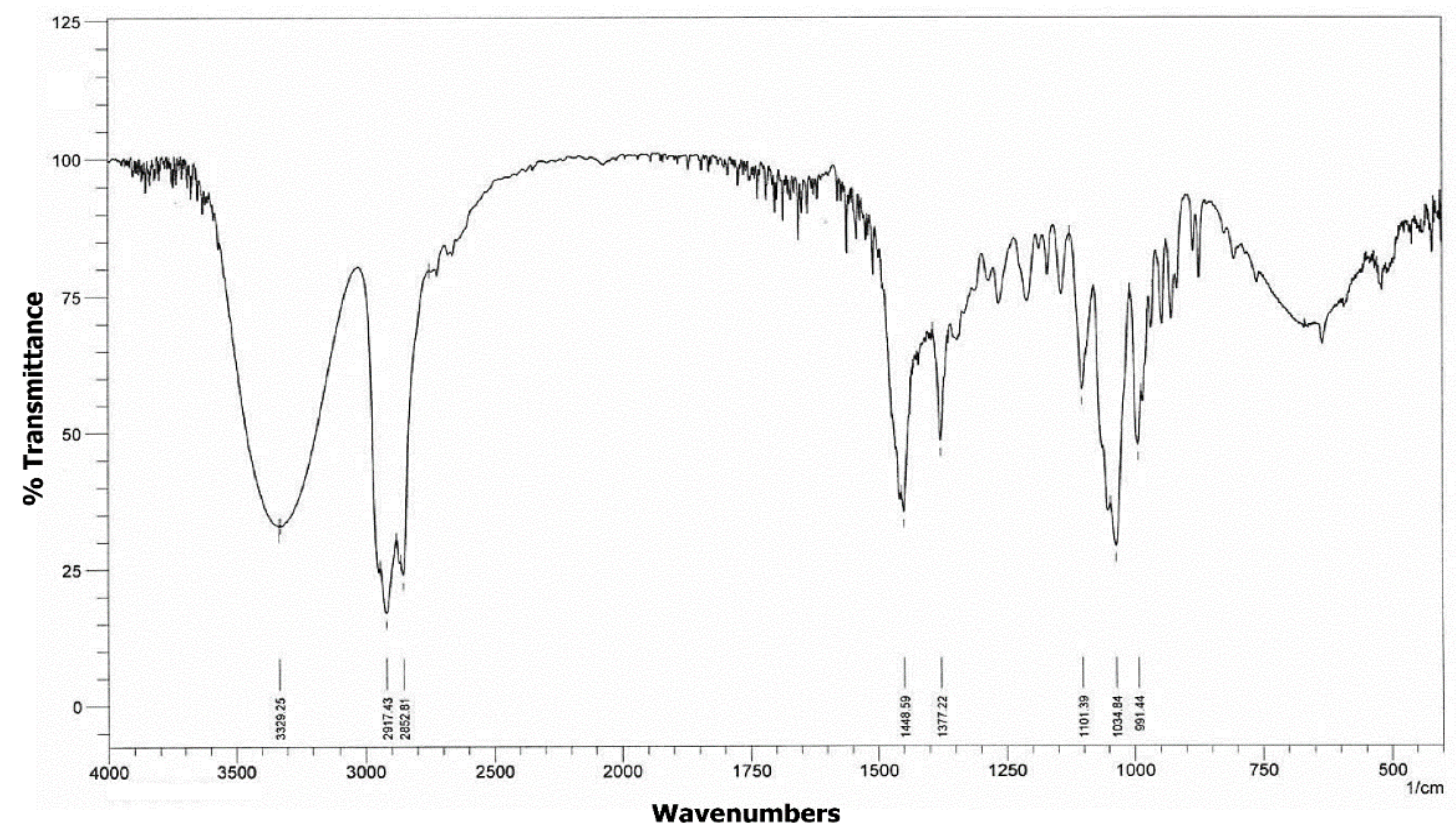

Figure A-1. Fourier Transform Infrared Absorption Spectrum of 4-Methylcyclohexanemethanol

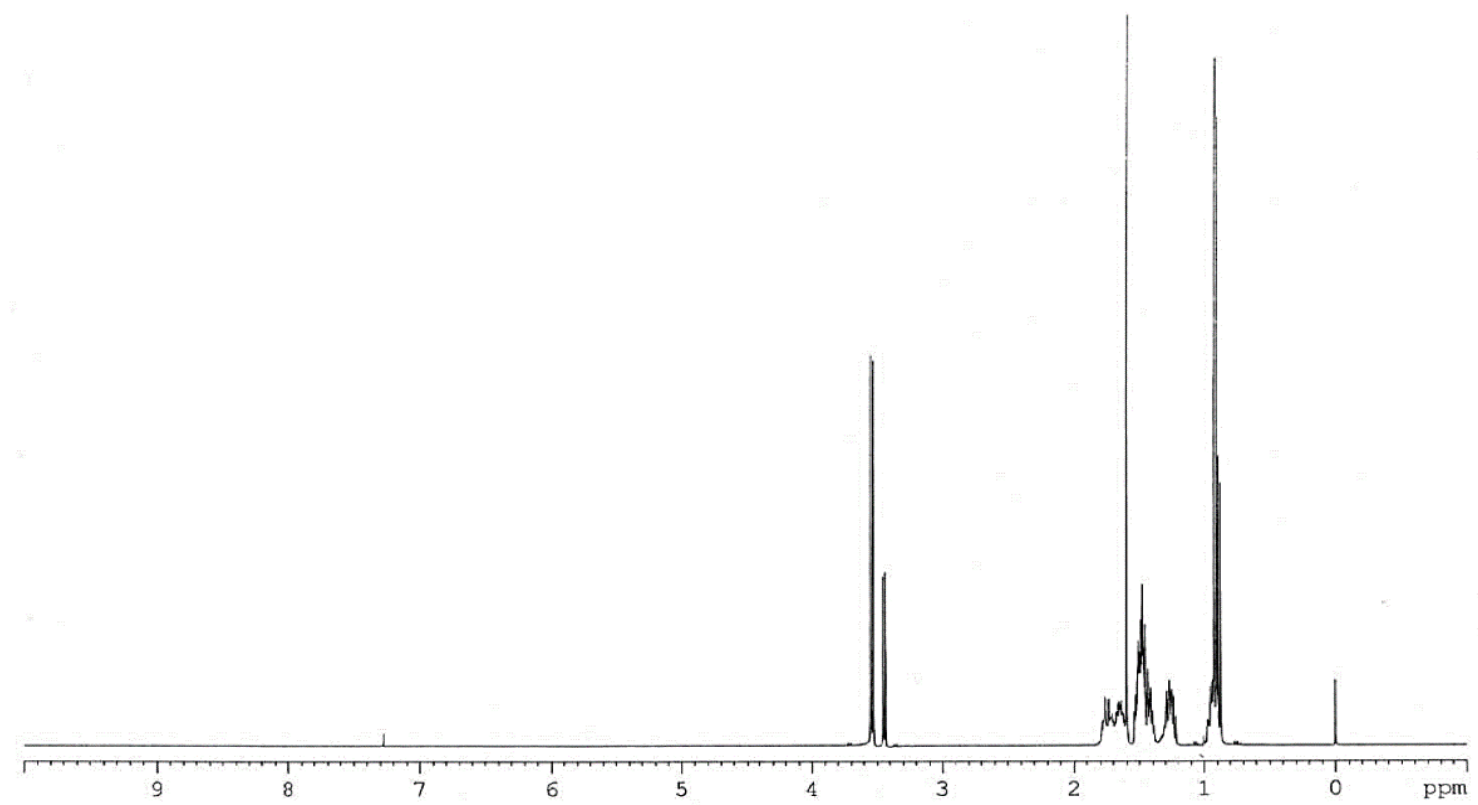

Figure A-2. Fourier Transform Proton Nuclear Magnetic Resonance Spectrum of 4-Methylcyclohexanemethanol 
Table A-1. Gas Chromatography Systems Used in the Gavage Studies of 4-Methylcyclohexanemethanol ${ }^{\mathrm{a}}$

\begin{tabular}{|c|c|c|c|}
\hline Detection System & Column & Carrier Gas & $\begin{array}{l}\text { Oven Temperature } \\
\text { Program }\end{array}$ \\
\hline \multicolumn{4}{|l|}{ System A } \\
\hline Flame Ionization & $\begin{array}{l}\text { Zebron }{ }^{\mathrm{TM}} \mathrm{ZB}-624, \\
30 \mathrm{~m} \times 0.53 \mathrm{~mm}, 3.0 \mu \mathrm{m} \text { film } \\
\text { (Phenomenex, Torrance, CA) }\end{array}$ & Helium at $5 \mathrm{~mL} /$ minute & $\begin{array}{l}50^{\circ} \mathrm{C} \text { for } 2 \text { minutes, then } \\
10^{\circ} \mathrm{C} / \text { minute to } 240^{\circ} \mathrm{C} \text {, } \\
\text { held for } 4 \text { minutes }\end{array}$ \\
\hline \multicolumn{4}{|l|}{ System B } \\
\hline Flame Ionization & $\begin{array}{l}\text { Agilent DB-1, } \\
30 \mathrm{~m} \times 0.53 \mathrm{~mm}, 1.5 \mu \mathrm{m} \text { film } \\
\text { (Agilent Technologies, Inc., } \\
\text { Santa Clara, CA) }\end{array}$ & Helium at $5 \mathrm{~mL} /$ minute & $\begin{array}{l}50^{\circ} \mathrm{C} \text { for } 2 \text { minutes, then } \\
10^{\circ} \mathrm{C} / \text { minute to } 240^{\circ} \mathrm{C} \text {, } \\
\text { held for } 4 \text { minutes }\end{array}$ \\
\hline \multicolumn{4}{|l|}{ System C } \\
\hline Flame Ionization & $\begin{array}{l}\text { Rtx }^{\circledR}-\mathrm{VMS}, 30 \mathrm{~m} \times 0.53 \mathrm{~mm} \text {, } \\
3.0 \mu \mathrm{m} \text { film } \\
\text { (Restek, Bellefonte, PA) }\end{array}$ & , Helium at $5 \mathrm{~mL} /$ minute & $\begin{array}{l}50^{\circ} \mathrm{C} \text { for } 2 \text { minutes, then } \\
10^{\circ} \mathrm{C} / \text { minute to } 240^{\circ} \mathrm{C} \text {, } \\
\text { held for } 4 \text { minutes }\end{array}$ \\
\hline \multicolumn{4}{|c|}{$\begin{array}{l}\text { Table A-2. Preparation and Storage of Dose Formulations in the Gavage Studies of } \\
\text { 4-Methylcyclohexanemethanol }\end{array}$} \\
\hline \multicolumn{2}{|c|}{ Dose Range-finding Study } & \multicolumn{2}{|c|}{ Prenatal Developmental Toxicity Study } \\
\hline \multicolumn{4}{|l|}{ Preparation } \\
\hline \multicolumn{2}{|c|}{$\begin{array}{l}\text { The appropriate amounts of } \\
\text { 4-methylcyclohexanemethanol were weighed into } \\
500 \mathrm{~mL} \text { volumetric flasks, diluted to near volume with } \\
\text { corn oil, swirled to dissolve, diluted to volume with } \\
\text { corn oil, mixed by inversion, and then stirred with a } \\
\text { magnetic stir bar for } 30 \text { minutes. The dose formulations } \\
\text { were prepared once. }\end{array}$} & \multicolumn{2}{|c|}{$\begin{array}{l}\text { Same as the dose range-finding study except that the } \\
\text { formulations were prepared in } 1 \mathrm{~L} \text { volumetric flasks }\end{array}$} \\
\hline \multicolumn{4}{|l|}{ Chemical Lot Number } \\
\hline KDY3F & & \multicolumn{2}{|l|}{ KDY3F } \\
\hline \multicolumn{4}{|l|}{ Maximum Storage Time } \\
\hline 27 days & & \multicolumn{2}{|l|}{39 days } \\
\hline \multicolumn{4}{|l|}{ Storage Conditions } \\
\hline $\begin{array}{l}\text { Stored in amber glass bo } \\
\text { protected from light, at } r\end{array}$ & $\begin{array}{l}\text { s with Teflon }{ }^{\circledR} \text {-lined caps, } \\
\text { m temperature }\end{array}$ & \multicolumn{2}{|c|}{$\begin{array}{l}\text { Stored in amber glass bottles with Teflon }{ }^{\circledR} \text {-lined caps, } \\
\text { protected from light, at room temperature }\end{array}$} \\
\hline \multicolumn{4}{|l|}{ Study Laboratory } \\
\hline \multicolumn{2}{|c|}{ Southern Research (Birmingham, AL) } & \multicolumn{2}{|c|}{ Southern Research (Birmingham, AL) } \\
\hline
\end{tabular}


Table A-3. Results of Analyses of Dose Formulations Administered to Female Rats in the Dose Range-Finding Gavage Study of 4-Methylcyclohexanemethanol

\begin{tabular}{lcccc}
\hline Date Prepared & Date Analyzed & $\begin{array}{c}\text { Target } \\
\text { Concentration } \\
(\mathbf{m g} / \mathbf{m L})\end{array}$ & $\begin{array}{c}\text { Determined } \\
\text { Concentration } \\
(\mathbf{m g} / \mathbf{m L})\end{array}$ & $\begin{array}{c}\text { Difference } \\
\text { from Target } \\
\mathbf{( \% )}\end{array}$ \\
\hline August 13, 2014 & August 13, 2014 & 75 & 75.82 & +1 \\
& & 150 & 152.0 & +1 \\
& September 11, 2014 & 300 & 303.5 & +1 \\
& & 750 & 456.0 & +1 \\
& & 150 & 75.36 & 0 \\
& 300 & 152.1 & +1 \\
& 450 & 302.6 & +1 \\
\hline
\end{tabular}

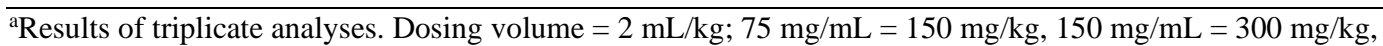
$300 \mathrm{mg} / \mathrm{mL}=600 \mathrm{mg} / \mathrm{kg} ; 450 \mathrm{mg} / \mathrm{mL}=900 \mathrm{mg} / \mathrm{kg}$.

${ }^{\mathrm{b}}$ Animal room samples.

Table A-4. Results of Analyses of Dose Formulations Administered to Female Rats in the Prenatal Developmental Toxicity Gavage Study of 4-Methylcyclohexanemethanol

\begin{tabular}{ccccc}
\hline Date Prepared & Date Analyzed & $\begin{array}{c}\text { Target } \\
\text { Concentration } \\
(\mathbf{m g} / \mathbf{m L})\end{array}$ & $\begin{array}{c}\text { Determined } \\
\text { Concentration } \\
(\mathbf{m g} / \mathbf{m L})\end{array}$ & $\begin{array}{c}\text { Difference } \\
\text { from Target } \\
(\mathbf{\%})\end{array}$ \\
\hline October 30, 2014 & 25 & 24.78 & -1 \\
& October 30, 2014 & 50 & 49.67 & -1 \\
& December 3, 2014 & 100 & 99.84 & 0 \\
& & 200 & 199.3 & 0 \\
& & 25 & 24.88 & 0 \\
& & 50 & 50.57 & +1 \\
& & 100 & 100.5 & +1 \\
& & 200 & 199.6 & 0 \\
& 25 & 25.00 & 0 \\
& 50 & 50.09 & 0 \\
\hline
\end{tabular}

${ }^{a}$ Results of triplicate analyses. Dosing volume $=2 \mathrm{~mL} / \mathrm{kg} ; 25 \mathrm{mg} / \mathrm{mL}=50 \mathrm{mg} / \mathrm{kg}, 50 \mathrm{mg} / \mathrm{mL}=100 \mathrm{mg} / \mathrm{kg}$, $100 \mathrm{mg} / \mathrm{mL}=200 \mathrm{mg} / \mathrm{kg}, 200 \mathrm{mg} / \mathrm{mL}=400 \mathrm{mg} / \mathrm{kg}$.

${ }^{\mathrm{b}}$ Animal room samples. 


\section{Appendix B. Ingredients, Nutrient Composition, and Contaminant Levels in NIH-07 Rat and Mouse Ration}

\section{Tables}

Table B-1. Ingredients of NIH-07 Rat and Mouse Ration.

B-2

Table B-2. Vitamins and Minerals in NIH-07 Rat and Mouse Ration ........................................3

Table B-3. Nutrient Composition of NIH-07 Rat and Mouse Ration ..........................................

Table B-4. Contaminant Levels in NIH-07 Rat and Mouse Ration............................................6 
Table B-1. Ingredients of NIH-07 Rat and Mouse Ration

\begin{tabular}{lc}
\hline \multicolumn{1}{c}{ Ingredients } & Percent by Weight \\
\hline Ground \#2 Yellow Shelled Corn & 24.25 \\
Ground Hard Winter Wheat & 23.00 \\
Soybean Meal (49\% Protein) & 12.00 \\
Fish Meal (60\% Protein) & 10.00 \\
Wheat Middlings & 10.00 \\
Dried Skim Milk & 5.00 \\
Alfalfa Meal (Dehydrated, 17\% Protein) & 4.00 \\
Corn Gluten Meal & 3.00 \\
Soy Oil (without Preservatives) & 2.50 \\
Dried Brewer's Yeast & 2.00 \\
Dried Molasses & 1.50 \\
Calcium Phosphate, Dibasic (USP) & 1.25 \\
Ground Limestone & 0.50 \\
Salt & 0.50 \\
Premixes (Vitamin and Mineral) & 0.40 \\
Choline Chloride (70\% Choline) & 0.10 \\
\hline USP = United States Pharmacopeia. &
\end{tabular}


Table B-2. Vitamins and Minerals in NIH-07 Rat and Mouse Ration ${ }^{\mathrm{a}}$

\begin{tabular}{lcl}
\hline & Amount & \multicolumn{1}{c}{ Source } \\
\hline Vitamins & & \\
$\mathrm{A}$ & $5,500,000 \mathrm{IU}$ & Stabilized vitamin A palmitate or acetate \\
$\mathrm{D}$ & $4,600,000 \mathrm{IU}$ & D-activated animal sterol \\
$\mathrm{K}$ & $2.8 \mathrm{mg}$ & Dimethylpyrimidinol bisulfite \\
$\mathrm{E}$ & $20 \mathrm{IU}$ & $\alpha$-Tocopheryl acetate \\
Niacin & $30 \mathrm{mg}$ & - \\
Folic Acid & $2.2 \mathrm{mg}$ & - \\
$d$-Pantothenic Acid & $18.0 \mathrm{mg}$ & $d$-Calcium pantothenate \\
Riboflavin & $3.4 \mathrm{mg}$ & \\
Thiamin & $10 \mathrm{mg}$ & Thiamine mononitrate \\
B 12 & $45.4 \mathrm{\mu g}$ & \\
Pyridoxine & $5.9 \mathrm{mg}$ & Pyridozine hydrochloride \\
Biotin & $140 \mathrm{mg}$ & $d$-Biotin \\
\hline Minerals & & \\
Iron & $120 \mathrm{mg}$ & Iron sulfate \\
Zinc & $16 \mathrm{mg}$ & Zinc oxide \\
Manganese & $60 \mathrm{mg}$ & Manganese oxide \\
Copper & $4.0 \mathrm{mg}$ & Copper sulfate \\
Iodine & $1.4 \mathrm{mg}$ & Calcium iodate \\
Cobalt & $0.4 \mathrm{mg}$ & Cobalt carbonate \\
\hline aPer kg of finished product. & \\
\hline
\end{tabular}


Table B-3. Nutrient Composition of NIH-07 Rat and Mouse Ration

\begin{tabular}{|c|c|c|c|}
\hline Nutrient & Mean \pm Standard Deviation & Range & Number of Samples \\
\hline Protein (\% by Weight) & 25.1 & - & 1 \\
\hline Crude Fat (\% by Weight) & 0.5 & - & 1 \\
\hline Crude Fiber (\% by Weight) & 3.15 & - & 1 \\
\hline Ash (\% by Weight) & 6.33 & - & 1 \\
\hline \multicolumn{4}{|l|}{ Amino Acids (\% of Total Diet) } \\
\hline Arginine & $1.375 \pm 0.065$ & $1.3-1.49$ & 8 \\
\hline Cysteine & $0.321 \pm 0.035$ & $0.274-0.372$ & 8 \\
\hline Glycine & $1.145 \pm 0.077$ & $1.06-1.31$ & 8 \\
\hline Histidine & $0.516 \pm 0.023$ & $0.497-0.553$ & 8 \\
\hline Isoleucine & $0.982 \pm 0.025$ & $0.952-1.03$ & 8 \\
\hline Leucine & $1.996 \pm 0.054$ & $1.93-2.08$ & 8 \\
\hline Lysine & $1.261 \pm 0.032$ & $1.22-1.32$ & 8 \\
\hline Methionine & $0.487 \pm 0.015$ & $0.468-0.515$ & 8 \\
\hline Phenylalanine & $1.091 \pm 0.020$ & $1.07-1.12$ & 8 \\
\hline Threonine & $0.919 \pm 0.032$ & $0.883-0.961$ & 8 \\
\hline Tryptophan & $0.280 \pm 0.022$ & $0.266-0.326$ & 8 \\
\hline Tyrosine & $0.855 \pm 0.039$ & $0.785-0.894$ & 8 \\
\hline Valine & $1.134 \pm 0.0245$ & $0.11-1.17$ & 8 \\
\hline \multicolumn{4}{|c|}{ Essential Fatty Acids (\% of Total Diet) } \\
\hline Linoleic & $2.33 \pm 0.211$ & $2.04-2.59$ & 8 \\
\hline Linolenic & $0.25 \pm 0.028$ & $0.217-0.296$ & 8 \\
\hline \multicolumn{4}{|l|}{ Vitamins } \\
\hline Vitamin A (IU/kg) & 6,020 & - & 1 \\
\hline$\alpha$-Tocopherol (ppm) & $48.07 \pm 4.38$ & $40.3-52.73$ & 8 \\
\hline Thiamine $^{\mathrm{b}}$ (ppm) & 16.1 & - & 1 \\
\hline Riboflavin (ppm) & $14.3 \pm 3.58$ & 10-19.8 & 8 \\
\hline Niacin (ppm) & $99.4 \pm 9.10$ & $87-112$ & 8 \\
\hline Pantothenic Acid (ppm) & $45.6 \pm 3.13$ & $40.4-51.1$ & 8 \\
\hline Pyridoxine $^{\mathrm{b}}$ (ppm) & $12.33 \pm 2.25$ & $9.63-15.6$ & 8 \\
\hline Folic Acid (ppm) & $2.47 \pm 0.550$ & $1.68-3.09$ & 8 \\
\hline Biotin (ppm) & $0.342 \pm 0.125$ & $0.25-0.64$ & 8 \\
\hline Vitamin $B_{12}(p p b)$ & $50.21 \pm 7.47$ & $41.8-61.6$ & 8 \\
\hline Choline (as Chloride) (ppm) & $1,776 \pm 197$ & $1,570-2,200$ & 8 \\
\hline
\end{tabular}


4-Methylcyclohexanemethanol, NTP DART 02

\begin{tabular}{lccc}
\hline \multicolumn{1}{c}{ Nutrient } & Mean \pm Standard Deviation & Range & Number of Samples \\
\hline Minerals & 1.170 & - & 1 \\
Calcium (\%) & 0.885 & - & 1 \\
Phosphorus (\%) & $0.829 \pm 0.036$ & $0.77-0.88$ & 8 \\
Potassium (\%) & $0.625 \pm 0.102$ & $0.441-0.8$ & 8 \\
Chloride (\%) & $0.368 \pm 0.047$ & $0.318-0.469$ & 8 \\
Sodium (\%) & $0.183 \pm 0.009$ & $0.170-0.194$ & 8 \\
Magnesium (\%) & $376.3 \pm 52.5$ & $276-455$ & 8 \\
Iron (ppm) & $91.03 \pm 7.93$ & $80.7-104$ & 8 \\
Manganese (ppm) & $64.07 \pm 11.32$ & $52.4-89.2$ & 8 \\
Zinc (ppm) & $14.11 \pm 2.91$ & $11.9-21.1$ & 8 \\
Copper (ppm) & $1.71 \pm 0.886$ & $0.54-3.45$ & 8 \\
Iodine (ppm) & $3.96 \pm 0.033$ & $3.91-4.00$ & 8 \\
Chromium (ppm) & $0.53 \pm 0.293$ & $0.01-0.963$ & 8 \\
Cobalt (ppm) & & & \\
\hline IU = international unit. & & & \\
\hline
\end{tabular}

$\mathrm{IU}=$ international unit.

${ }^{\mathrm{a} F r o m}$ formulation.

${ }^{\mathrm{b}}$ As hydrochloride (thiamine and pyridoxine). 
Table B-4. Contaminant Levels in NIH-07 Rat and Mouse Ration ${ }^{\mathrm{a}}$

\begin{tabular}{|c|c|c|}
\hline & Mean \pm Standard Deviation ${ }^{\mathrm{b}}$ & Number of Samples \\
\hline \multicolumn{3}{|l|}{ Contaminants } \\
\hline Arsenic (ppm) & 0.472 & 1 \\
\hline Cadmium (ppm) & 0.069 & 1 \\
\hline Lead (ppm) & 0.169 & 1 \\
\hline Mercury (ppm) & $<0.02$ & 1 \\
\hline Selenium (ppm) & 0.523 & 1 \\
\hline Aflatoxins (ppb) & $<5.00$ & 1 \\
\hline Nitrate Nitrogen ${ }^{\mathrm{c}}$ (ppm) & 10 & 1 \\
\hline Nitrite Nitrogen ${ }^{c}$ (ppm) & $<0.61$ & 1 \\
\hline $\mathrm{BHA}^{\mathrm{d}}(\mathrm{ppm})$ & 2.37 & 1 \\
\hline $\mathrm{BHT}^{\mathrm{d}}(\mathrm{ppm})$ & $<1.0$ & 1 \\
\hline Aerobic Plate Count (CFU/g) & 10 & 1 \\
\hline Coliform (MPN/gm) & 3.0 & 1 \\
\hline Escherichia coli (MPN/g) & $<3$ & 1 \\
\hline Salmonella (MPN/g) & Negative & 1 \\
\hline Total Nitrosamines (ppb) ${ }^{\mathrm{e}}$ & 4.6 & 1 \\
\hline$N$-Nitrosodimethylamine (ppb) & 0 & 1 \\
\hline$N$-Nitrosopyrrolidine (ppb) ${ }^{\mathrm{e}}$ & 4.6 & 1 \\
\hline \multicolumn{3}{|l|}{ Pesticides (ppm) } \\
\hline$\alpha$-BHC & $<0.01$ & 1 \\
\hline$\beta$-BHC & $<0.02$ & 1 \\
\hline$\gamma$-BHC & $<0.01$ & 1 \\
\hline$\delta$-BHC & $<0.01$ & 1 \\
\hline Heptachlor & $<0.01$ & 1 \\
\hline Aldrin & $<0.01$ & 1 \\
\hline Heptachlor Epoxide & $<0.01$ & 1 \\
\hline DDE & $<0.01$ & 1 \\
\hline DDD & $<0.01$ & 1 \\
\hline DDT & $<0.01$ & 1 \\
\hline HCB & $<0.01$ & 1 \\
\hline Mirex & $<0.01$ & 1 \\
\hline Methoxychlor & $<0.05$ & 1 \\
\hline Dieldrin & $<0.01$ & 1 \\
\hline Endrin & $<0.01$ & 1 \\
\hline Telodrin & $<0.01$ & 1 \\
\hline
\end{tabular}




\begin{tabular}{lcc}
\hline & Mean \pm Standard Deviation & Number of Samples \\
\hline Chlordane & $<0.05$ & 1 \\
Toxaphene & $<0.10$ & 1 \\
Estimated PCBs & $<0.20$ & 1 \\
Ronnel & $<0.01$ & 1 \\
Ethion & $<0.02$ & 1 \\
Trithion & $<0.05$ & 1 \\
Diazinon & $<0.10$ & 1 \\
Methyl Chlorpyrifos & 0.041 & 1 \\
Methyl Parathion & $<0.02$ & 1 \\
Ethyl Parathion & $<0.02$ & 1 \\
Malathion & 0.164 & 1 \\
Endosulfan I & $<0.01$ & 1 \\
Endosulfan II & $<0.01$ & 1 \\
Endosulfane Sulfate & $<0.03$ & 1 \\
\hline BHA = butylated hydroxyanisole; BHT = butylated hydroxytolnen & CFU colony-forming units; MPN $=$ most probble
\end{tabular}

BHA = butylated hydroxyanisole; BHT = butylated hydroxytoluene; CFU = colony-forming units; MPN = most probable number; BHC = hexachlorocyclohexane or benzene hexachloride; DDE = dichlorodiphenyldichloroethylene;

DDD = dichlorodiphenyldichloroethane; DDT = dichlorodiphenyltrichloroethane; HCB = hexachlorobenzene;

PCB = polychlorinated biphenyl; PCB = polychlorinated biphenyl.

${ }^{a}$ All samples were irradiated.

${ }^{\mathrm{b}}$ For values less than the limit of detection, the detection limit is given as the mean.

'Sources of contamination: alfalfa, grains, and fish meal.

dSources of contamination: soy oil and fish meal.

eAll values were corrected for percent recovery. 


\section{Appendix C. Summary of Peer Review Panel Comments}

\section{Table of Contents}

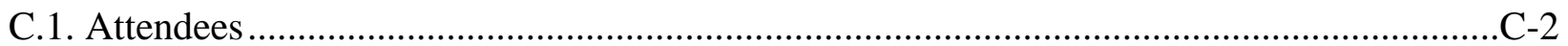

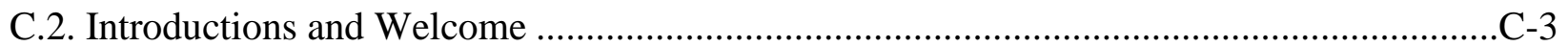

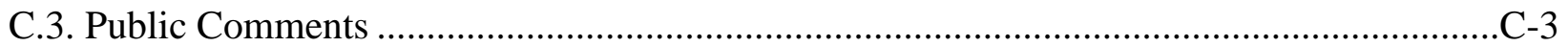

C.4. Background and Charge to the Panel ..............................................................................

C.5. Prenatal Developmental Toxicity Studies of Tris(chloropropyl) Phosphate ......................C-4

C.6. Prenatal Developmental Toxicity Studies of 4-Methylcyclohexanemethanol ......................-6

C.7. Prenatal Developmental Toxicity Studies of Vinpocetine ..............................................10

C.8. Prenatal Developmental Toxicity Studies of Dimethylaminoethanol Bitartrate................. -13

C.9. Closing Remarks on the Draft Reports .........................................................................14

C.10. Approval of the Peer Review Report by the Chair of the Peer Review Panel .................C-15 


\section{C.1. Attendees}

\section{Peer Review Panel}

Chair: George Daston, The Procter and Gamble Company

Cheryl Broussard, Centers for Disease Control and Prevention

Alan Hoberman, Charles River Laboratories Preclinical Services

Linda Roberts, NapaTox Consulting LLC

Mary Alice Smith, University of Georgia

Kimberley Treinen, Sunovion Pharmaceuticals Inc.

\section{National Toxicology Program Board of Scientific Counselors Liaison}

Donald Stump, Charles River Laboratories International

\section{National Institute of Environmental Health Sciences Staff}

Brian Berridge

Chad Blystone

Bradley Collins

Michelle Cora

Helen Cunny

Shawn Harris

Michelle Hooth

Angela King-Herbert

Elizabeth Maull, Designated Federal Official

Barry McIntyre

Georgia Roberts

Kristen Ryan

Sheena Scruggs

Keith Shockley

Matthew Stout

Vicki Sutherland

Nigel Walker 
AtLee Watson

Mary Wolfe

\section{Other Federal Agency Staff}

Gonçalo Gamboa, FDA

\section{Contract Support Staff}

Susan Blaine, ICF

Dave Burch, ICF

Lindsey Green, ICF

Ernie Hood, Bridport Services

Steve McCaw, Image Associates

Blake Riley, ICF

Samantha Snow, ICF

\section{C.2. Introductions and Welcome}

The National Toxicology Program (NTP) convened a peer review panel for the draft NTP Developmental and Reproductive Toxicity Technical Reports on the Prenatal Development Studies of Tris(chloropropyl) Phosphate, 4-Methylcyclohexanemethanol, Vinpocetine, and Dimethylaminoethanol Bitartrate on July 31, 2019, in Conference Room F193, Rall Building, National Institute for Environmental Health Sciences (NIEHS), Research Triangle Park, North Carolina (or via webcast).

- Dr. George Daston, panel chair, called the meeting to order at 8:30 a.m., welcomed everyone to the meeting, asked all attendees to introduce themselves, and reviewed the format for the peer review meeting for the panel and audience.

- Dr. Elizabeth Maull read the conflict of interest policy statement and briefed the attendees on meeting logistics.

- Dr. Donald Stump attended as the liaison to the NTP Board of Scientific Counselors.

\section{C.3. Public Comments}

Dr. Daston noted that no written public comments or requests for oral public comments on the draft technical reports had been received.

\section{C.4. Background and Charge to the Panel}

Dr. Chad Blystone gave a brief presentation on NTP draft technical reports, including information about the levels of evidence for developmental toxicity. He also described the 
Developmental and Reproductive Toxicity (DART) historical controls and the charge to the panel for the individual peer reviews:

- Review and evaluate the scientific and technical elements of each study and its presentation.

- Determine whether each study's experimental design, conduct, and findings support NTP's conclusions regarding the developmental toxicity of the substances tested.

\section{C.5. Prenatal Developmental Toxicity Studies of Tris(chloropropyl) Phosphate}

\section{C.5.1. Presentation and Clarifying Questions}

Dr. Kristen Ryan summarized the studies and conclusions reported in the draft NTP Developmental and Reproductive Toxicity Technical Report on the Prenatal Development Studies of Tris(chloropropyl) Phosphate (CASRN 13674-84-5) in Sprague Dawley (Hsd:Sprague Dawley ${ }^{\circledR} S D^{\circledR}$ ) Rats (Gavage Studies).

Tris(chloropropyl) phosphate (TCPP) is a flame retardant found in a variety of commercial and consumer products. It is ubiquitous but not bioaccumulative in the environment. Exposure can occur via dermal, oral, or inhalation routes. TCPP is a mixture constituted primarily of four isomers; the research focus is often on the primary isomer due to its abundance. The test article used for the NTP studies contained all four isomers. The goal of this study was to characterize the effects of TCPP exposure on pregnant rats and developing fetuses.

The dose range-finding study was conducted in 11 time-mated female rats using doses of 0,300 , 650 , and $1,000 \mathrm{mg} / \mathrm{kg} / \mathrm{day}$, administered via gavage. Adverse signs at $1,000 \mathrm{mg} / \mathrm{kg} / \mathrm{day}$ occurred throughout gestation. These results informed the use in the main study of doses of $0,162.5,325$, and $650 \mathrm{mg} / \mathrm{kg} /$ day in 25 time-mated female rats per group. An additional 25 control dams were added to this study to supplement historical control data for maternal and fetal findings. The main study findings revealed:

- No maternal treatment-related effects on mortality or body weights during gestation

o Clinical observations were of low incidence and limited to the $650 \mathrm{mg} / \mathrm{kg} /$ day group

o At $650 \mathrm{mg} / \mathrm{kg} /$ day, absolute and relative liver weights were increased approximately $26 \%$

- No treatment-related effects on uterine or litter parameters, such as implantations, litter size, live fetuses per litter, or fetal weight

- Fetal skeletal malformations of limited toxicological relevance (e.g., lumbar rudimentary ribs) or those that occurred as single or sporadic incidence

Under the conditions of this prenatal study, NTP's draft conclusion was:

- No evidence of developmental toxicity of TCPP in Hsd:Sprague Dawley rats administered $162.5,325$, or $650 \mathrm{mg} / \mathrm{kg} /$ day in the absence of overt maternal toxicity

There were no clarifying questions or comments about the presentation. 


\section{C.5.2. Peer Review Comments and Panel Discussion}

\section{C.5.2.1. First Reviewer - Dr. Cheryl Broussard}

Dr. Broussard indicated that the study was clearly described, well conducted, and the conclusions followed logically from the presented findings. She agreed with NTP's draft conclusions. Dr. Broussard then recommended adding language explaining the rationale for limiting soft tissue examination to only $50 \%$ of the heads. She also requested that NTP clarify more specifically where the audit procedures and findings were located to aid in transparency. The comments regarding soft tissue allocations and audit procedures applied to all reports. Finally, Dr. Broussard questioned why blood was not collected from the dams for clinical pathology.

- Dr. Ryan noted that the allocation for fetal exams was based on the study guidelines, with every other fetus allocated for head examination. She agreed that NTP could consider adding more information on fetal exam allocations and the use and location of the audit procedures and findings, which are archived electronically, to the reports.

- Dr. Ryan stated that blood chemistry was not typically required in this type of study. Furthermore, these endpoints were not identified in the literature as a primary concern for TCPP exposure.

\section{C.5.2.2. Second Reviewer - Dr. Alan Hoberman}

Dr. Hoberman stated that the study was well conducted, and he did not disagree with the conclusion. However, he noted that the only individual data presented in the reports were fetal data and that the public would benefit from having access to all individual animal data. This comment applied to all reports. The presence or absence of deviations should be included in the report. The historical control data lacked information on postimplantation loss percentages as well as other fetal information. The report failed to comment on an earlier study by Kawasaki (1982) that noted an increase in cervical ribs. Although Dr. Hoberman understood the use of two control groups, he noted that inclusion of group variations would have been informative. He also noted that this class of compound is known to produce enlarged livers, which may be considered an adaptive change rather than maternal toxicity. Because NTP referenced the changes in liver weights, the authors must have considered that the change in weight represented some sort of system perturbation. He recommended adding some discussion detailing why the enlarged liver was not considered as maternal toxicity.

In response to Dr. Hoberman's comments, Dr. Ryan indicated:

- NTP would consider adding language to the report specifying the location of the individual animal data.

- Deviations are listed in the good laboratory practices report. NTP would consider adding a line to the main report such as "no other deviations were noted."

- NTP is currently evaluating the historical control data and will be adding information (i.e., fetal and uterine parameters) to the database. Postimplantation loss observed in this study was limited to a single litter and was not considered an exposure-related finding.

- NTP evaluates cervical ribs as part of the fetal examinations. Although an increase in cervical ribs had been observed in the Kawasaki study, they were not seen in the NTP 
study, and, therefore, not populated in the historical control database. This information could be added.

- She reviewed the cross-reference data from dams to fetuses from the two control groups prior to the data being pooled and found that there were comparable findings in both control groups.

- NTP chose to report that no developmental toxicity was observed in the absence of overt maternal toxicity in this study and indicated that NTP would consider adding language to clarify the issues related to enlarged liver in the discussion.

\section{C.5.3. Vote on NTP Conclusion}

Dr. Daston called for a motion from the panel to approve the conclusion as written. Dr. Hoberman so moved and Dr. Kimberley Treinen seconded the motion. The panel voted unanimously (5 yes, 0 no, 0 abstentions) to approve the conclusion as written.

\section{C.6. Prenatal Developmental Toxicity Studies of 4-Methylcyclohexanemethanol}

\section{C.6.1. Presentation and Clarifying Questions}

Dr. AtLee Watson summarized the studies and conclusions reported in the draft NTP Developmental and Reproductive Toxicity Technical Report on the Prenatal Development Studies of 4-Methylcyclohexanemethanol (CASRN 34885-03-5) in Sprague Dawley (Hsd:Sprague Dawley ${ }^{\circledR} S D^{\circledR}$ ) Rats (Gavage Studies).

4-Methylcyclohexanemethanol (MCHM) was the chemical involved in the 2014 Elk River Chemical Spill in West Virginia. An estimated 10,000 gallons of crude MCHM leaked into the river, contaminated the municipal water supply, and likely led to human exposure. This prenatal developmental toxicity study resulted from concern for women of childbearing potential and developing embryos/fetuses, and provided an opportunity to evaluate the adequacy of the 1 part per million advisory level set forth by the Centers for Disease Control and Prevention (CDC) and the Agency for Toxic Substances and Disease Registry (ATSDR) for MCHM in drinking water.

The dose range-finding study tested doses of $0,150,300,600$, and $900 \mathrm{mg} / \mathrm{kg} / \mathrm{day}$ in groups of 10 time-mated female rats each and examined maternal and fetal endpoints. In this study, exposure to 600 and $900 \mathrm{mg} / \mathrm{kg} /$ day resulted in dose-related mortality and clinical observations of toxicity. These results informed the selection of doses of $0,50,100,200$, and $400 \mathrm{mg} / \mathrm{kg} / \mathrm{day}$ for the main study in 25 time-mated female rats per group. Main study findings included:

- Reduced maternal serum total protein and globulin at doses $\geq 100 \mathrm{mg} / \mathrm{kg} /$ day

- Fetal findings at $400 \mathrm{mg} / \mathrm{kg} /$ day:

o Decreased fetal body weights (15\%) and gravid uterine weight (18\%) compared with controls

o Increased incidences of malformations of the axial skeleton

o Misshapen adrenal glands (malformation)

- No exposure-related fetal findings at doses $\leq 200 \mathrm{mg} / \mathrm{kg} / \mathrm{day}$ 
Under the conditions of this prenatal study, NTP's draft conclusion was:

- Clear evidence of developmental toxicity of MCHM in Hsd:Sprague Dawley rats at $400 \mathrm{mg} / \mathrm{kg} /$ day in the absence of overt maternal toxicity based on findings of:

o Reduced fetal weight

o Malformations of the axial skeleton

o Malformations of the adrenal glands

As a follow-up to the presentation, panelists had the following clarifying questions and discussion:

\section{Topic - Malformation of the adrenal glands}

- Dr. Linda Roberts asked for a description of the criteria for classifying the adrenal glands as misshapen.

- Dr. Hoberman asked if histopathology is routinely performed when necrotic masses are observed on adrenal glands. Although this finding appeared in three fetuses from different litters, the genealogy of the litters was unknown, which may play a role in the occurrence rate. Responding to a question posed by Dr. Roberts, Dr. Hoberman stated he could not recall ever seeing a misshapen adrenal with a necrotic mass. Dr. Sutherland agreed that it was an unusual finding.

o Dr. Watson indicated that the misshapen adrenal designation was attributed to the presence of a necrotic mass on the adrenal glands.

o Dr. Watson stated that while histopathology could inform whether the occurrence of a necrotic mass on the adrenal gland represents a permanent change or would alter postnatal or subsequent development, guideline prenatal developmental toxicity studies do not routinely call for it.

\section{Topic - Clinical chemistry endpoints}

- Dr. Daston inquired if the clinical chemistry findings on glucose, triglycerides, and blood urea nitrogen levels were also observed in other subchronic MCHM studies or if the changes in the clinical chemistry endpoints were specific to the pregnancy in the rat.

o Dr. Watson noted that there was a decrease in some of the red blood cells in the repeat dose oral gavage study that was conducted by the Eastman Chemical Company. He indicated that Eastman Chemical Company did not observe the same glucose findings.

\section{Topic - Potential MCHM review article}

- Dr. Daston noted that NTP played a significant role in quickly developing information on MCHM and wondered if there will be a larger synthesis of information based on this and other recently conducted studies. He added that there would be interest in these types of summary reports from people who were exposed and who had made health decisions based on what the scientific community conveyed to them. The current report format may be difficult for the general public to understand given the dry and science-based conclusions they contain. 
o Dr. Watson indicated that NTP's website currently has summary findings, but the development of a report summarizing all MCHM-related NTP studies would be addressed in subsequent NTP discussions.

o Dr. Blystone noted that prior communications to the stakeholders were less dry and more informal.

\section{C.6.2. Peer Review Comments and Panel Discussion}

\section{C.6.2.1. First Reviewer - Dr. Mary Alice Smith}

Dr. Smith indicated that the study was designed and conducted according to accepted DART guidelines. She stated that the findings in the study, including reduced fetal weight, adrenal malformations, and increased malformations of the axial skeleton, support the conclusion of clear evidence of developmental toxicity of MCHM in the fetuses from dams exposed to $400 \mathrm{mg} / \mathrm{kg} /$ day. Dr. Smith recommended adding historical normal pregnant rat clinical chemistry ranges (as reported for human studies) to the report, which would help interpret the exposurerelated data. Adding to this comment, Dr. Daston asked if some of the qualitative statements on clinical chemistry endpoints found in the report might be expanded on to put this type of data in context. Dr. Smith recommended that the report clearly state that the dose-related changes are significantly different from the controls based on a dose-related trend or a pairwise comparison effect and to include this type of information in the conclusion statements. Finally, she requested inclusion of a 2018 human epidemiology study investigating the possible association of adverse birth defects with exposure to crude MCHM from the spill site.

- Dr. Michelle Cora, NTP Clinical Pathologist, responding to the clinical chemistry questions, noted that currently NTP does not have historical control data for pregnant rats. She added that reporting values from the study's controls are preferred over those of historical controls due to the number of uncontrolled variables (i.e., animal diet, conditions of the study, type of machine the samples were run on) that influence historical control data. She added that the range for clinical chemistry data indicated in these reports is typically the standard error. Expansion beyond qualitative statements would not be feasible.

- Dr. Watson agreed that inclusion of dose-related response in the fetal body weight conclusion would improve the comprehension of the data but was concerned that it could overcomplicate the conclusion statement. He indicated that NTP would consider implementing this recommendation if it could be done in a concise manner.

- Dr. Watson indicated that he would incorporate the 2018 study, which found no adverse birth outcomes following the spill, in the report's discussion.

\section{C.6.2.2. Second Reviewer - Dr. Cheryl Broussard}

Dr. Broussard found the study design clearly described and well conducted, and that the conclusions followed logically from the presented findings. She agreed with the draft conclusion of clear evidence of developmental toxicity. She suggested adding the rationale for why approximately $50 \%$ of the heads were examined for soft tissue alterations, as well as being more transparent about where to find the audit procedures and findings. She wondered whether the Sentinel Animal Program described in some of the other reports was relevant here also. 
- Dr. Watson replied:

o NTP would add the rationale to the methodology section of the report.

o Given the short duration of these studies, a Sentinel Animal Program is not required. The dams received by the lab underwent a full evaluation by the staff animal veterinarian before they were cleared to be included in the study. That information is included in the report.

\section{C.6.2.3. Third Reviewer - Dr. Linda Roberts}

Dr. Roberts indicated that the studies were conducted properly and agreed, with a single caveat, with the NTP conclusion. She was not as confident with a classification of "clear evidence" versus "some or equivocal" evidence based on the absence of statistical significance in misshapen adrenal glands in the historical controls. The strongest evidence for developmental toxicity was the reduction in fetal body weight. To clarify Dr. Roberts' comments, Dr. Daston asked her to confirm that she thought there was clear evidence that MCHM causes developmental effects based on fetal weight and skeletal malformations, but not changes in adrenal malformation. Dr. Roberts confirmed that this was a correct interpretation of her thoughts.

Dr. Roberts also expressed appreciation that the fetal no-observed-effect level (NOEL) was included in the report and noted that the maternal NOEL of $50 \mathrm{mg} / \mathrm{kg} / \mathrm{day}$ was based on the clinical chemistry endpoints. She stated that although there was statistical significance in these endpoints, she was less confident that there was biological significance.

- Dr. Watson agreed that additional information discriminating between structural malformations and alterations that might affect postnatal development would be useful to help understand the significance of the effect. It was difficult to confirm whether there was a pairwise significant difference in the highest dose group for this finding due to the very low incidences. Dr. Watson noted that NTP takes litter incidence into account. The fact that the findings occurred in three single fetuses from three separate litters support the conclusion that the adrenal malformation was a treatment-related effect.

\section{C.6.2.4. Panel Discussion}

Dr. Kimberley Treinen questioned the choice of reporting NOEL for maternal toxicity rather than the no-observed-adverse-effect level (NOAEL). She mentioned that the entire call was characterized as being "in the absence of overt maternal toxicity," by which she assumes to be a NOAEL. Dr. Treinen also recommended adding a line to the summary table correcting for uterine weight. She noted that the study reported high nonpregnancy rates, along with a high rate of misshapen aortic valves. She would like to have seen a lower background rate, given concern about cardiovascular malformations in the controls. The relatively large increase in the axial skeletal malformations with limited variations in other endpoints was an unusual finding. Dr. Treinen recommended that further elaboration is needed in the report to describe the misshapen adrenal glands, perhaps by providing images, given that this is an unusual finding. Dr. Daston agreed that this issue needs more attention in the report. 
- Dr. Watson indicated that NTP avoided distinguishing between adverse and nonadverse effects. Using the NOEL designation avoided some of the close calls that would have been generated by using NOAEL.

- $\quad$ Dr. Vicki Sutherland noted:

o NTP would consider adding language to the tables as recommended.

o At the time of the study, there was a concern about successful pregnancy rates, which has since improved with increased training, suggesting this was not a strain-related effect. NTP uses the same strain across all its studies.

o NTP will consider directing the lab to follow up with histopathology in the future if this finding is present. NTP will also ascertain if this finding is specific to this strain of rat.

Dr. Daston noted that the significant decrease in dam body weight with a significant increase in food consumption was a remarkable finding that, combined with the findings on blood glucose, suggests something interesting going on beyond general maternal toxicity-something that may yield an indication of a mechanism of action. The phenomenon deserved more treatment in the report.

- Dr. Watson said that data from a MCHM toxicogenomics study suggested that fatty acid metabolism may be involved as a mechanism of action. He indicated that NTP would add a discussion to the report.

- Dr. Cora remarked that although she thought the change in blood glucose levels was real, the rats would not be considered hypoglycemic, and the mild decrease is seen with some frequency. She said the triglycerides were affected by what the dams were eating and when they had last ingested food.

\section{C.6.3. Vote on NTP Conclusion}

Dr. Daston called for a motion to accept the conclusion as written, understanding that there would be information added to the report on the adrenal malformations. Dr. Roberts said she would prefer that the reference to adrenal gland malformations be removed from the conclusion. Dr. Smith moved to accept the conclusion as written and Dr. Broussard seconded. The panel passed the motion (4 yes, 1 no, 0 abstentions). Dr. Roberts voted no, citing her discomfort with including the adrenal malformations as the reason for her vote.

\section{C.7. Prenatal Developmental Toxicity Studies of Vinpocetine}

\section{C.7.1. Presentation and Clarifying Questions}

Dr. Sutherland summarized the studies and conclusions reported in the draft NTP Developmental and Reproductive Toxicity Technical Report on the Prenatal Development Studies of Vinpocetine (CASRN 42971-09-5) in Sprague Dawley (Hsd:Sprague Dawley ${ }^{\circledR} S D^{\circledR}$ ) Rats and New Zealand White (Hra:NZW SPF) Rabbits (Gavage Studies).

Vinpocetine is marketed as a dietary supplement for cognitive enhancement. It is also a semisynthetic/synthetic pharmaceutical agent for treatment of cerebrovascular and cognitive disorders. NTP chose to study vinpocetine due to concerns of consumer exposure through dietary 
supplement use, signals of developmental toxicity in the literature, and lack of adequate toxicity data.

The rat dose range-finding study used doses of $0,20,40,80,160$, or $320 \mathrm{mg} / \mathrm{kg} /$ day via gavage, with 10 time-mated female rats per group. A dose-related decrease in maternal body weight correlated with fetal loss at the higher two doses in this study. These results informed the selection of doses of $0,5,20$, and $60 \mathrm{mg} / \mathrm{kg} /$ day for the main study in 25 time-mated female rats per group. Findings from the main study included:

- Dose-related increase in the incidence of vaginal discharge (20 and $60 \mathrm{mg} / \mathrm{kg} /$ day)

- Decreased maternal body weight

- Exposure-related increases in postimplantation loss (83\% at $60 \mathrm{mg} / \mathrm{kg} /$ day)

- Fetal examination findings such as:

o Increased incidences of fetuses with ventral septal defect (malformation)

o Increased incidences of incomplete ossification of the thoracic centra (variation) and full thoracolumbar ribs (malformation)

The above findings provided sufficient concern to examine the effects of vinpocetine in a second species, the rabbit. The dosages chosen for the rabbit study were $0,25,75,150$, and $300 \mathrm{mg} / \mathrm{kg} /$ day, administered via gavage to eight time-mated female animals per group. The main rabbit study findings revealed:

- Decreased maternal body weight gains at 150 and $300 \mathrm{mg} / \mathrm{kg} / \mathrm{day}$

- Exposure-related effect on embryo-fetal survival at $300 \mathrm{mg} / \mathrm{kg} / \mathrm{day}$

Data from the rabbit study supported the findings observed in the rat dose range-finding study and rat prenatal developmental toxicity studies.

Under the conditions of the rat prenatal study, NTP's draft conclusion was:

- Clear evidence of developmental toxicity of vinpocetine in Hsd:Sprague Dawley rats in the absence of overt maternal toxicity based on findings of:

o Increased postimplantation loss

o Increased incidences of ventricular septum defects

o Increased incidences of thoracolumbar ribs (full)

o Increased incidences of incomplete ossification of the thoracic centrum

As a follow-up to the presentation, participants had the following clarifying question and discussion:

\section{Topic - No-observed-effect levels}

- Dr. Roberts noted that the study did not include NOEL values and asked whether that was intentional.

o Dr. Sutherland responded that NTP had internal discussion about the language; if the panel feels that NOELs should be included in all the reports, the team will consider modifying the text. 


\section{C.7.2. Peer Review Comments and Panel Discussion}

\section{C.7.2.1. First Reviewer - Dr. Alan Hoberman}

Dr. Hoberman expressed appreciation to NTP for completing the study of this dietary supplement, approved performing the studies in both the rat and rabbit, and overall agreed with the conclusion. He recommended that individual animal data be made available for this report and all other studies and thought that including the onset and duration for clinical signs, such as vaginal discharge, could be informative. Recognizing that the studies were hazard assessments and not risk assessments, Dr. Hoberman also thought it would be beneficial to report how the animal doses in the study compared with human doses.

Dr. Sutherland responded:

- $\quad$ The individual data are available online and indicated that NTP would consider how to make access more apparent in the reports.

- The vaginal discharge data did not directly correlate with embryonic loss.

- NTP considered risk assessment information outside the scope of this report.

\section{C.7.2.2. Second Reviewer - Dr. Linda Roberts}

Dr. Roberts commented that the study was well conducted and appreciated that a second species was included. She said that the body weight gain seen did not meet the criteria for overt maternal toxicity. She agreed with the clear evidence conclusion as written.

\section{C.7.2.3. Third Reviewer - Dr. Kimberley Treinen}

Dr. Treinen recommended that an additional line be added to the summary table with corrected numbers for maternal body weight. She noted that there was a comment made in the rabbit study that food consumption might have contributed to the body weight decrement, but it appeared that it was more attributable to the decrease in implants.

In response to Dr. Treinen’s comments, Dr. Sutherland indicated:

- NTP would consider adding corrected body weight in the text and tables if that would add clarity.

- The food consumption was not directly correlated to embryonic loss.

\section{C.7.2.4. Other Comments}

Dr. Gonçalo Gamboa, FDA, thanked NTP for keeping the FDA apprised as to the results. He noted that FDA released a statement cautioning women of childbearing ages from consuming this chemical. He appreciated the good communication.

\section{C.7.3. Vote on NTP Conclusion}

Dr. Daston asked for a motion and second from the panel to approve the conclusion as written. Dr. Roberts so moved and Dr. Hoberman seconded the motion. The panel voted unanimously (5 yes, 0 no, 0 abstentions) to approve the conclusion as written. 


\section{C.8. Prenatal Developmental Toxicity Studies of Dimethylaminoethanol Bitartrate}

\section{C.8.1. Presentation and Clarifying Questions}

Dr. Sutherland summarized the studies and conclusions reported in the draft NTP Developmental and Reproductive Toxicity Technical Report on the Prenatal Development Studies of Dimethylaminoethanol Bitartrate (CASRN 5988-51-2) in Sprague Dawley (Hsd:Sprague Dawley ${ }^{\circledR} D^{\circledR}$ ) Rats (Gavage Studies).

Dimethylaminoethanol bitartrate (DMAE) is a close structural analog of the essential nutrient choline. It is marketed as a dietary supplement to improve memory and general cognitive function. NTP chose to study DMAE because of its potential for widespread human exposure through its use in industrial and consumer products and limited evidence from the literature that it may be a teratogen and reproductive toxicant.

The dose range-finding study used doses of $0,250,500$, and $1,000 \mathrm{mg} / \mathrm{kg} /$ day via gavage, with 10 time-mated female rats per group. No maternal or fetal toxicity were present at the doses used in the range-finding study. The same doses were employed in the main study, which used 25 time-mated female rats per group. Findings from the main study revealed:

- No treatment-related effects on mortality, body weights, or feed consumption o Effects were sporadic or without a dose response

- No effects on uterine or litter parameters such as implantations, litter size, live fetuses per litter, or fetal weight

- Fetal examination findings of:

o Increased incidence of short thoracolumbar ribs (a variation) at the $1,000 \mathrm{mg} / \mathrm{kg} /$ day dose

o Increased incidence in the number of supernumerary sites, or ossification sites, in the skull at the $1,000 \mathrm{mg} / \mathrm{kg} /$ day dose

Under the conditions of this prenatal study, NTP's draft conclusion was:

- Equivocal evidence of developmental toxicity of DMAE in Hsd:Sprague Dawley rats in the absence of overt maternal toxicity based on increased incidences of:

o Short thoracolumbar ribs

o Supernumerary sites in the skull

There were no clarifying questions or comments about the presentation.

\section{C.8.2. Peer Review Comments and Panel Discussion}

\section{C.8.2.1. First Reviewer - Dr. Kimberley Treinen}

Dr. Treinen commented that the study was well conducted and met the standard for this type of study. She wondered why the absent innominate artery in the high dose group was not considered a finding, even though it was statistically different from controls and was present across multiple litters. When combined with short innominate arteries, it potentially looked like a 
dose-related effect. Dr. Hoberman commented that the absent innominate artery is a very common variation. However, he added that it and other similar variations do seem to indicate a perturbation in the system and should be investigated.

Dr. Treinen recommended breaking down the historical controls rather than lumping them together.

Dr. Sutherland noted that the absent innominate artery is an extremely common finding and therefore was not included as a potential toxicity endpoint.

\section{C.8.2.2. Second Reviewer - Dr. Mary Alice Smith}

Dr. Smith thought that the maternal death in the $1,000 \mathrm{mg} / \mathrm{kg} /$ day dose group raised a question and recommended adding more historical control data in the report. She remarked that there was not a lot of evidence for dose-related outcomes in this study. In addition, Dr. Smith cautioned against concluding that there were no brain effects and recommended qualifying the statement by indicating that there were no lesions noted in the brain because functional outcomes were not evaluated. Dr. Smith said that it should be made clear that there were no structural changes in the brain.

Dr. Sutherland responded to Dr. Smith:

- More historical control data would be helpful.

- NTP only looked for structural changes in the brain. NTP will ensure that it is clear that there were no structural changes in the brain in the revised report.

- Individual data tables were available, but NTP needs to consider how to make them easier to access.

- The primary report focused on bringing forward positive findings; therefore, negative findings were not highlighted. She mentioned that this distinction would be clarified in the report.

\section{C.8.2.3. Panel Discussion}

Dr. Roberts indicated that the innominate artery finding should have received more attention in the report. Dr. Sutherland asked if she was suggesting more detail in the discussion or an addition to the conclusion. Dr. Roberts responded both.

\section{C.8.3. Vote on NTP Conclusion}

Dr. Daston proposed adding a third bullet to the draft NTP conclusion to read "increased incidence of absent innominate artery." He called for a motion to add the bullet to the NTP conclusion. Dr. Treinen so moved and Dr. Smith seconded. Dr. Daston called for a vote on the conclusion, including the addition. The panel voted unanimously (5 yes, 0 no, 0 abstentions) to approve the conclusion with the addition.

\section{C.9. Closing Remarks on the Draft Reports}

Dr. Daston welcomed additional panel comments on the overall organization of the reports. Dr. Hoberman suggested clarifying the definition of the term "natural death" used throughout the reports. 
Dr. Sutherland noted that they would revise the term to "found dead" in the reports.

Dr. Treinen recommended that litter data, as well as individual data, be added to the reports or compiled as a stand-alone report to assist with understanding the rate of resorptions and other important fetal findings. Dr. Hoberman added that it was standard to have that type of information in a toxicology report.

Dr. Blystone remarked that NTP could explore adding some of the selected endpoints in an appendix.

Dr. Roberts appreciated having the pharmacokinetic information in the report along with its relevance to humans. She added that the value of including the NOEL eliminates the possibility of other researchers calculating their own NOEL based on the data in the report.

Closing the meeting, Dr. Maull thanked all the peer review panelists.

Dr. Daston added his thanks to NTP staff and the panel members for their efforts.

Dr. Daston adjourned the meeting at 11:22 a.m. EDT on July 31, 2019.

\section{C.10. Approval of the Peer Review Report by the Chair of the Peer Review Panel}

This peer review report has been read and approved by the chair of the July 31, 2019, Peer Review of the Draft NTP Developmental and Reproductive Toxicity Technical Reports on the Prenatal Development Studies of Tris(chloropropyl) Phosphate, 4-Methylcyclohexanemethanol, Vinpocetine, and Dimethylaminoethanol Bitartrate.

George Daston, Ph.D.

Peer Review Panel Chair

Date: July 31, 2019 


\section{Appendix D. Supplemental Files}

The following supplemental files are available at https://doi.org/10.22427/NTP-DATA-DART-02.

\section{D.1. Prenatal Developmental Toxicity Dose Range-finding Study - Rats}

Readme File - Prenatal Dose Range Finding Study

Materials and Methods - Prenatal Developmental Toxicity Dose Range Finding Study

Chemical Methods - WV Chemical Spill NTP Studies

Animal Removal Summary

Clinical Observations Summary

Fetal Defect Summary

Fetal Defects

Gross Pathology Summary

Growth Curve

Mean Body Weight Gain

Mean Body Weights and Survival

Mean Feed Consumption

Organ Weights Summary

Placental Findings

Uterine Content Summary

Individual Animal Body Weights

Individual Animal Clinical Observations

Individual Animal Dam Findings

Individual Animal Food Consumption

Individual Animal Gross Pathology

Individual Animal Implant Findings

Individual Animal Organ Weights

Individual Animal Removal Reasons 


\section{D.2. Prenatal Developmental Toxicity Study - Rats}

Readme File - Prenatal Main Study

Materials and Methods - Prenatal Developmental Toxicity Study

Chemical Methods - WV Chemical Spill NTP Studies

Animal Removal Summary

Clinical Chemistry Summary

Clinical Observations Summary

Dam Pup Cross Reference

Fetal Defect Cross Reference Summary

Fetal Defect Summary

Fetal Defects

Gross Pathology Summary

Growth Curve

Hematology Summary

Mean Body Weight Gain

Mean Body Weights and Survival

Mean Feed Consumption

Placental Findings

Uterine Content Summary

Individual Animal Body Weights

Individual Animal Clinical Chemistry

Individual Animal Clinical Observations

Individual Animal Dam Findings

Individual Animal Food Consumption

Individual Animal Gross Pathology

Individual Animal Hematology

Individual Animal Implant Findings

Individual Animal Removal Reasons 


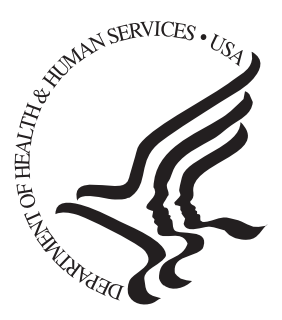

\section{National Toxicology Program}

NTP Central Data Management, MD EC-03

National Institute of Environmental Health Sciences

P.O. Box 12233

Research Triangle Park, NC 27709

http://ntp.niehs.nih.gov 